\title{
Pompéi, Pistrina
}

Recherches sur les boulangeries de l'Italie romaine - campagne 2014

Nicolas Monteix, Sanna Aho, Audrey Delvigne-Ryrko et Arnaud Watel

\section{(2) OpenEdition \\ Journals}

Édition électronique

URL : http://journals.openedition.org/cefr/1380

DOI : $10.4000 /$ cefr. 1380

ISSN : 2282-5703

Éditeur

École française de Rome

Référence électronique

Nicolas Monteix, Sanna Aho, Audrey Delvigne-Ryrko et Arnaud Watel, « Pompéi, Pistrina », Chronique des activités archéologiques de l'École française de Rome [En ligne], Les cités vésuviennes, mis en ligne le 01 juillet 2015, consulté le 10 décembre 2020. URL : http://journals.openedition.org/cefr/1380 ;

DOI : https://doi.org/10.4000/cefr.1380

Ce document a été généré automatiquement le 10 décembre 2020.

(c) École française de Rome 


\section{Pompéi, Pistrina}

Recherches sur les boulangeries de l'Italie romaine - campagne 2014

Nicolas Monteix, Sanna Aho, Audrey Delvigne-Ryrko et Arnaud Watel

\section{NOTE DE L'AUTEUR}

Ont participé à la campagne de fouilles 2014 : Sanna Aho, Arnaud Coutelas, Laetitia Cavassa, Saverio De Rosa, Audrey Delvigne-Ryrko, François Fouriaux, Sandrine Mencarelli, Frédéric Pauvarel, Arnaud Watel, ainsi que Benjamin Bauvit, Alexandre Béranger, Audrey Delfonds et Clément Salviani.

L'auteur remercie l'École française de Rome, Centre Jean Bérard (USR 3133 CNRS/EFR), ministère des Affaires étrangères et du développement international (Paris), Soprintendenza speciale per $i$ beni archeologici di Pompei - Ercolano e Stabia, Groupe de recherches en Histoire (EA 3831 Université de Rouen) - Eveha International.

Depuis l'été 2012, les opérations menées dans le cadre du projet « Pistrina - recherches sur les boulangeries de l'Italie romaine " ont changé d'orientation, abandonnant la fouille stratigraphique pour de "simples » nettoyages permettant de compléter le catalogage des aménagements associés à la production boulangère. Cette année, deux campagnes ont été menées. La première s'est déroulée du $1^{\mathrm{er}}$ juillet au $1^{\mathrm{er}}$ août, la seconde du 28 octobre au 5 novembre. Ces deux campagnes ont permis d'achever, dans la mesure du possible, le relevé des boulangeries, assorti parfois de nettoyages plus ou moins extensifs. Certains locaux (VI 2, 6; VII 2, 51; VII 16,6) n'ont pas pu être relevés, en raison de leur inaccessibilité temporaire liée aux travaux de mise en sécurité dans le cadre du Grande Progetto Pompei.

Selon un protocole documentaire désormais bien rodé, quelque soixante-quatorze relevés de fours au 1/50 ont été réalisés dans treize boulangeries distinctes. En parallèle et en complément à ces relevés, neuf boulangeries ont bénéficié d'un nettoyage d'ampleur variable, avec au minimum la remise au jour du dallage délimitant les espaces de meunerie. Nous ne détaillerons ici que les principaux résultats obtenus dans les boulangeries nettoyées, présentées par ordre topographique. 


\section{3, 27}

2 Cette boulangerie a bénéficié d'un nettoyage extensif: la longue salle des meules et la pièce de façonnage des pâtons ont été presque intégralement remises au jour; seule la probable écurie ${ }^{1}$, située à l'extrémité occidentale, n'a pas été nettoyée pour des raisons tenant autant de la logistique que de la sécurité (fig. 1).

Fig. 1 - Pompéi, boulangerie I 3, 27 - Relevé de l'ensemble de la boulangerie.

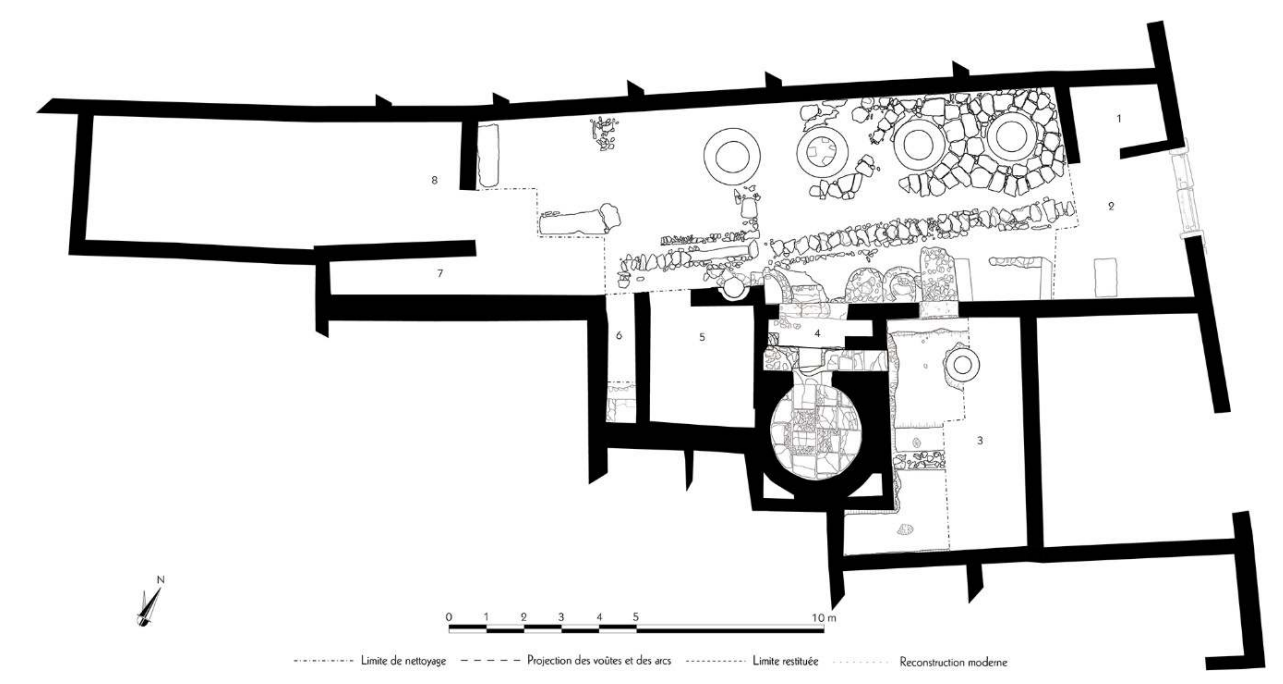

Échelle : 1/100

Relevé / dessin : F. Fouriaux / N. Monteix / S. Mencarelli - EFR.

\section{Pièce 2 (salle des meules)}

3 Au moment de l'éruption, la salle des meules est aménagée en longueur, sur $19 \mathrm{~m}$ de long pour 4,70 $\mathrm{m}$ de large, sans aucune division, à l'exception de l'aménagement d'une petite pièce (1) immédiatement après l'entrée ${ }^{2}$. Contre le mur méridional, un bloc de calcaire «du Sarno » servait de base à un escalier permettant d'accéder à l'étage. Derrière cet escalier, un muret en équerre fortement dégradé a été observé; il délimite une surface enclose à l'ouest par un muret construit en moellons de basalte ${ }^{3}$. Sur presque toute sa longueur, la salle des meules est parcourue par une canalisation dont la couverture est assurée par des blocs de basalte, (cf. infra §11-12). Seules quatre bases de meules subsistent : aucun élément pertinent à un moulin n'a été observé. Alignées selon l'axe de la pièce, ces bases sont de plus en plus dégradées d'est en ouest ${ }^{4}$ (fig. 2). 
Fig. 2 - Pompéi, boulangerie I 3, 27 - La salle des meules après son nettoyage.

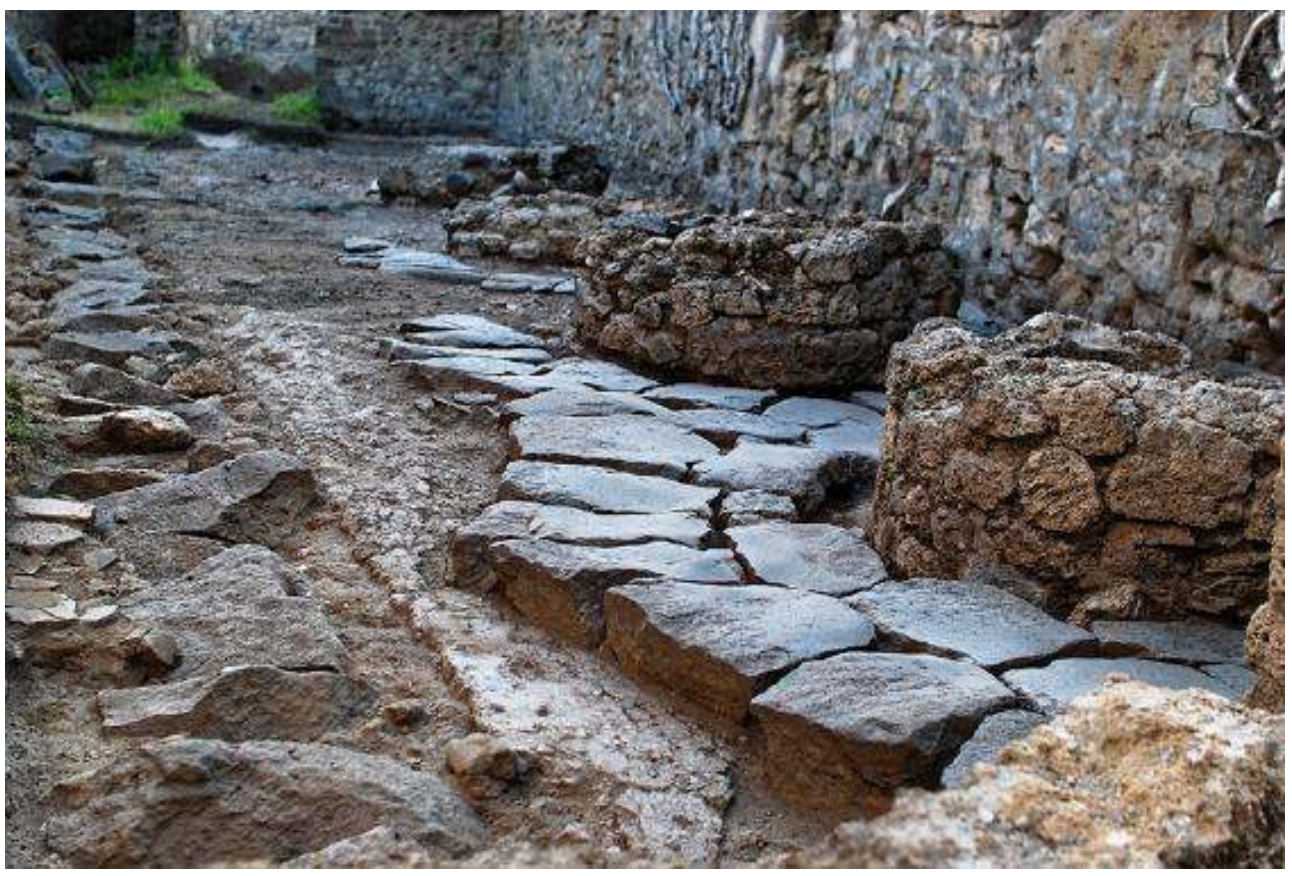

Vue de l'ouest.

Cliché : N. Monteix - EFR.

4 Cette situation a permis d'observer le mode d'insertion des metae: pour régler leur hauteur par rapport au sol, soit un plan est maçonné (meule 4), soit des blocs servant de support rayonnent vers le centre de l'espace délimité par le muret (meules 1-3). Si les bases sont directement posées sur les niveaux de sol préexistant, le dallage les entourant a généralement nécessité de creuser ce sol pour intégrer les blocs de basalte (fig. 3).

Fig. 3 - Pompéi, boulangerie I 3, 27

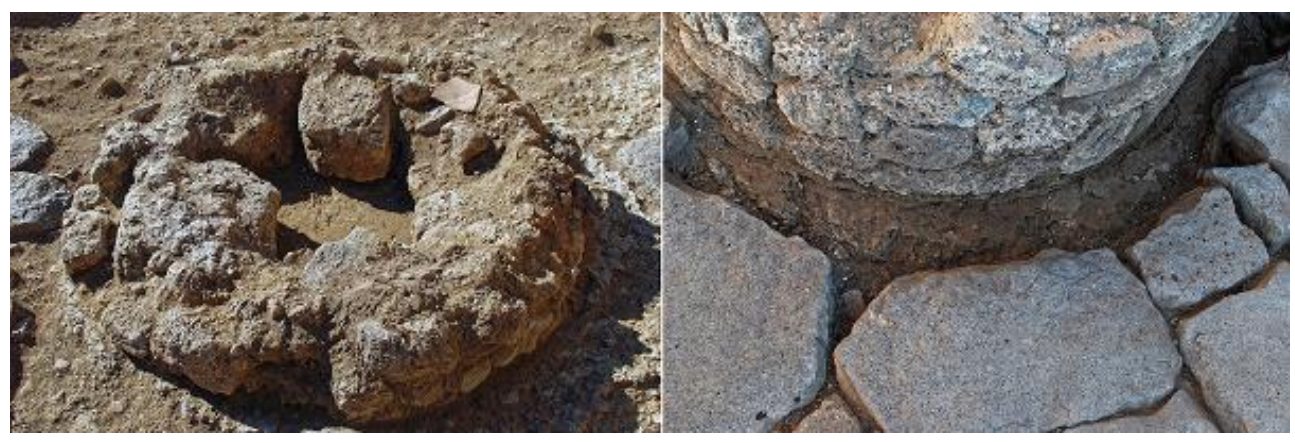

(à dr.) Base de la première meule depuis l'entrée, vue du sud. Le sol préexistant a été entamé pour insérer les blocs de basalte.

(à g.) Base de la troisième meule depuis l'entrée, vue du nord. Cette base est construite directement sur le sol antérieur. Au centre, des blocs permettaient de recevoir la meta.

Clichés : N. Monteix - EFR.

5 Étonnamment au premier abord, seule la meule 1 dispose d'un dallage complet : comme pour les bases, l'état du dallage tend à se dégrader d'est en ouest, la meule 4 ne présentant plus aucun bloc sur son pourtour. La surface du sol préexistant autour de la meule 3 a été préservée par endroits, au même niveau que les rares blocs conservés en 
place. Autour de la meule 4, la surface antérieure a cependant été creusée. Cette situation ne saurait cependant s'expliquer par l'arrêt de la construction à cause de l'éruption : le dallage présente de claires traces d'usure indiquant que la boulangerie a fonctionné (fig. 4).

Fig. 4 - Pompéi, boulangerie I 3, 27 - Usure du dallage de basalte entre les meules 1 et 2.

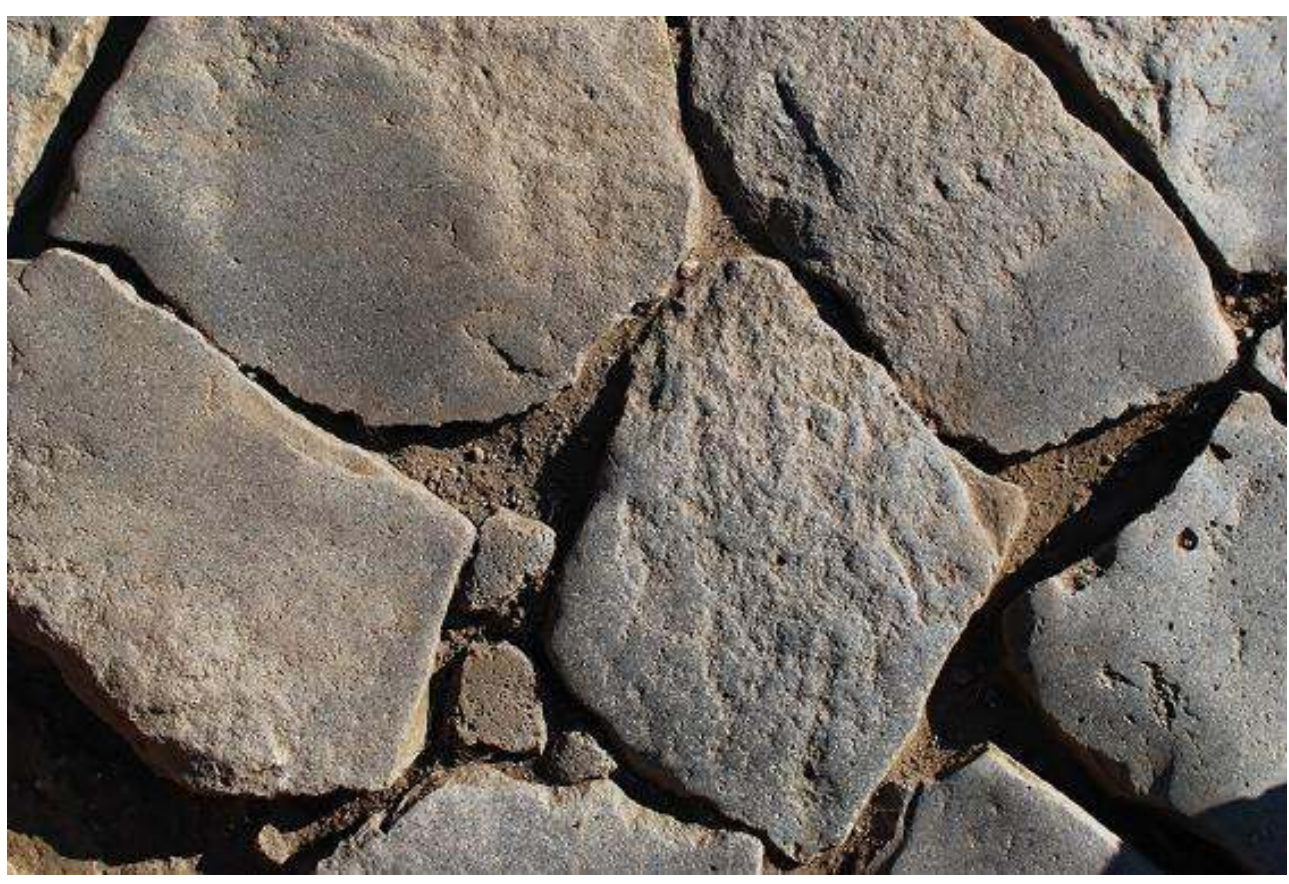

Le piquetage initial, lié au débitage des blocs, ne subsiste en surface qu'en dehors du parcours des équidés ayant fait tourner la meule.

Cliché : N. Monteix - EFR.

Il faut donc supposer que cette boulangerie était en voie de démantèlement en 79.

Le long du mur méridional, immédiatement à l'ouest de l'accès à la salle du pétrin, sont disposées deux maçonneries de plan sub-circulaire (fig. 5). 
Fig. 5 - Pompéi, boulangerie I 3, 27 - Maçonneries servant de support de jatte de pointage dans la salle des meules (vue du nord).

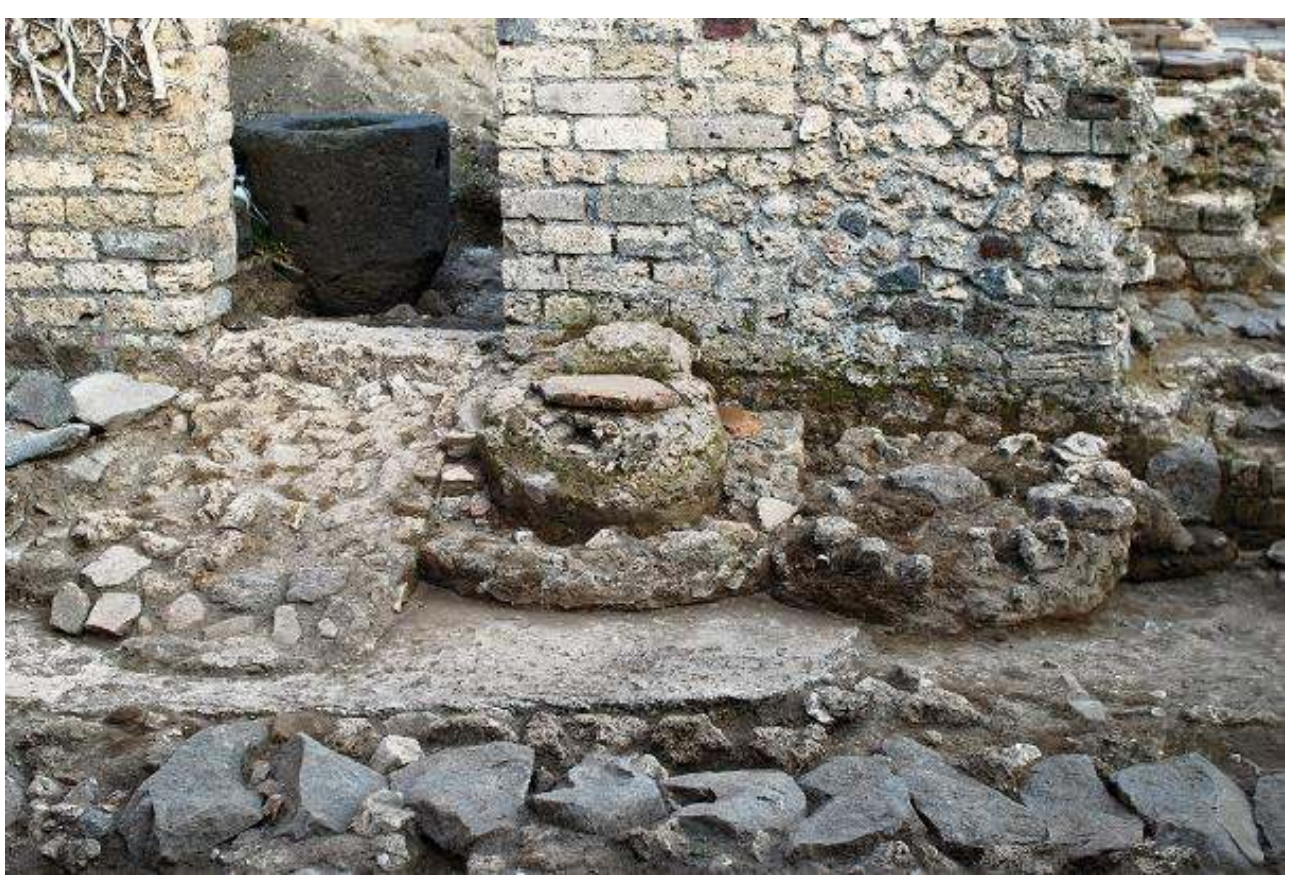

Celle de gauche pourrait avoir été un conduit de citerne comblé lors de la construction de la boulangerie.

Cliché : N. Monteix - EFR

Leur association et leur forme permettent de les interpréter comme des supports destinés à recevoir des jattes de pointage. La construction du support oriental diffère de celle du support occidental, simple massif de maçonnerie. En effet, son centre est constitué par un cylindre de maçonnerie à la paroi lissée, comme s'il avait été coulé contre un muret désormais partiellement disparu. Cette forme et les dimensions de ce cylindre autorisent à l'interpréter comme le bouchage d'un orifice de citerne.

8 Au-delà de l'espace strictement consacré aux meules, les seules traces observées renvoient à la situation antérieure à l'installation de la boulangerie. Au niveau de la meule 4, un mur arasé décrit un plan en équerre (fig. 6). Un passage se serait situé sous la meule, permettant une circulation d'est en ouest. 
Fig. 6 - Pompéi, boulangerie I 3, 27 - Vestiges d'un mur arasé et de son sol en éclats de calcaire (vue du sud).

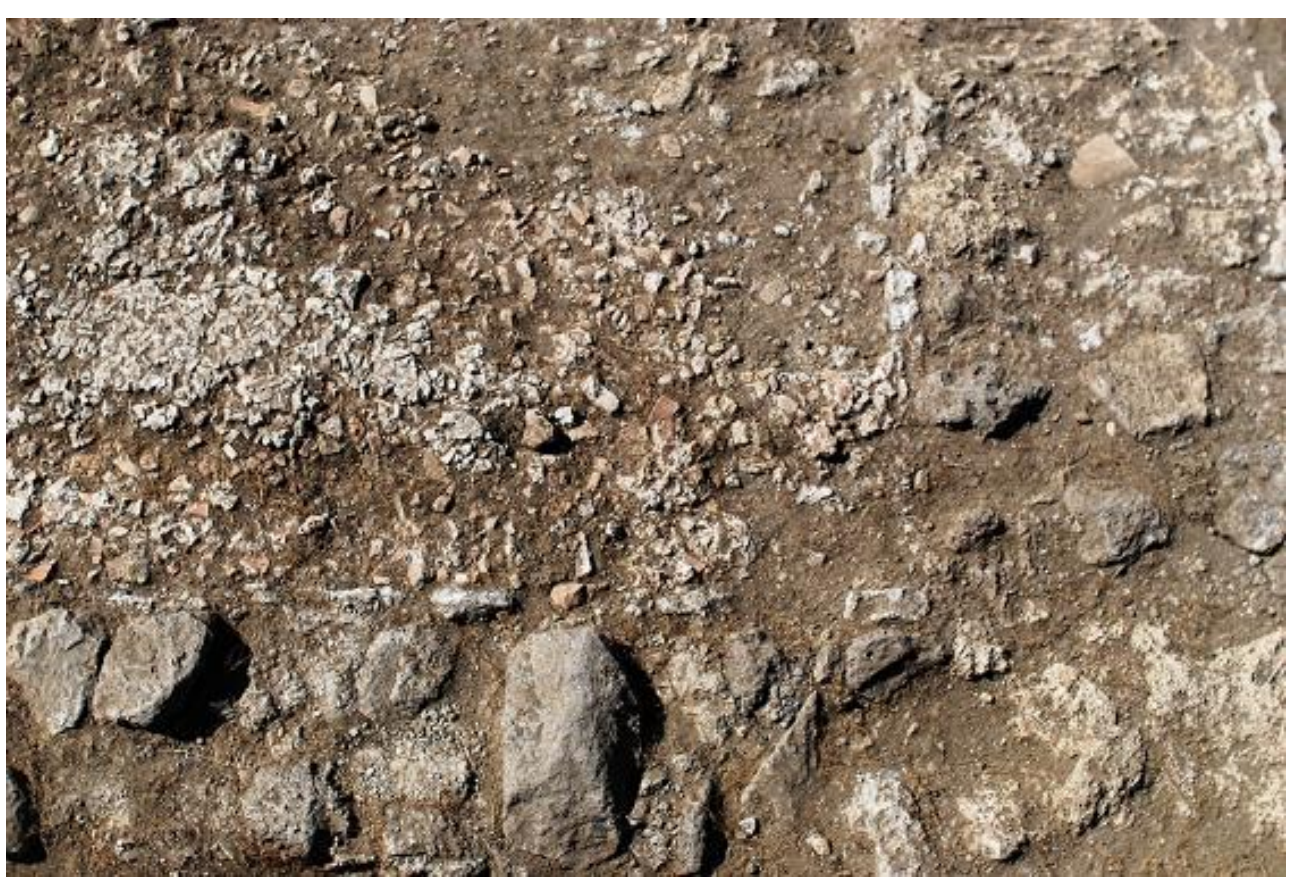

Cliché : N. Monteix - EFR.

Fig. 7 - Pompéi, boulangerie I 3, 27 - Rigole arasée, vestige d'un état antérieur à la boulangerie (vue du sud).

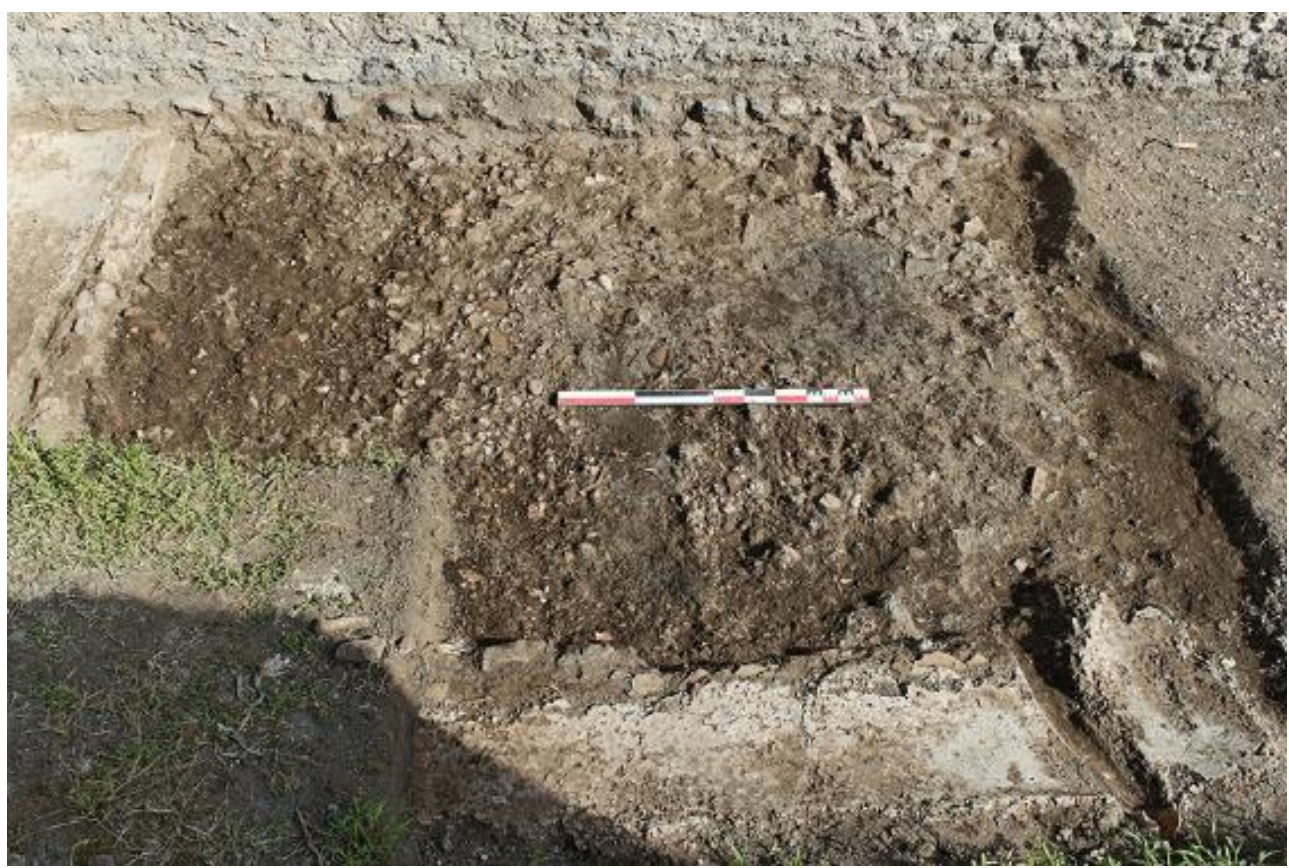

La zone charbonneuse au centre correspond à un probable feu d'ouvriers lors du dégagement. Cliché : C. Salviani - EFR.

9 Si le sol des espaces orientaux était constitué de cocciopesto, celui de la pièce occidentale a été réalisé en éclats de calcaire blanc. Plus à l'ouest, les vestiges d'une rigole décrivant un 
plan trapézoïdal ont été observés (fig. 7). Cette rigole, probable trace d'un péristyle, continuait vers le nord avant l'érection du mur séparant en ce point la boulangerie I 3, 27 de la Casa dei guerrieri (I 3, 25).

\section{Pièce 3 (salle du pétrin)}

Selon un dispositif qui n'a été observé par ailleurs qu'à une seule reprise, en VI 14, 28-325, on accède à la salle du pétrin par une rampe maçonnée avec des moellons en calcaire « du Sarno ». Le sol de cette pièce était initialement constitué d'un cocciopesto. La moitié septentrionale a été enlevée, laissant en vue le remblai de préparation où une fosse a été creusée pour installer le pétrin mécanique. Lors de notre nettoyage, cette fosse s'est avérée remplie de matériel éruptif éventuellement remanié. Le pétrin gisait en son centre, dans une position verticale. Réalisé en basalte local, il diffère considérablement de tous les autres observés sur le site, par sa forme et par le système de fixation de la lame de frasage (fig. 8). Le fond de la cuve est usé par le passage de cette dernière.

Fig. 8 - Pompéi, boulangerie I 3, 27 - Vues du pétrin.

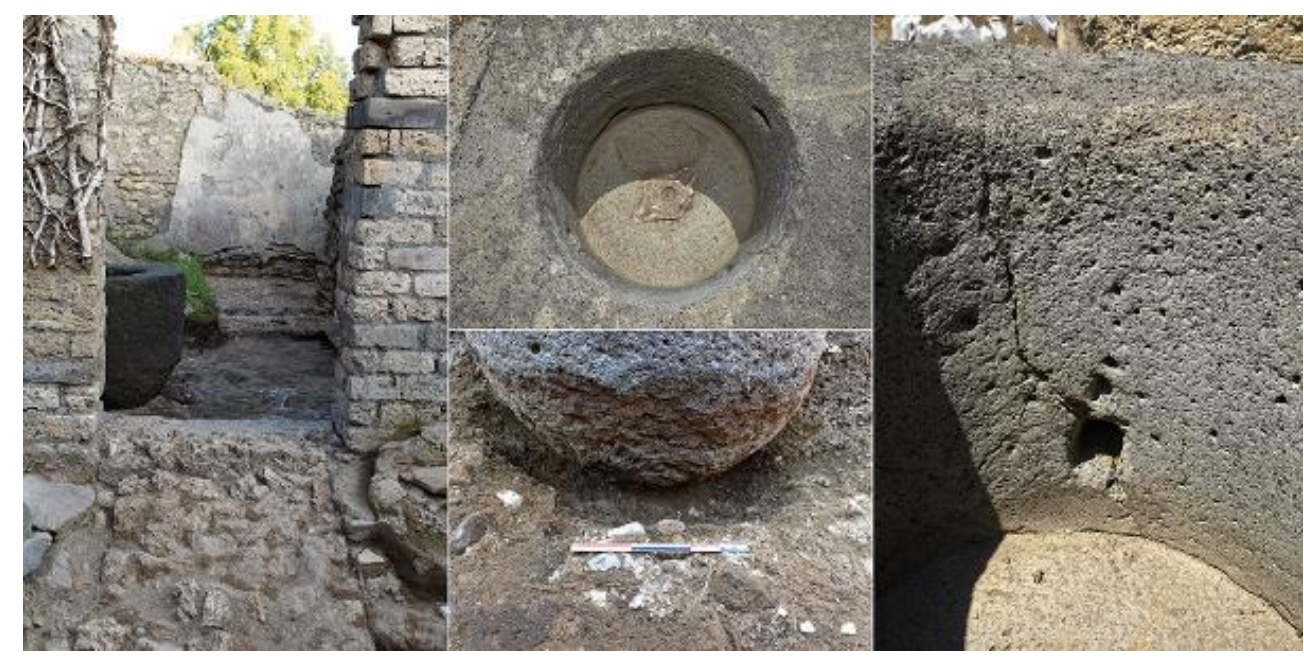

Salle du pétrin depuis la salle des meules (à g., vue du sud). Le pétrin dans sa fosse de récupération (? ) (au centre en bas, vue de l'ouest). Intérieur du pétrin : on observe le système d'insertion de l'axe au fond de la cuve (au centre en haut, vue de l'ouest). Intérieur du pétrin : I'utilisation de la lame de frasage a considérablement usé la paroi de la cuve (à dr., vue du sud).

Clichés : N. Monteix / F. Pauvarel / C. Salviani - EFR.

La situation observée, en particulier la position du pétrin, si elle n'est pas liée à des remaniements effectués au sortir de la fouille, trahit ici encore une instance de démantèlement de la boulangerie. Le nettoyage du reste de la salle n'a pas permis de mettre en évidence des aménagements liés au façonnage des pains. Cependant, des informations concernant les phases antérieures ont pu être recueillies. Avant l'installation du four, la salle était ainsi divisée en deux par un mur de refend orienté estouest (fig. 9). 
Fig. 9 - Pompéi, boulangerie I 3, 27 - Mur arasé dans la salle du pétrin (vue de l'est).

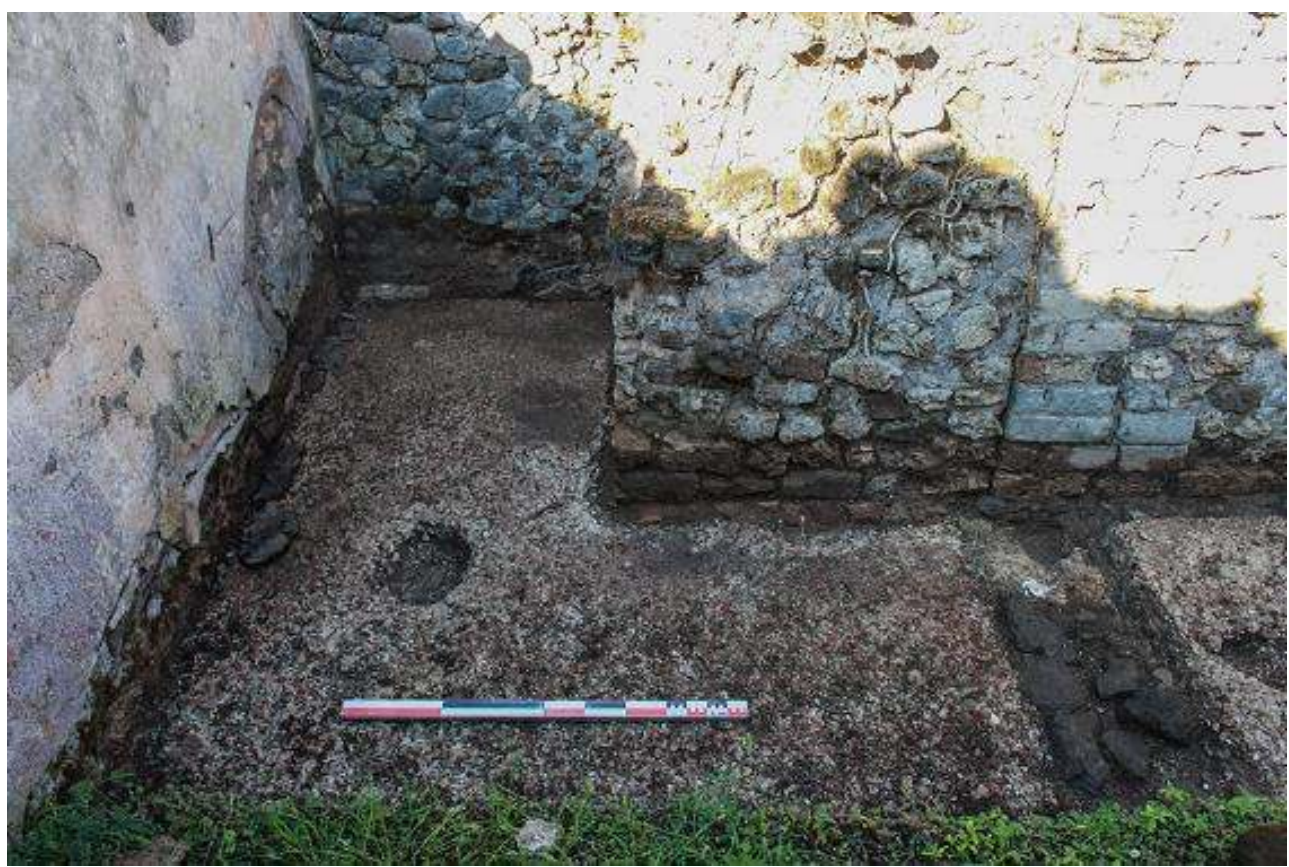

Cliché : C. Salviani - EFR.

La transformation de cet espace en laboratoire n'a pas amené à la réalisation d'un nouveau sol : le mur a été arasé au niveau du cocciopesto, la ligne d'arasement servant de niveau de circulation.

\section{Pièce 4 (four)}

11 Le four est installé dans un espace quadrangulaire auquel on accède par une volée de deux marches, la première maçonnée, la seconde étant constituée d'un seuil en remploi (fig. 10-11). 
Fig. 10 - Pompéi, boulangerie I 3, 27 - Coupes longitudinale et transversale du four (en haut) ; salle des meules, élévation sud (au milieu); salle du pétrin, élévation occidentale (en bas).
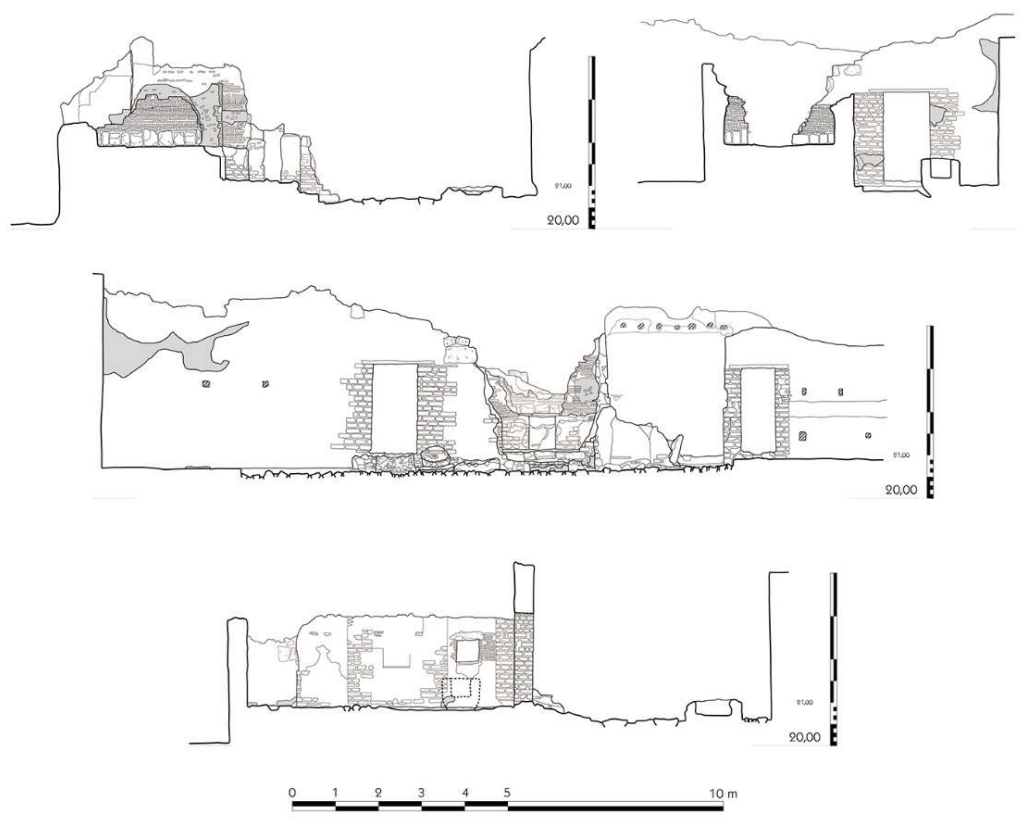

Échelle : 1/100

Relevé / dessin : F. Fouriaux / S. Mencarelli - EFR.

Fig. 11 - Pompéi, boulangerie I 3, 27 - Le four vu depuis la salle des meules.

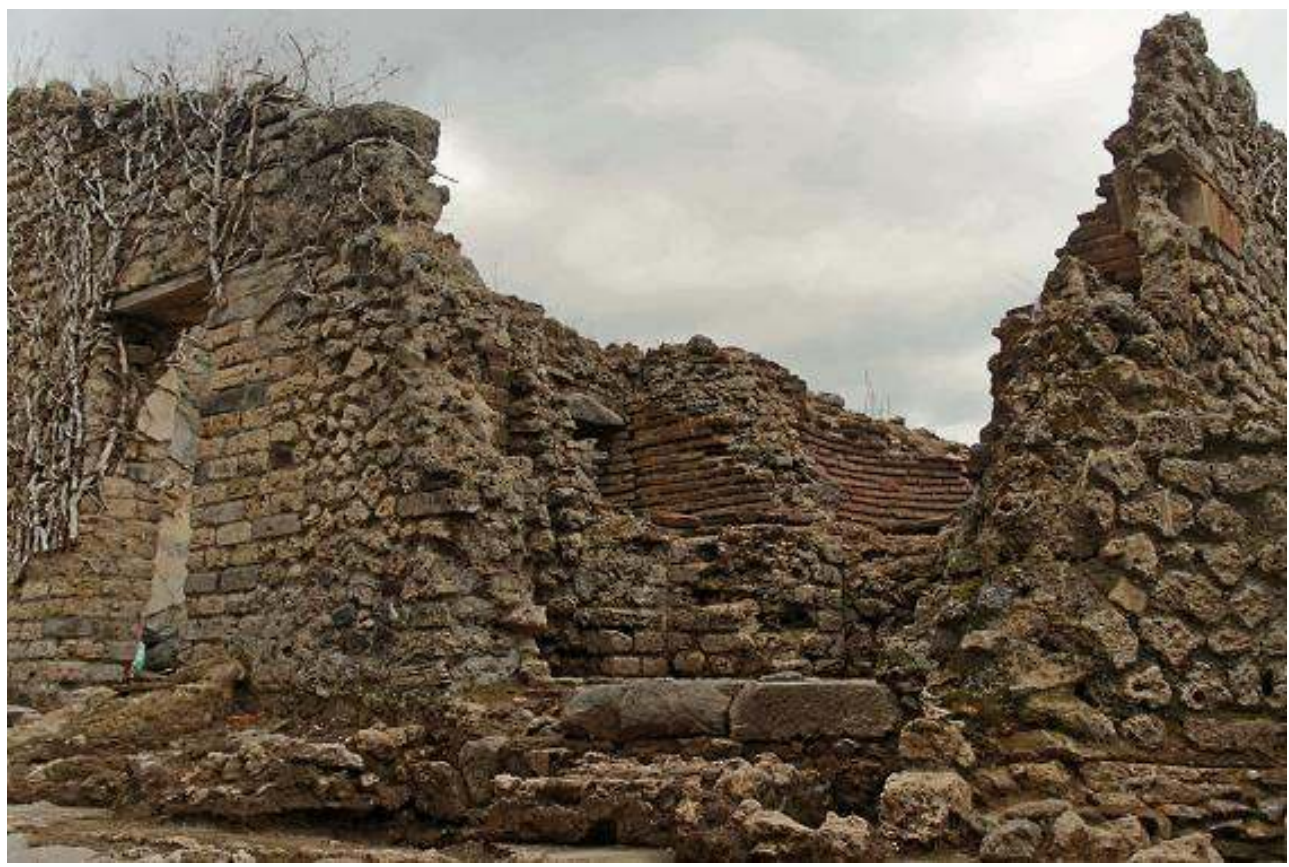

On accède à l'autel (/table) par deux marches (vue du nord-ouest).

Cliché : C. Salviani - EFR. 
Bien que l'essentiel des élévations du four ait disparu, il est possible de le restituer doté d'un mur diaphragme, d'un passe-pains communiquant avec la pièce 3 à l'est, et d'un probable chauffe-eau à l'ouest. Une technique de construction n'avait cependant jamais été relevée, en raison des bonnes conditions de conservation des autres fours étudiés jusqu'alors : lorsque le four est construit entre des murs préexistant délimitant une pièce quadrangulaire, l'espace subsistant entre les murs et la chambre de cuisson - circulaire est laissée vide (fig. 12).

Fig. 12 - Pompéi, boulangerie I 3, 27 - Espace laissé libre entre le mur contenant le four et celui formant la coupole.

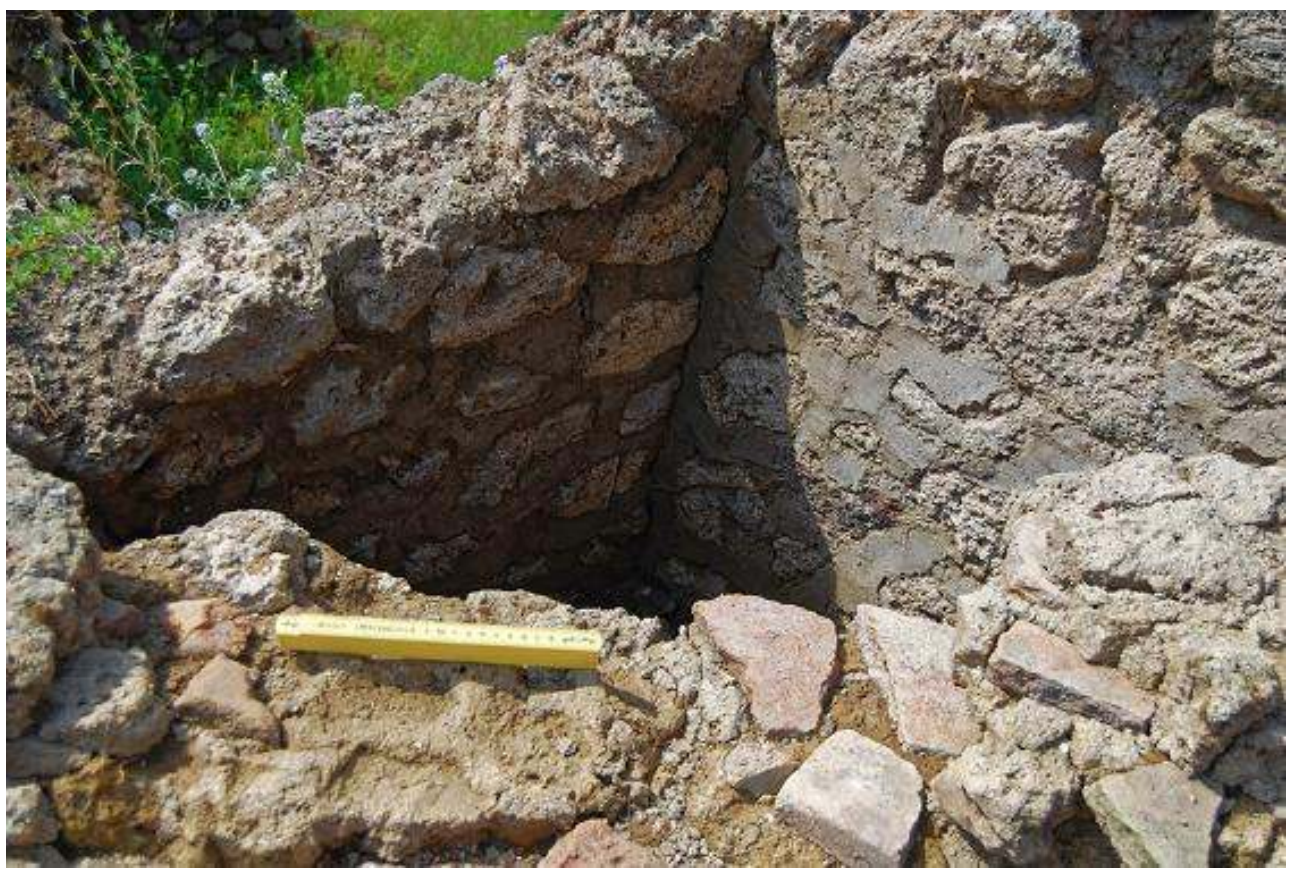

Vue du nord-est.

Cliché : A. Béranger - EFR.

Pour le reste, il convient de noter que le four s'appuie à l'est sur un mur nord-sud initialement percé d'une fenêtre; pour la construction du four, il a été nécessaire d'ajouter un mur en équerre complétant ce mur nord-sud et effectuant un retour.

\section{Pièce 6 (latrine) et aménagements hydrauliques}

12 La longue pièce 6 s'achève par une latrine qu'il n'a pas été possible d'explorer pour comprendre le devenir de la matière fécale. Le siège, une planche, était inséré dans le mur oriental et reposait sur un massif maçonné construit contre le mur occidental. Seul l'espace au-dessus du siège était protégé par une toiture dont l'amorce est conservée au sommet du mur méridional. Cette toiture permettait de recueillir les eaux météoriques, convoyées vers l'est par la canalisation qui commence à l'entrée de la pièce 6 . Lors du fonctionnement de la boulangerie, l'eau était déviée vers la bouche de citerne située dans la pièce 2 , contre le mur septentrional de la pièce 5 . Cependant, au moment de l'éruption, cette dérivation était bouchée et l'eau partait directement vers la rue. Une dernière hypothèse doit être mentionnée quant à l'emplacement de la citerne proprement dite. Si l'un des deux supports destinés au levage de la pâte présente toute les caractéristiques d'une bouche condamnée, il serait possible de supposer que la citerne s'étende sous le 
four et sous la pièce 3. En appui de cette suggestion vient le fait que cet espace, surélevé par rapport à toutes pièces environnantes, n'est absolument - et n'a jamais été - utilisé par la Casa di Innulus voisine (I 3,29), alors que la déclivité du terrain aurait permis l'installation d'une pièce de plain-pied pour cette maison.

13 L'étude des maçonneries de l'ensemble de la boulangerie et d'une partie des pièces situées dans les maisons environnantes permet de proposer la chronologie relative suivante. L'espace I 3, 27 est créé dans une phase unique qui exploite des blocs de calcaire « du Sarno" issus de la destruction de murs construits en opera a telaio. Lors de cette construction, cet espace se sépare de la partie occidentale de la Casa dei guerrieri par l'érection d'un mur orienté est-ouest ${ }^{6}$. Les travaux de construction de I 3, 27 commencent par une réfection complète de la façade, réalisée en opus reticulatum et en opus vittatum mixtum utilisant notamment des moellons de tuf jaune. Les murs de refend antérieurs sont arasés et la construction se déploie d'est en ouest. Cependant, au cours de ces travaux, le projet évolue et une boulangerie est installée, comme en témoigne le mur en équerre qui sépare la salle du pétrin du four et qui s'appuie sur un mur initialement percé d'une fenêtre et installé sur un mur antérieur arasé (fig.10, en bas). Suite à ce changement, les murs méridionaux des pièces 5 et 6 sont doublés. La boulangerie est installée. Il est probable qu'au cours de son fonctionnement, elle s'étende vers l'ouest ${ }^{7}$. Avant l'éruption, le démantèlement de la boulangerie est cependant initié.

\section{4, 12 et $\mid 4,13-17$}

14 Ces deux espaces ont bénéficié d'un nettoyage partiel au cours de la campagne d'octobre. Il a ainsi été possible en particulier de remettre au jour le dallage de basalte de la boulangerie I 4, 12 (fig. 13). 
Fig. 13 - Pompéi, boulangeries I 4, 12 et I 4, 13-17 - Relevé des deux boulangeries.

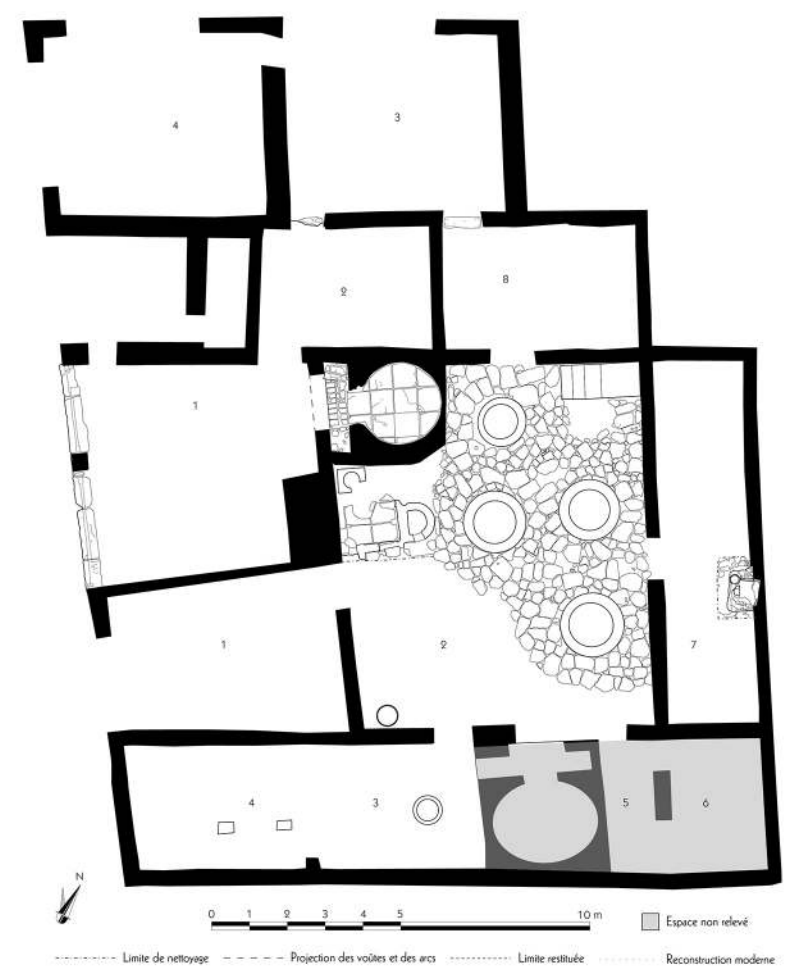

Échelle : 1/100.

Relevé / dessin : N. Monteix / S. Mencarelli - EFR.

L'étude qui aurait permis de comprendre les transformations de ces deux boulangeries n'a pu qu'être initiée et devra être achevée dans un second temps. Cependant, les prémices de cette étude ainsi que l'analyse du dallage permettent d'ores et déjà quelques remarques. Cinq emplacements de meules ont été remis au jour, mais seules quatre d'entre elles étaient intégralement dégagées au moment de l'éruption. La cinquième, située dans l'angle nord-est de la salle des meules, est partiellement oblitérée par un massif maçonné servant de fondement à un escalier permettant de gagner les étages. La forme des dalles laisse également présumer que la meule située au sud-est de la salle a été ajoutée dans un second par rapport aux trois autres. De la sorte, l'oblitération de la meule nord-est a amené à la création d'une nouvelle meule, les capacités de meunerie restant inchangées. Ces travaux paraissent devoir être associés à des transformations dans les accès à l'étage entre les différentes boutiques accessibles depuis les entrées 12 à 17 de l'îlot I 4. Plus spécifiquement, ces travaux ont amené au déplacement de l'escalier situé dans la pièce 8 vers la salle des meules. Ce déplacement apparaît lui-même lié à la mise en place d'un escalier ou d'une échelle de meunier pour accéder à l'étage situé au-dessus de la pièce 8 depuis la boutique I 4, 17, suite au percement de son mur méridional (fig. 14). 
Fig. 14 - Pompéi, boulangeries I 4, 12 - Porte ouverte au nord de la pièce 8.

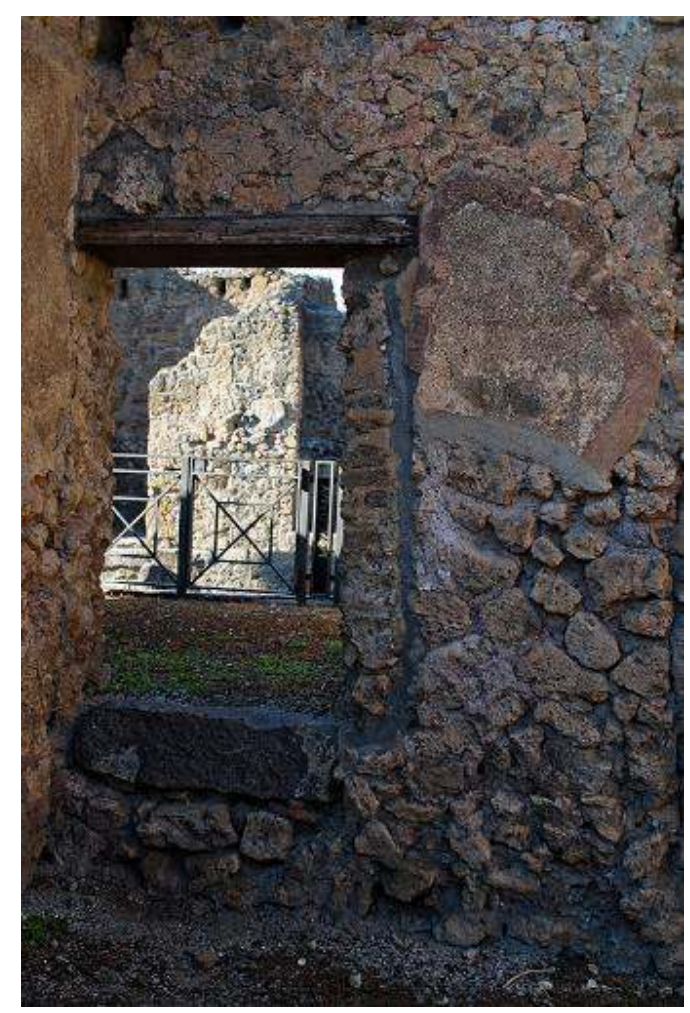

Vue du sud.

Cette porte marque un changement dans la répartition de la surface du premier étage. Celui situé audessus de la pièce 8 est accessible depuis | 4, 17 par cette porte. Le dénivelé entre les deux espaces est de $0,40 \mathrm{~m}$.

Cliché : N. Monteix - EFR.

Ces remaniements, qui ne prendront tout leur intérêt que replacés dans le contexte plus général de ces différents espaces, permettent surtout de souligner un point qui pourrait sembler trivial : les boulangeries I 4, 12 et I 4, 13-17 constituent deux entités distinctes au moment de l'éruption ${ }^{8}$. De la sorte, le nombre de boulangeries identifiées à Pompéi, qu'elles aient ou non été en fonction en 79 , s'élève donc désormais à quarante, chiffre que l'on supposera définitif.

\section{1, 36-37}

Après un premier nettoyage limité au four et à la zone principale de basalte pendant la campagne 2013, cette boulangerie a bénéficié d'un nettoyage étendu à l'«atrium » (pièce 2), à la pièce 5 et à la zone située en avant du four (fig. 15). 
Fig. 15 - Pompéi, boulangerie VII 1, 36-37 - Relevé de l'ensemble de la boulangerie.

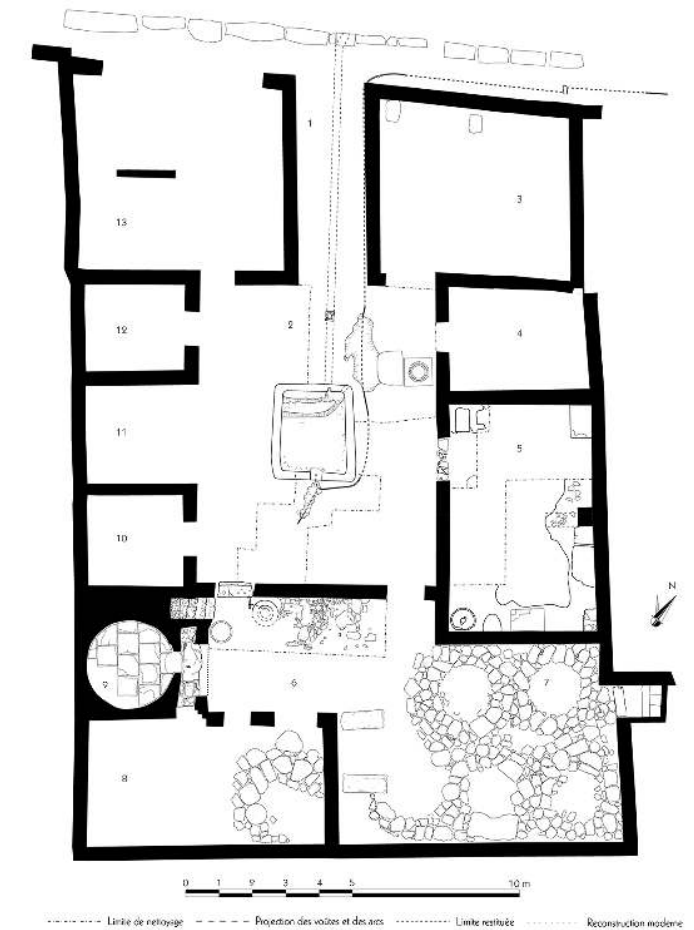

Échelle : $1 / 100$

Relevé / dessin : N. Monteix / S. Mencarelli / A. Watel / A. Béranger- EFR.

\section{Pièce 2 (atrium)}

Un peu moins de la moitié de la surface de cette pièce a été nettoyée afin d'appréhender les divers aménagements hydrauliques, partiellement décrits par G. Fiorelli, et leur évolution. L'approvisionnement en eau de la maison était assuré par un tuyau en plomb provenant vraisemblablement du château d'eau secondaire situé à l'angle sud-oriental de l'îlot VII 2. En passant sous le seuil de l'entrée VII 1, 36, le tuyau devient invisible sous le niveau de sol. Il ne réapparaît qu'épisodiquement à l'est - à deux reprises - et au sud de la vasque du compluvium. Là, après une possible bifurcation permettant d'alimenter également la vasque, il prend une orientation vers le sud - sud-ouest par rapport au nord théorique - en direction du seuil séparant l'atrium de la salle du four. Les premières descriptions, de la maison mentionnent le passage de ce tuyau, sans indiquer s'il est alors complet ou non'. L'état dans lequel le sol de l'atrium a été observé, présentant d'importantes lacunes en particulier sur le passage du tuyau, interdit de déterminer si sa disparition est antérieure à l'éruption ou consécutive à celle-ci.

$\mathrm{Au}$ centre de la pièce se trouve l'impluvium, entouré au moment de la fouille d'un muret haut d'environ $80 \mathrm{~cm}$, assez fortement restauré depuis sa mise au jour. L'étude des rapports entre les maçonneries et les niveaux de sols conservés permet de proposer une séquence chronologique relative. Lors d'une première phase, l'impluvium est construit. Son fond, certainement plus étendu que ce qui est visible actuellement est constitué d'un béton de tuileau rehaussé de tesselles de mosaïque formant des motifs de losange sur son périmètre. Le sol entourant ce bassin de réception des eaux pluviales est réalisé en lava 
pesta dont des fragments ont été observés au sud. Au cours d'un second état, la surface de l'impluvium est rétrécie par l'adjonction d'un bourrelet de béton de tuileau qui couvre partiellement la décoration de tesselles (fig. 16). La seconde phase touchant cette pièce consiste en un rehaussement général, suite à la mise en place d'un système d'adduction en eau destiné à alimenter, au sud de l'impluvium, une fontaine, dont des vestiges de la pile subsistent encore. Un nouveau niveau de sol, réalisé en béton très clair, décoré de fragments de céramiques épars, est mis en place tout autour de l'atrium, ainsi que dans l'entrée VII 1, 36.

Fig. 16 - Pompéi, boulangerie VII 1, 36-37 - Profil de l'atrium lors de sa seconde phase et vue du nord de la pile de fontaine.

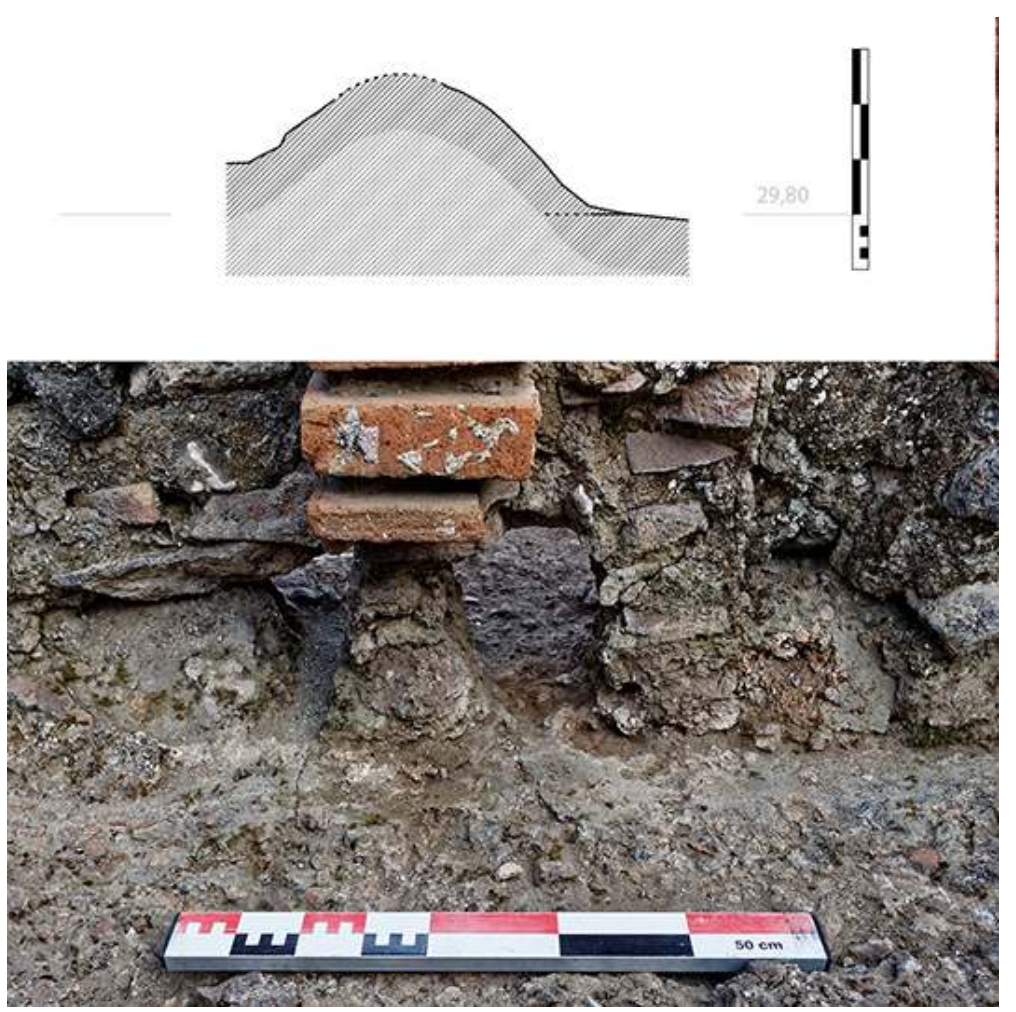

Échelle : 1/10.

L'ensemble a été pris dans un muret successif, lors de la transformation de l'impluvium en bassin pour I'humidification du grain.

Relevé / dessin / cliché : N. Monteix - EFR.

Ce n'est qu'au cours de la troisième phase, en lien probable avec la construction de la boulangerie, que l'impluvium change de fonction. Les bords sont en effet rehaussés par des murets en opus incertum composé de blocs de basalte et de calcaire. Un revêtement en mortier de tuileau, maintenant très dégradé, recouvre ces murets et déborde en partie sur le fond. Au nord de ce bassin, une canalisation verticale en terre cuite est implantée dans la maçonnerie. Il pourrait s'agir d'un tuyau de récupération des eaux de pluie. À la base du muret, deux autres conduits en terre cuite ont été insérés horizontalement. Le premier, au droit de la canalisation verticale, parait constituer un avaloir drainant l'eau, grâce à une canalisation percée d'un regard en calcaire blanc, débouchant dans la rue (fig. 17). Le débouché du second conduit, orienté vers la bouche de citerne située au nordest de l'atrium ${ }^{10}$, n'a pas été observé. Deux creusements longilignes perforent le bassin sur 
toute sa largeur, l'un sensiblement parallèle au mur nord, le second présentant une courbure avant de devenir parallèle au premier.

Fig. 17 - Pompéi, boulangerie VII 1, 36-37 - Intérieur du bassin utilisé pour l'humidification du grain avant mouture et des différents tuyaux et creusements qu'il présente.

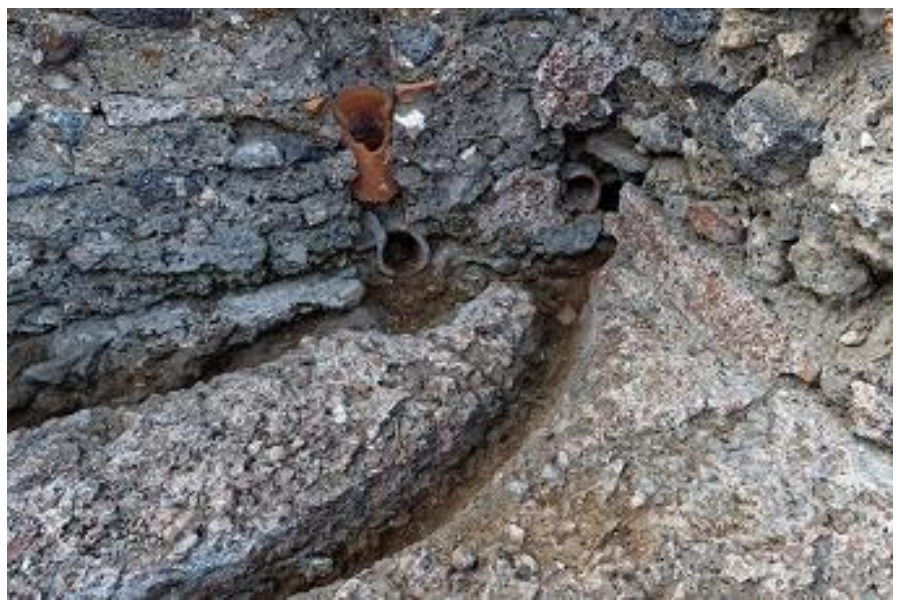

Vue du sud-ouest.

Cliché : N. Monteix- EFR.

Il pourrait s'agir de traces marquant le passage de tuyaux en plomb, non déposés avant l'éruption ou récupérés. Par-delà l'explication à donner à ces creusements, nous suivrons l'interprétation proposée par G. Fiorelli, faisant de cette transformation de l'impluvium un aménagement destiné au lavage du grain ${ }^{11}$, ou mieux à son humidification avant mouture.

\section{Pièce 5}

$\mathrm{Au}$ moment de l'éruption, cette pièce rectangulaire communique avec l'atrium par une porte percée dans la partie nord de son mur occidental. Les nettoyages se sont concentrés dans les deux-tiers sud de la pièce afin de rechercher la trace de l'installation d'un éventuel pétrin, attesté dans la boulangerie, déplacé dans l'atrium. Aucun aménagement de ce type n'a été mis en évidence sur le niveau de terre battue occupant manifestement la plus grande partie de la pièce (fig. 18). 
Fig. 18 - Pompéi, boulangerie VII 1, 36-37 - Vue générale de la salle de façonnage après nettoyage.

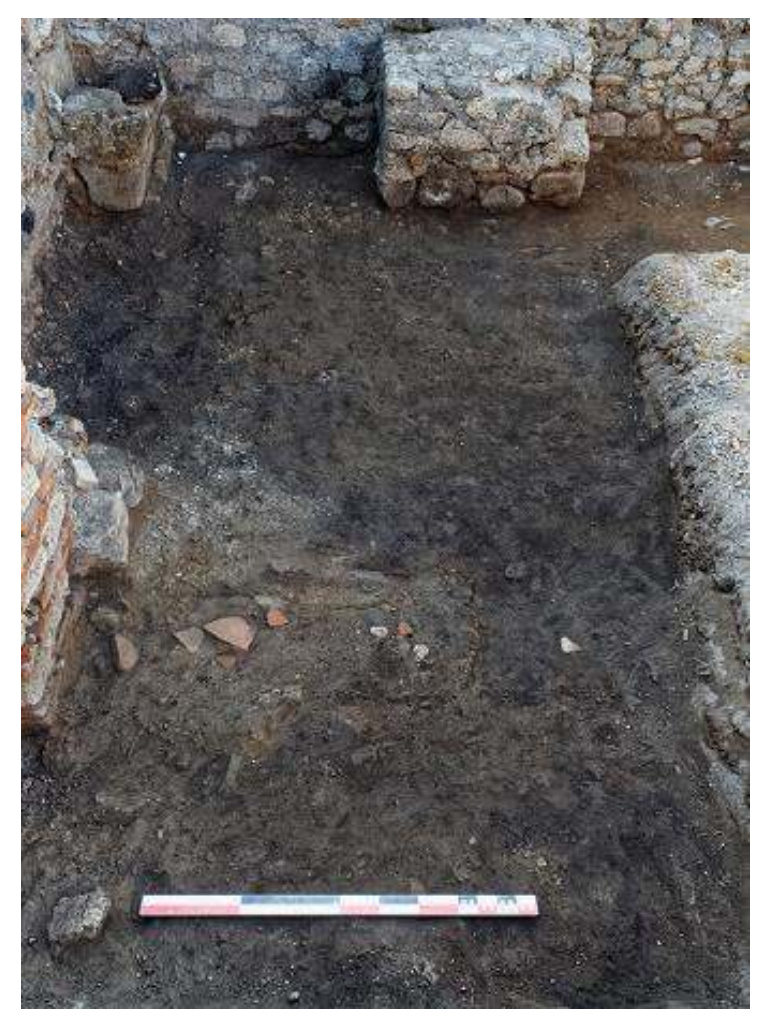

Vue du nord.

Cliché : A. Watel - EFR.

21 En surface, ce niveau, de couleur noire, présente une concentration importante de noyaux d'olives fragmentés. Cinq massifs maçonnés sont disposés le long des murs septentrional (2), oriental (1) et méridional (2). La surface délimitée par ces massifs, au sud-est et au sud, n'est qu'incomplètement recouverte par ce niveau d'épandage de cendres mêlées de rejets issus du four qui laisse entrevoir le remblai sous-jacent. Cette disposition permet, malgré l'absence du pétrin, de proposer que cet espace était destiné à la formation des pâtons, les massifs maçonnés servant d'appui à des planches pour former des tables de préparation. Cette hypothèse paraît également soutenue par la présence, dans l'angle sud-ouest de la pièce, d'un catillus partiellement brisé mais de toute façon rendu inutilisable par son usure perforante, probablement destiné à devenir le support pour une jatte de pointage, comme observé dans d'autres boulangeries.

L'étude des maçonneries permet de percevoir que cet aménagement ne correspond qu'à la dernière phase de vie de la boulangerie. En effet, alors que les murs périmétraux sont pour l'essentiel construits en opus incertum mélangeant calcaire « du Sarno » et moellons de basalte -correspondant à l'état le plus ancien de cette pièce, le mur occidental présente d'importants remaniements successifs. Dans un premier temps, le montant nord de l'accès a été réparé en fragments de tuiles. Il est possible qu'à ce moment, la pièce ait été divisée en deux par un mur est-ouest. Au cours d'une seconde phase, c'est l'intégralité du mur occidental qui a été reconstruit en déployant deux piliers érigés en opus vittatum mixtum dont l'intervalle intègre une porte munie d'un seuil (fig. 19). 
Fig. 19 - Pompéi, boulangerie VII 1, 36-37 - Mur oriental de l'atrium montrant le bouchage d'une porte initialement encadrée par des montants en opus vittatum mixtum.

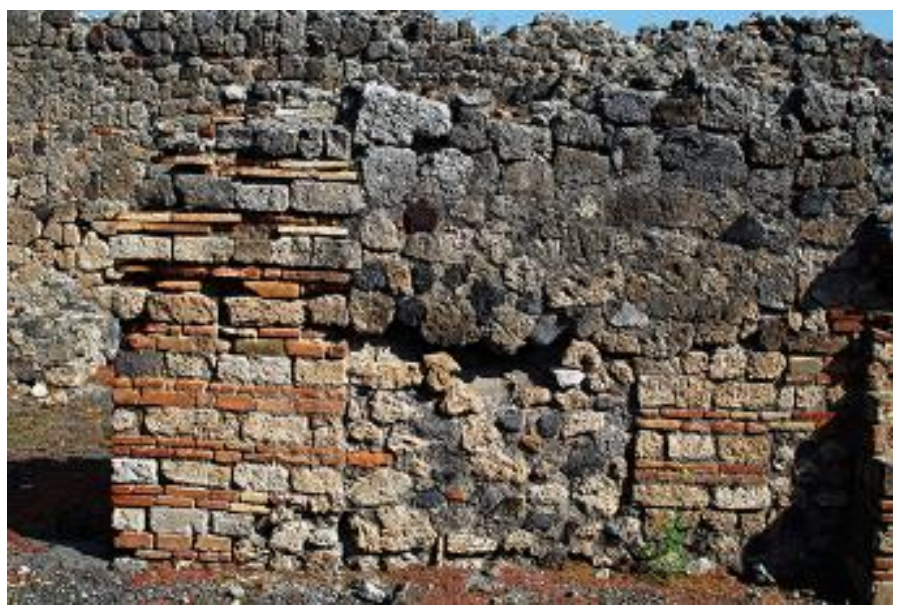

Vue de l'ouest.

Cliché : N. Monteix - EFR.

La troisième et dernière phase voit cette porte bouchée, la porte située au nord réduite en extension par l'adjonction d'un massif d'opus incertum et un pilier installé contre le mur oriental, en remplacement probable du mur de refend. Ce n'est qu'alors que les supports pour les tables de façonnage sont installés.

\section{Pièce 6}

Dans cette pièce, le nettoyage a été limité à la zone située immédiatement au sud du mur séparant la pièce de l'atrium 2. Les différents aménagements mis au jour sont difficiles à interpréter en raison de leur très fort arasement. Tout au plus peut-on signaler ce qui semble être une longue banquette de maçonnerie, formant un ensemble unitaire se développant entre un dolium à l'ouest et la seconde porte de communication avec l'atrium à l'est. Des blocs de calcaire « du Sarno » constituent l'extrémité de cet aménagement. En son centre, les possibles vestiges d'une canalisation sont perceptibles, à proximité de l'extrémité de laquelle la trace d'un possible poteau a été observée (fig. 20). 
Fig. 20 - Pompéi, boulangerie VII 1, 36-37 - Maçonnerie arasée à l'est du four.

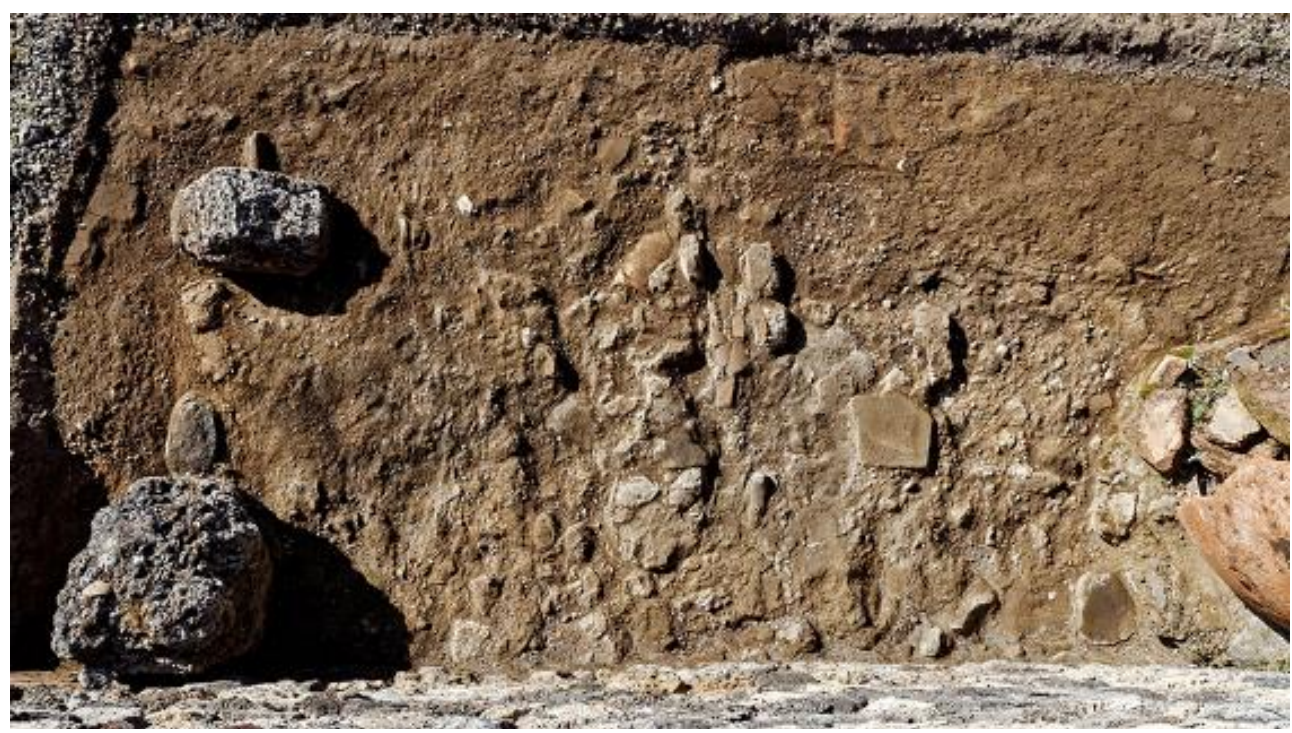

Vue du nord.

Cliché : A. Watel - EFR.

D'après les premières descriptions, le dolium, alors intact, était alimenté en eau grâce à un tuyau de plomb provenant de l'atrium ${ }^{12}$. Une fraction de cette fistula a été observée au droit du seuil permettant de passer de l'atrium à la pièce 7, à l'ouest (fig. 21). Elle présente effectivement une dérivation au niveau du dolium.

Fig. 21 - Pompéi, boulangerie VII 1, 36-37 - Tuyau de plomb destiné à alimenter le chauffe-eau du four, passant sous le seuil entre l'atrium et la pièce 6 .

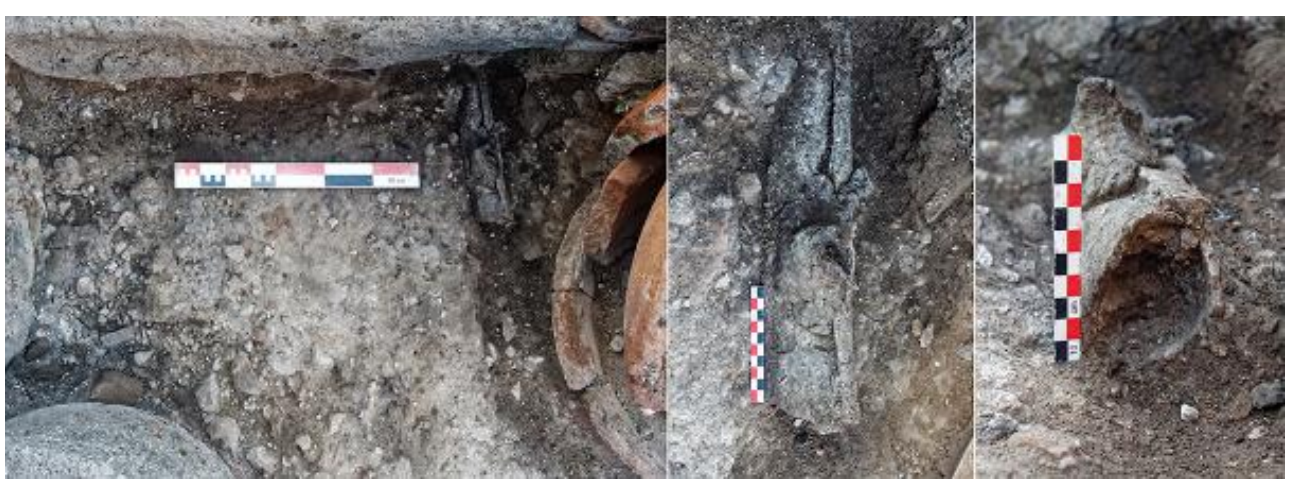

Vues de l'est et zénithale.

Clichés : N. Monteix / A. Watel - EFR.

L'aspect le plus frappant reste sa section (ca. 7 x $5 \mathrm{~cm}$ ), largement supérieur à celui du tuyau observé dans la pièce 2 (ca. 5 x $2 \mathrm{~cm}$ ). Bien que nous ne sachions si et comment la liaison entre ces deux tuyaux se faisait, il est probable qu'à l'usage, s'ils étaient reliés entre eux, cela n'ait guère influé sur la quantité d'eau débitée au robinet, que ce soit dans le dolium et dans le probable chauffe-eau du four ${ }^{13}$. 


\section{Pièce 8}

Dans la salle 8, seul un complément de nettoyage a pu être effectué. Il s'est agi de comprendre la raison de la disparition d'une partie du dallage en basalte observé en 2013 dans cette pièce. Le dégagement des comblements modernes a permis de mettre en évidence une poche de lapilli comblant, au moment de l'éruption, un creusement lié au démantèlement de ce dallage alors en cours (fig. 22).

Fig. 22 - Pompéi, boulangerie VII 1, 36-37 - État du dallage de basalte dans la pièce 7 au moment de l'éruption.

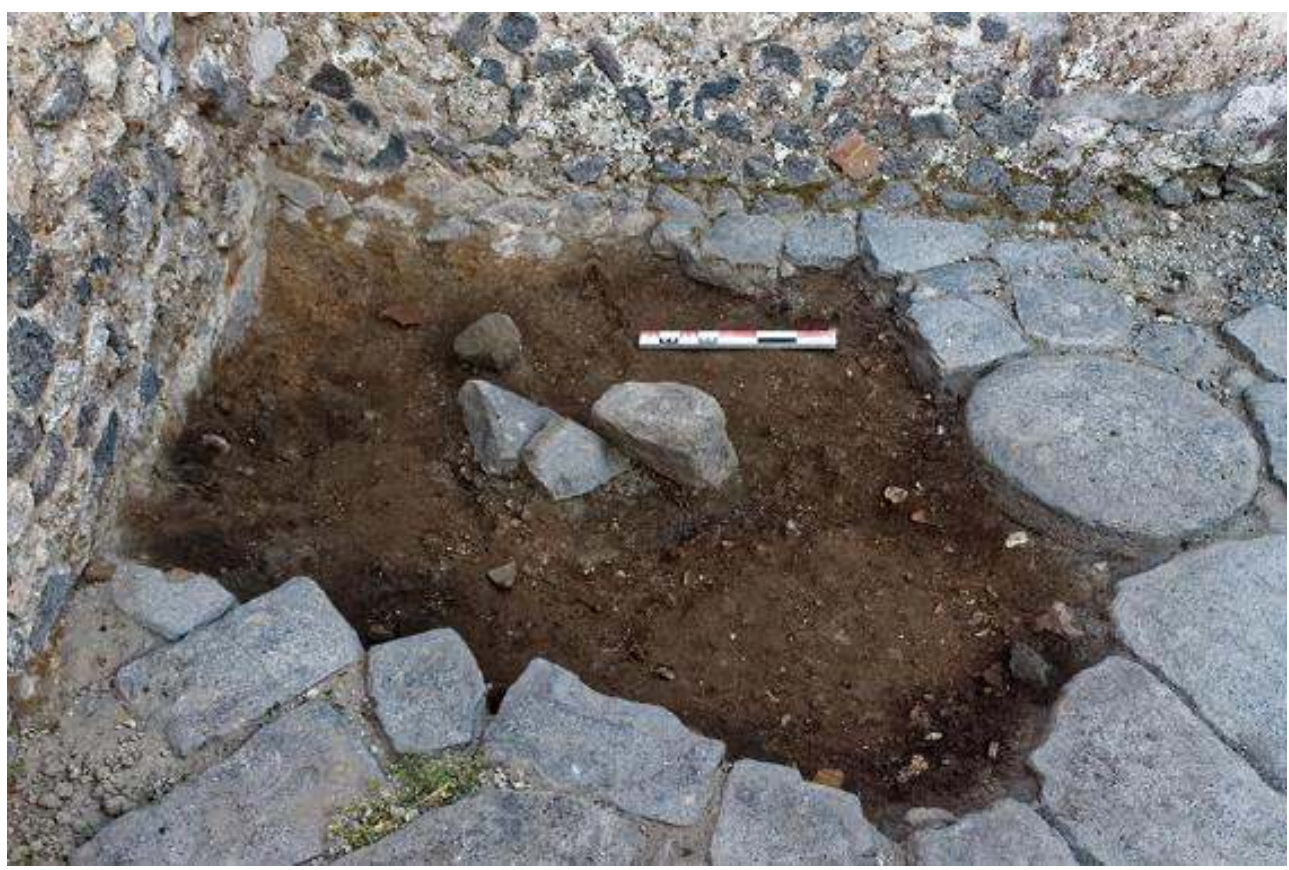

Vue du nord.

Cliché : A. Watel - EFR.

\section{2, 3.6}

Lors de la campagne 2013, un premier nettoyage avait été effectué dans la boulangerie VII 2, 3.6, essentiellement dans la salle des meules et dans la salle de façonnage. Un dégagement limité du péristyle avait également été entrepris. Au cours de la campagne 2014, ce dernier a été étendu, permettant de mettre au jour le système d'adduction et d'évacuation de l'eau, ainsi que de proposer une première hypothèse d'évolution de ces aménagements (fig. 23) ${ }^{14}$. Trois phases principales ont été mises en évidence, dont deux paraissent devoir être associées avec la présence d'une boulangerie dans l'édifice. Aucune de ces évolutions ne saurait être cependant datée. 
Fig. 23 - Pompéi, boulangerie VII 2, 3.6 - Relevé de l'ensemble de la boulangerie.

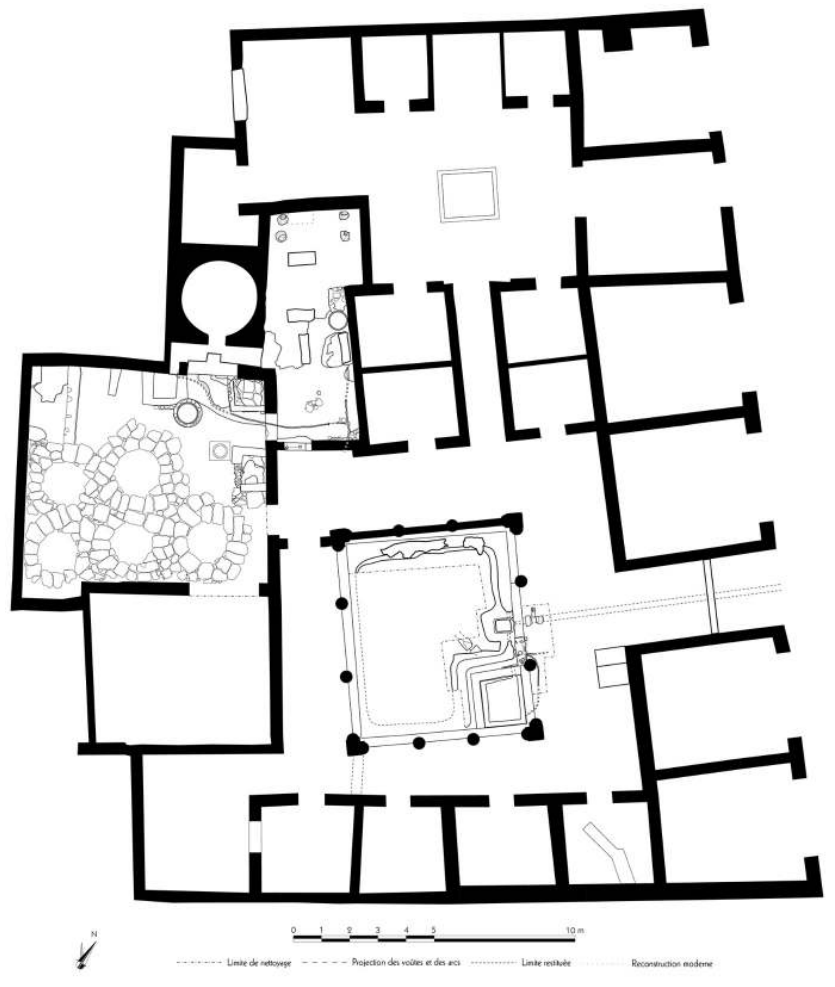

Échelle : 1/100.

Relevé / dessin : A. Delvigne-Ryrko / A. Dufond / R. Cuvilier / P. Larrieu / N. Monteix / S. Mencarelli EFR.

La première phase présente un péristyle dont la colonnade est formée de douze supports. Chacun des angles est marqué par un pilier à encoignure à deux demi colonnes conjointes. Entre chacun de ces supports d'angles sont disposées deux colonnes, d'un diamètre de 0,44 $\mathrm{m}$ avec un entrecolonnement de 1,44 $\mathrm{m}$. L'espace délimité par ces supports est complètement fermé sur les trois côtés septentrional, occidental et méridional par un muret, tandis que le côté oriental est ouvert au niveau de l'entrecolonnement central (fig. 24), les entrecolonnements méridional et septentrional restant fermés. L'ensemble était recouvert par un enduit de couleur rouge, probablement un mortier hydraulique surpeint. 
Fig. 24 - Pompéi, boulangerie VII 2, 3.6 - Le bras oriental du péristyle en cours de nettoyage.

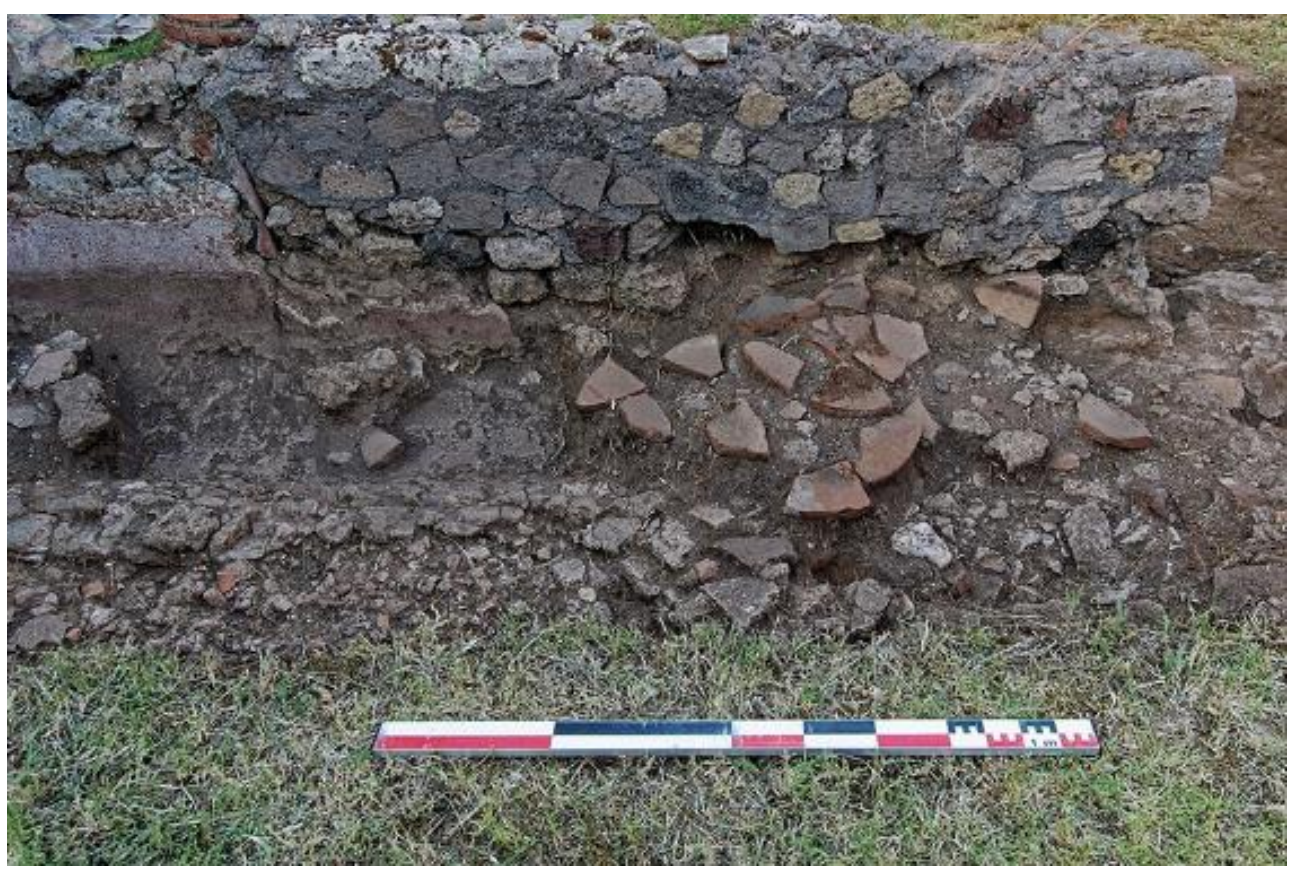

Vue de l'ouest.

On note la réduction d'ouverture effectuée dans un second temps.

Cliché : A. Delvigne-Ryrko - EFR.

Les transformations successives et la limitation de nos travaux au seul nettoyage ont interdit de mettre en évidence la forme de la très probable rigole courant à l'intérieur des murets pour la collecte des eaux météoriques. En revanche, la canalisation couverte permettant de convoyer ces eaux vers une possible citerne - de localisation indéterminée - a été aperçue dans l'une des portions dégagées (fig. 25). Le canal, maçonné en béton hydraulique, présente une direction sud-est / nord-ouest. Sa couverture était assurée par des plaques ennoyées dans le béton constituant le sol du péristyle. Il a vraisemblablement été coupé lors des transformations survenues lors de la troisième phase - si ce n'est avant. 
Fig. 25 - Pompéi, boulangerie VII 2, 3.6 - Canalisation de récupération de l'eau ( ?) dans la première phase du péristyle.

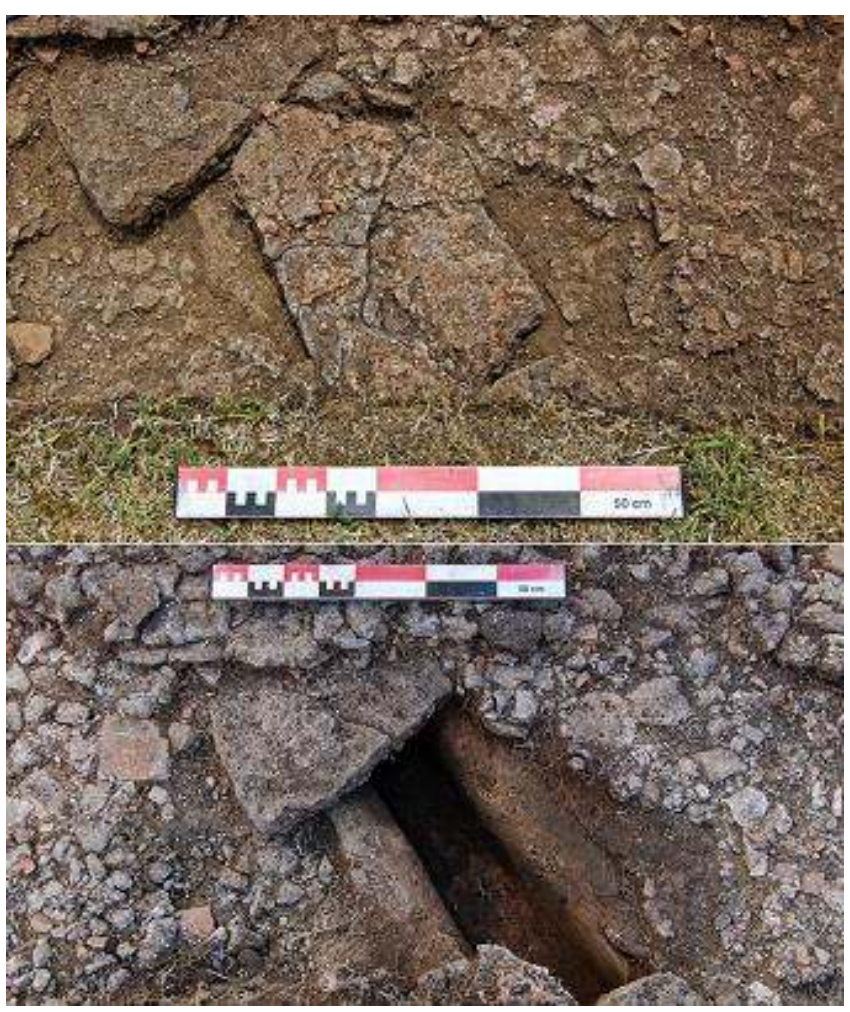

Vues du nord.

Clichés : A. Delvigne-Ryrko - EFR.

Lors de la phase successive, l'accès par l'entrecolonnement central du côté oriental du péristyle est considérablement réduit par l'érection d'une extension du muret. Parallèlement à cette modification de l'accès, un bassin maçonné est ménagé dans l'angle sud-est du péristyle. Cette construction implique la modification du parcours des eaux météoriques : la rigole les recevant doit contourner le bassin. Seuls de maigres fragments du mortier hydraulique alors mis en place ont été préservés autour du bassin (fig. 26). 
Fig. 26 - Pompéi, boulangerie VII 2, 3.6 - Angle sud-oriental du péristyle, au point de contact entre le bassin et le bras méridional.

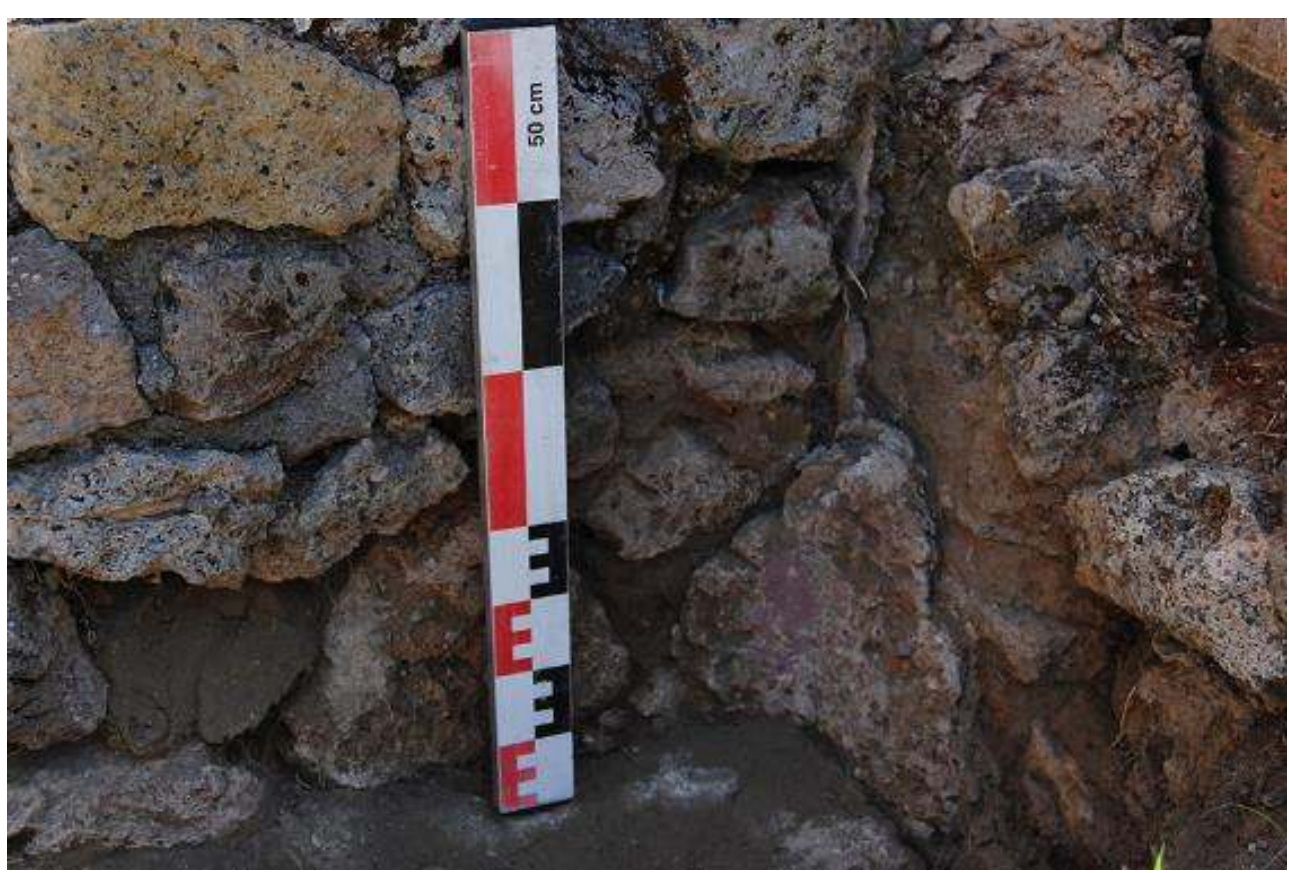

Vue du nord-ouest.

La succession des enduits et mortier permet de suivre les trois phases : construction du péristyle aménagement du bassin, réfection de la rigole.

Cliché : N. Monteix - EFR.

En revanche, la réfection de cet enduit de protection est bien visible sur le côté oriental du péristyle. En ce qui concerne le bassin, se posent les questions de l'alimentation en eau et de son évacuation. Pour l'alimentation, aucune hypothèse ne peut être étayée : les tuyaux en plomb observés lors du nettoyage paraissent devoir être liés à la phase suivante. L'absence de remaniement visible et la remarquable qualité du béton de tuileau utilisé pour revêtir les parois et le fond autorisent de considérer que la structure du bassin n'a pas changé après sa construction. L'évacuation de l'eau qu'il contenait se faisait donc vraisemblablement par l'avaloir observé dans son angle nord-est (fig. 27). 
Fig. 27 - Pompéi, boulangerie VII 2, 3.6 - Bassin destiné à l'humidification du grain avant mouture : avaloir.

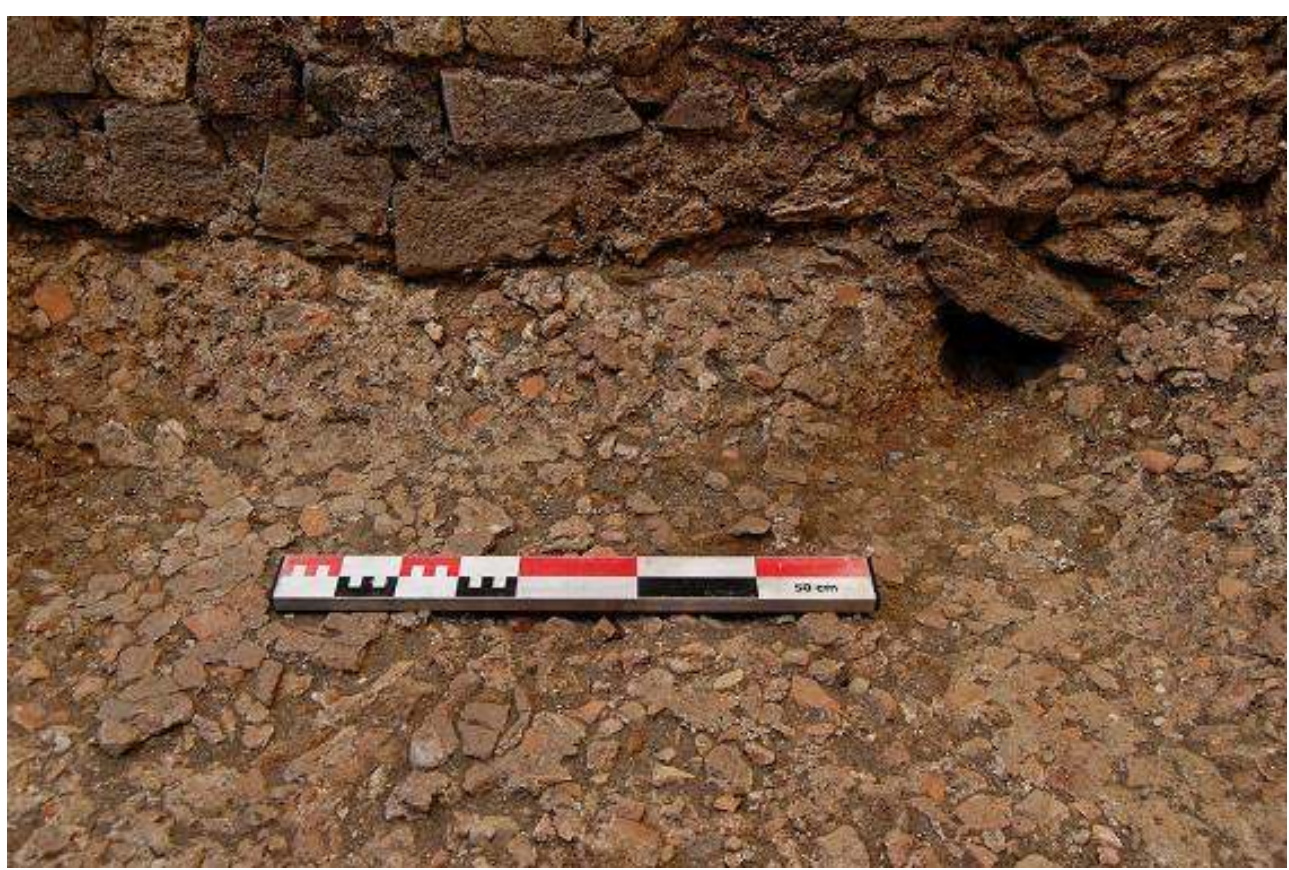

Vue du sud. La maçonnerie au-dessus du béton de tuileau est moderne.

Cliché : A. Delvigne-Ryrko - EFR.

30 À ce stade, il est impossible de déterminer la destination de l'eau contenue dans le bassin, même s'il est probable que l'aménagement mis en place dans la phase successive ait déjà été présent lors de cette phase. Tout porte à croire que la canalisation observée dans la phase précédente a nécessairement été condamnée suite à la mise en place du bassin. Enfin, il importe de soulever la question de la fonction de ce bassin. Selon G. Fiorelli, il s'agirait d'une piscine de substitution ${ }^{15}$. Cependant, cet aménagement est un hapax : tous les bassins décoratifs ou fonctionnels intégrés à des péristyles sont creusés dans le sol et généralement centrés par rapport à l'axe de vue principal ${ }^{16}$. Par ses dimensions et par le fait qu'il soit en surélévation au-dessus du sol, ce bassin renvoie aux compluvia des boulangeries V 3, 8, VII 1, 36-37 et VII 2, 22, transformés par l'érection de murets latéraux en bassins utilisés pour l'humidification du grain avant mouture ${ }^{17}$. Nous retiendrons le même usage pour le bassin construit dans le péristyle de VII 2, 3.6.

31 Lors de la troisième phase, d'importantes transformations ont lieu. Tout d'abord, les entrecolonnements $\mathrm{du}$ bras septentrional du péristyle sont bouchés ${ }^{18}$, détruisant partiellement l'enduit hydraulique mis en place lors de la phase précédente (fig. 28). 
Fig. 28 - Pompéi, boulangerie VII 2, 3.6 - Vue générale du bouchage de l'entrecolonnement du bras septentrional du péristyle.

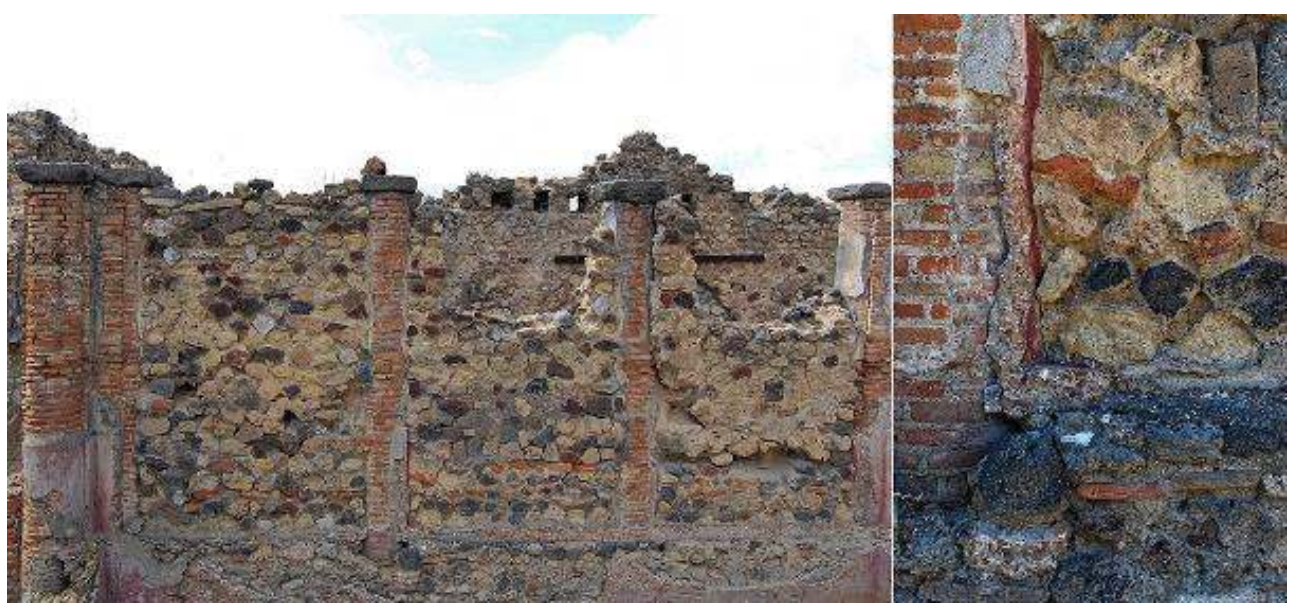

Vues du sud.

La vue de détail à droite souligne qu'il a été nécessaire de détruire partiellement le revêtement hydraulique pour effectuer ce bouchage.

Clichés : A. Delvigne-Ryrko / N. Monteix - EFR.

La maçonnerie employée pour ce bouchage a comme particularité d'être de l'opus incertum présentant de nombreux moellons de tuf jaune. Une réfection ou un réaménagement de l'ensemble du système hydraulique est perceptible, sans qu'il ne soit toutefois possible de discerner si cela relève de la simple réparation ou de la véritable transformation. L'édifice est désormais relié au réseau d'eau sous pression (fig. 29). 
Fig. 29 - Pompéi, boulangerie VII 2, 3.6 - Tuyaux en plomb alimentant la boulangerie en eau sous pression.

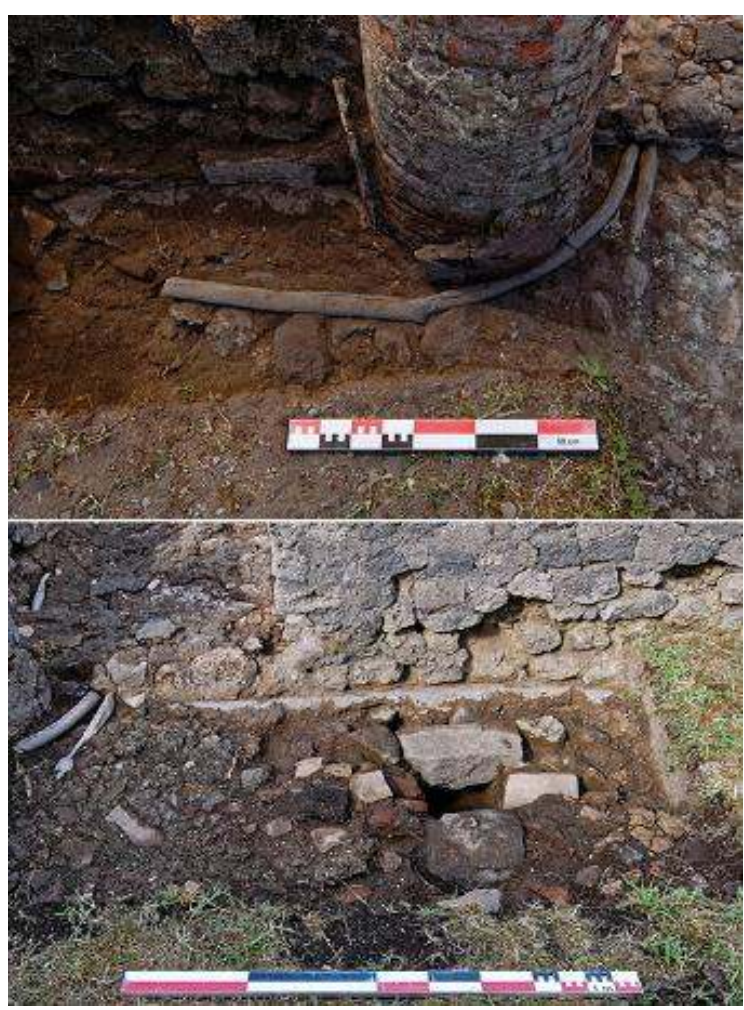

On note le tuyau d'acheminement initial qui passe, rectiligne au nord de la colonne ; après avoir débouché dans un probable caisson de répartition, un tuyau alimente le bassin en contournant la colonne (en haut), tandis qu'un second longe le bassin, probablement pour alimenter la salle de façonnage et le four (en bas; vues du sud).

Clichés : A. Delvigne-Ryrko / A. Dufond - EFR.

Un tuyau en plomb parcourt le couloir d'entrée, vraisemblablement en provenance du château d'eau secondaire situé à l'angle sud-est de l'îlot, avant de disparaître sous le petit massif de maçonnerie servant de marche d'accès au péristyle. Sans alignement avec le précédent tuyau, un second tuyau part de ce massif, longeant vers l'ouest le bassin. Inversement, un troisième tuyau repart vers le sud, contourne la colonne pour prendre la direction de l'angle sud-est du bassin. Il faudrait donc restituer, sous le massif maçonné, un caisson de répartition permettant de maintenir la pression tout en facilitant la multiplication des points de déversement de l'eau, sans recourir au simple embranchement en $" T »^{19}$. Cette fraction du réseau d'adduction en eau est ennoyée dans une chape de béton gris qui a été observée sur presque toute la surface dégagée du péristyle. C'est avec ce matériau qu'ont en effet été refaits à la fois la rigole recueillant les eaux météoriques et le système d'évacuation de l'eau hors du péristyle (fig. 30-31). Un bassin de décantation est ainsi ajouté juste en arrière de la tête du muret oriental. Alimenté au nord et au sud par deux tuyaux céramiques insérés dans la maçonnerie qui coupe la rigole, ce bassin est profond de 0,30 m. À $12 \mathrm{~cm}$ du fond, dans sa paroi orientale, commence une canalisation qui passe sous le muret. On la suit à l'extérieur du péristyle grâce à un regard disposé contre le muret et qui collecte les eaux issues d'une canalisation se développant au nord. Elle se déversait dans la rue. 
Fig. 30 - Pompéi, boulangerie VII 2, 3.6 - Dernier état du système de collecte et d'évacuation de l'eau.

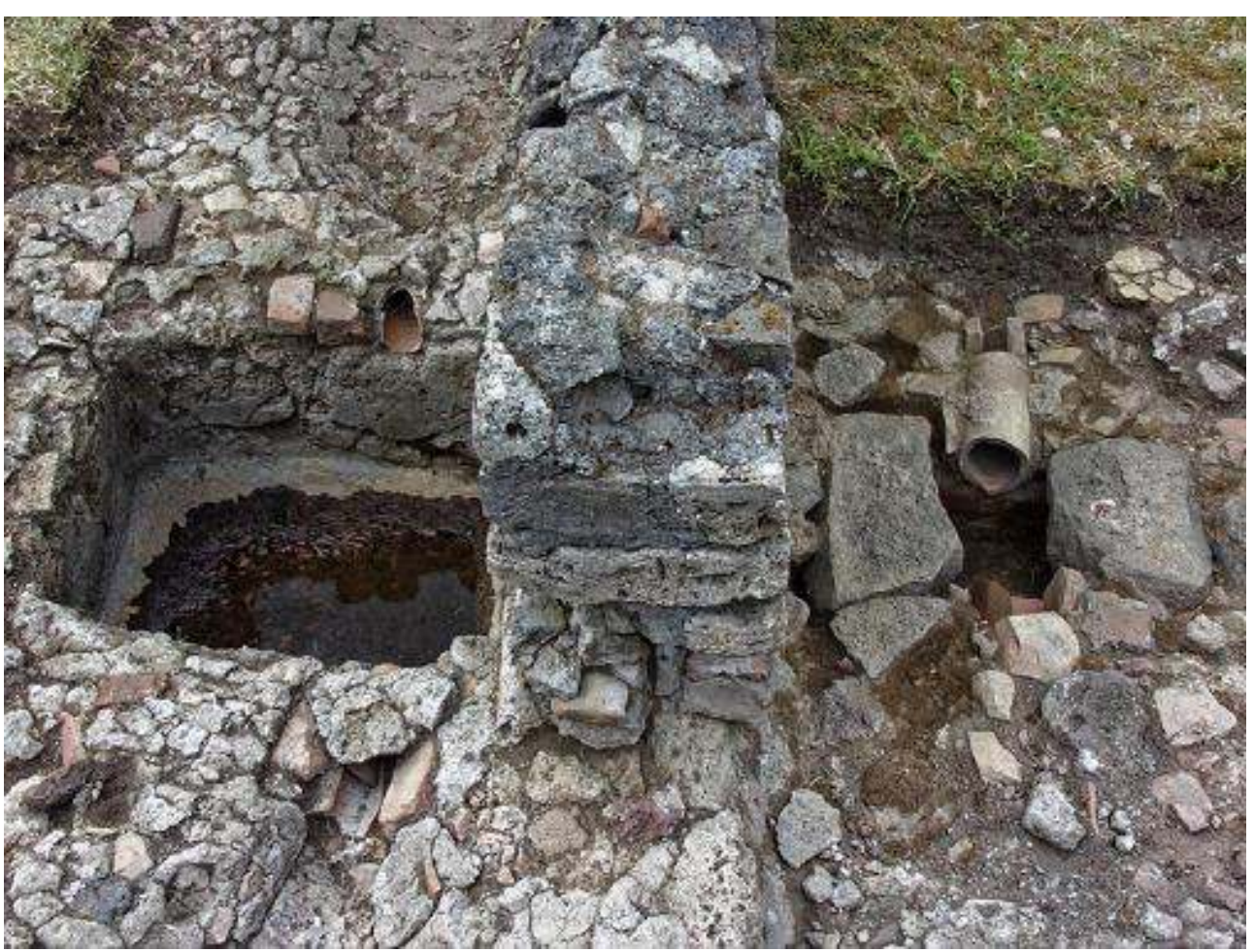

Vue du sud.

La rigole longeant le péristyle aboutit dans un bassin de décantation relié à une canalisation maçonnée qui file vers l'extérieur, à l'est.

Cliché : A. Delvigne-Ryrko - EFR. 
Fig. 31 - Pompéi, boulangerie VII 2, 3.6 - Coupe du bassin et du système d'évacuation des eaux à l'est du péristyle.
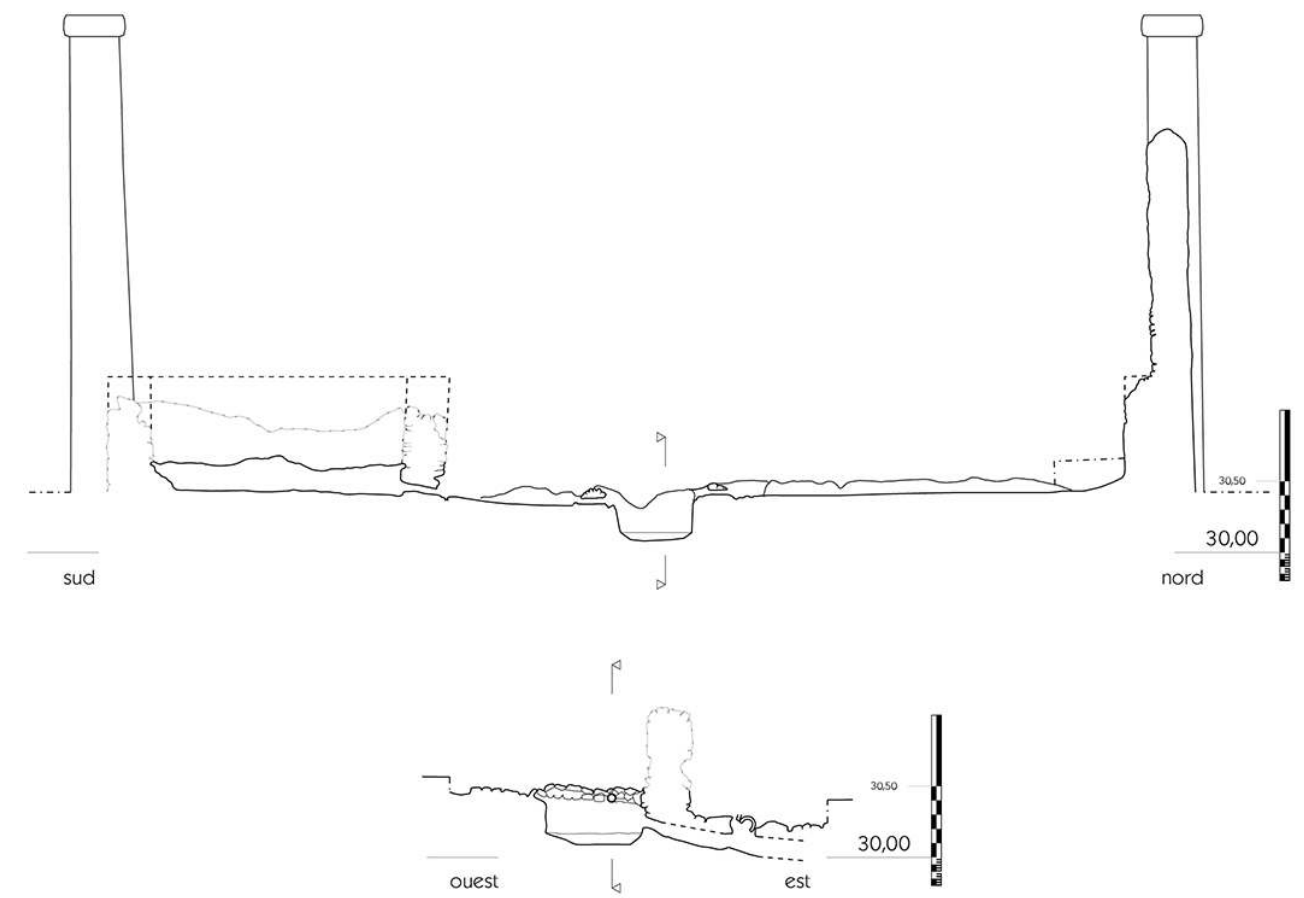

En haut, coupe sud-nord ; en bas, coupe ouest-est. Échelle : $1 / 50$.

Relevé /dessin : A. Delvigne-Ryrko / A. Dufond / N. Monteix - EFR.

$\mathrm{Si}$, avec ce nettoyage, il a été possible de comprendre les transformations de l'adduction et de l'évacuation de l'eau dans cette maison, en lien partiel avec des aménagements construits pour la production boulangère, une inconnue demeure: comment était remplie la citerne dont la bouche se situait, en 79 , entre les meules et le four?

\section{2, 22}

Située sur le parcours de la plupart des visites depuis sa découverte, cette boulangerie a subi de nombreuses transformations, dégradations et restaurations. En raison de cela, et en particulier de l'ensevelissement moderne qui a touché de nombreuses pièces, le nettoyage a finalement été limité pour l'essentiel à la salle des meules et à la partie en avant $\mathrm{du}$ four. Nous ne reviendrons pas dans ce cadre sur les données résultant des fouilles menées entre 2003 et 2006 par l'université d'Innsbruck dans la partie occidentale de l'îlot VII 2 en général et dans cette boulangerie en particulier ${ }^{20}$.

Le nettoyage de la salle des meules a permis d'effectuer le relevé des blocs de basalte constituant le dallage disposé autour des moulins (fig. 32-33). 
Fig. 32 - Pompéi, boulangerie VII 2, 22 - Relevé de l'ensemble de la boulangerie.

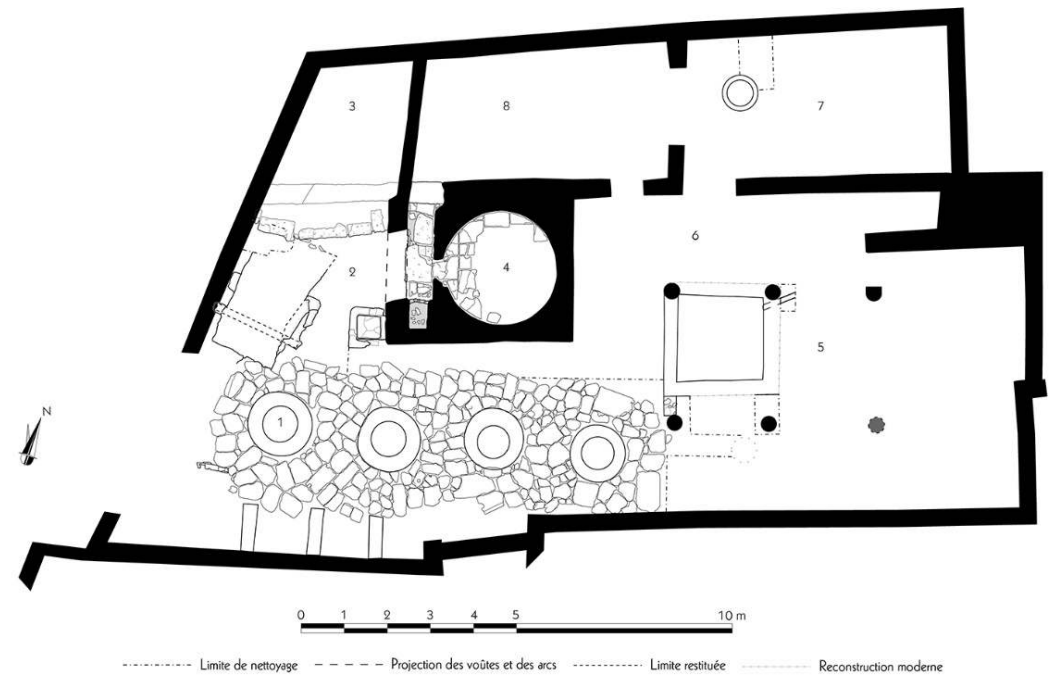

Échelle : 1/100

Relevé / dessin : F. Fouriaux / N. Monteix / S. Mencarelli - EFR.

Fig. 33 - Pompéi, boulangerie VII 2, 22 - Vue générale de la salle des meules.

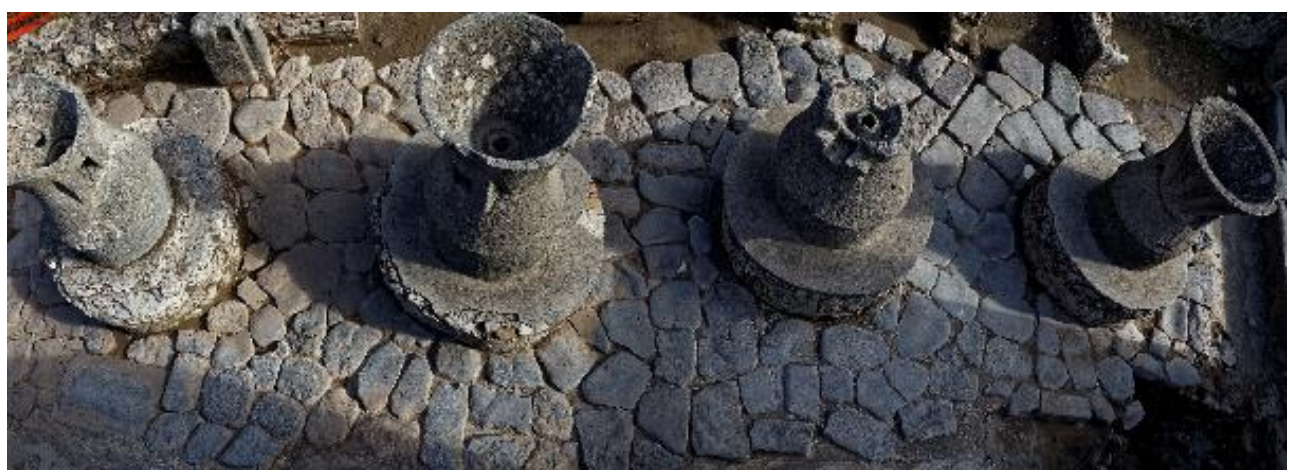

Mosaïque de photos.

Clichés : F. Pauvarel - EFR.

L'enchevêtrement des blocs est tel qu'il laisse supposer que les quatre meules ont été érigées au cours d'une phase unique. Il convient ensuite de signaler que cinq meules sont actuellement visibles dans la boulangerie, seules quatre sont véritablement en place. La cinquième repose sur de la terre moderne et apparaitt avoir été déplacée entre les années 1970 et les années 2000, après avoir longtemps été déposée en deux morceaux dans la boulangerie, la meta contre le mur méridional de la salle des meules, le catillus à l'est du four ${ }^{21}$. Dans la salle du pétrin, un test a été effectué pour vérifier si cet aménagement était en place et la nature de sa fixation au sol. L'épaisseur du remblai moderne, supérieure à $0,40 \mathrm{~m}$, nous a amené à abandonner cette exploration qu'il aurait fallu mener sur l'ensemble de la pièce. On signalera cependant l'extrême dégradation de la lame de 
frasage, réduite à moins d'une vingtaine de centimètres, alors qu'A. Mau l'a décrite intacte en 1886 (fig. 34) ${ }^{22}$. De la même manière, la salle située au nord du four, vraisemblable espace de façonnage des pâtons, en communication directe avec le four à travers un passe-pains, n'a pas été nettoyée eu égard à l'épaisseur supposée d'ensevelissement moderne.

Fig. 34 - Pompéi, boulangerie VII 2, 22 - Intérieur de la cuve du pétrin.

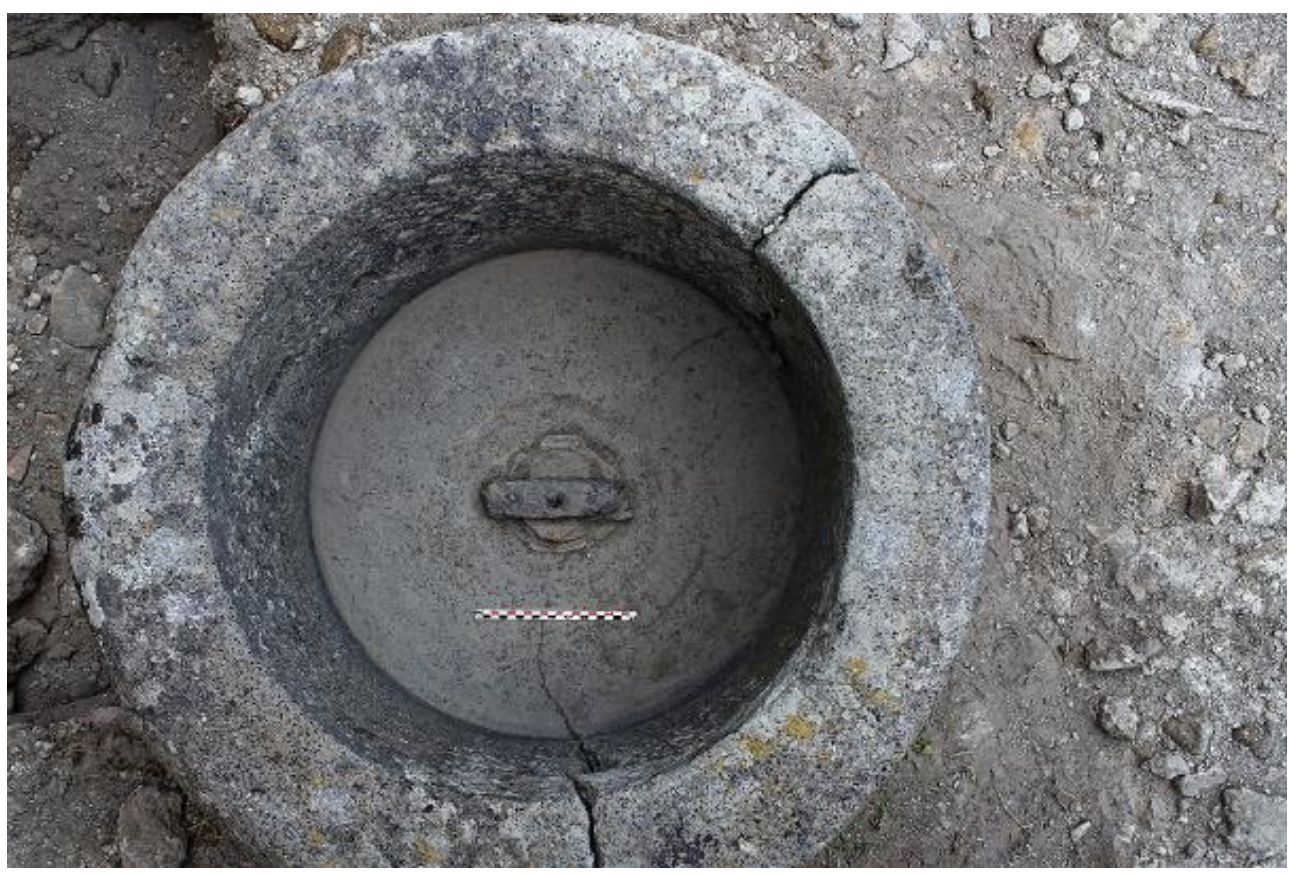

La lame de frasage, particulièrement endommagée, reste perceptible.

Cliché : C. Salviani - EFR.

Nous avons procédé au nettoyage du bassin construit pour partie dans l'emprise du péristyle se développant au sud du four (fig. 35-36). 
Fig. 35 - Pompéi, boulangerie VII 2, 22 - Vue générale du bassin construit dans le péristyle de la maison.

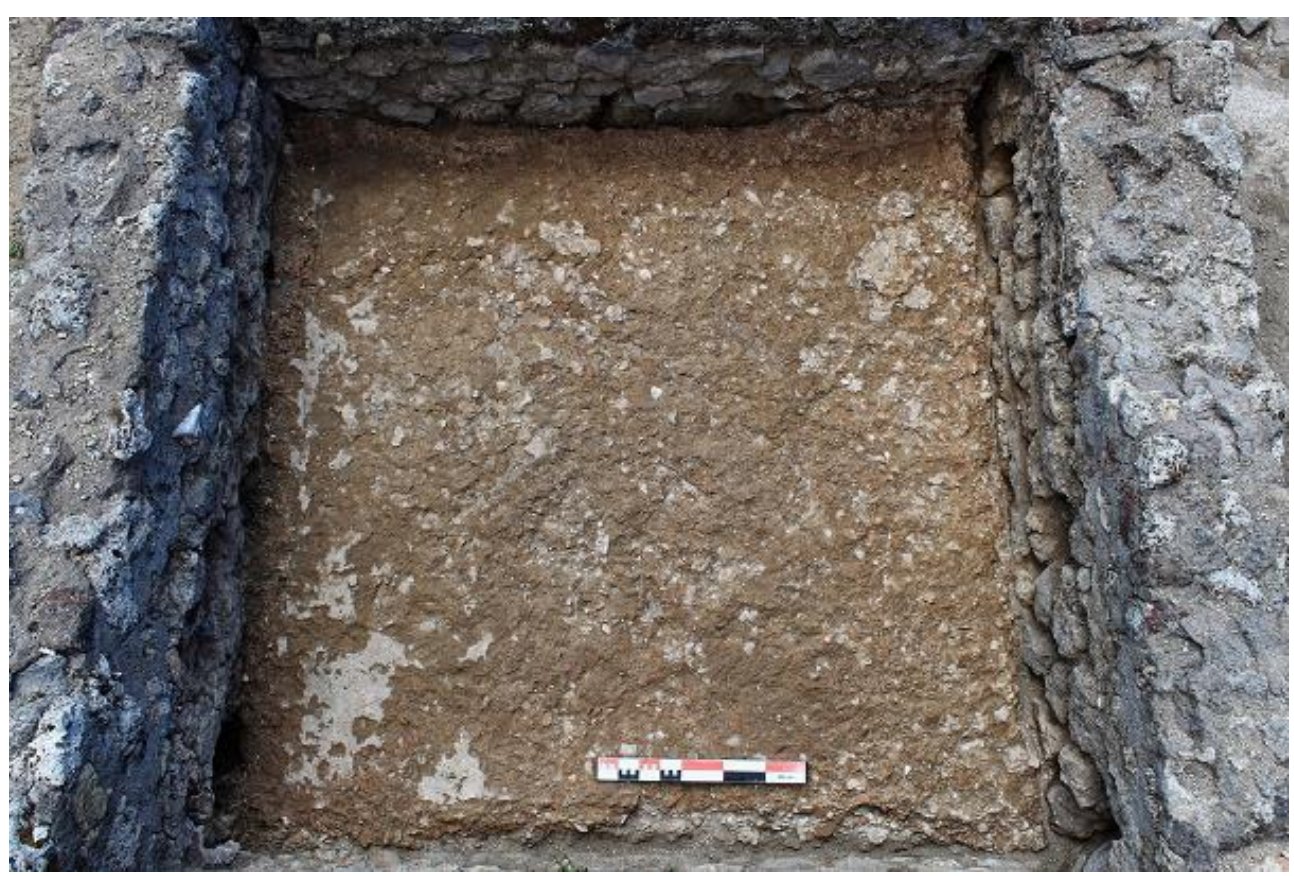

Les murs en élévation sont modernes. On perçoit l'avaloir à gauche et l'une des colonnes du péristyle à droite (vue du nord).

Cliché : A. Watel - EFR.

Fig. 36 - Pompéi, boulangerie VII 2, 22 - Restes de la colonne centrale du bras méridional du péristyle.

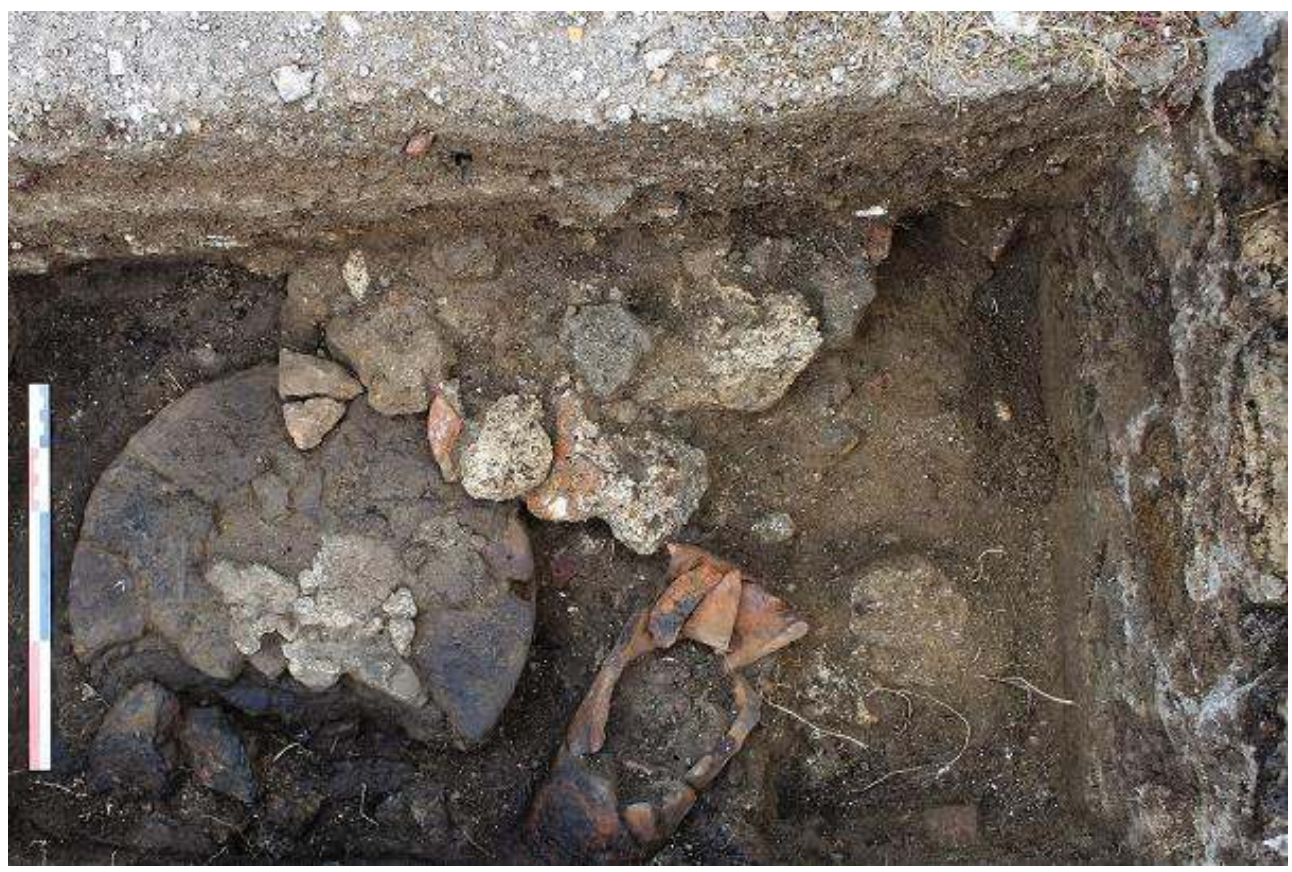

À droite, détaché de celle-ci, on perçoit le mur du bassin (vue de l'est).

Cliché : C. Salviani - EFR. 
En effet, sur les six colonnes délimitant le péristyle, les deux situées au nord et au nordouest ont servi d'appui au mur délimitant le bassin. Cette incorporation a ensuite été masquée par la restauration moderne de l'intégralité des murs sur la colonne septentrionale. Il ne reste donc de ce bassin de plan quadrangulaire que son fond, revêtu d'un épais béton hydraulique qui remontait sur les parois. Dans l'angle nord-est, côté oriental, un avaloir a été percé. Une canalisation composée d'imbrices a été observée (fig. 37). Dotée d'une forte pente initiale, elle se dirige vers le nord-est, où il n'a pas été possible de suivre son parcours. Enfin, aucun élément permettant la mise en eau du bassin n'a été perçu. On supposera que cette transformation du péristyle servait, comme en VII 2, 3.6, pour l'humidification du grain avant sa mouture.

Fig. 37 - Pompéi, boulangerie VII 2, 22 - Rigole de vidange du bassin construite avec des imbrices.

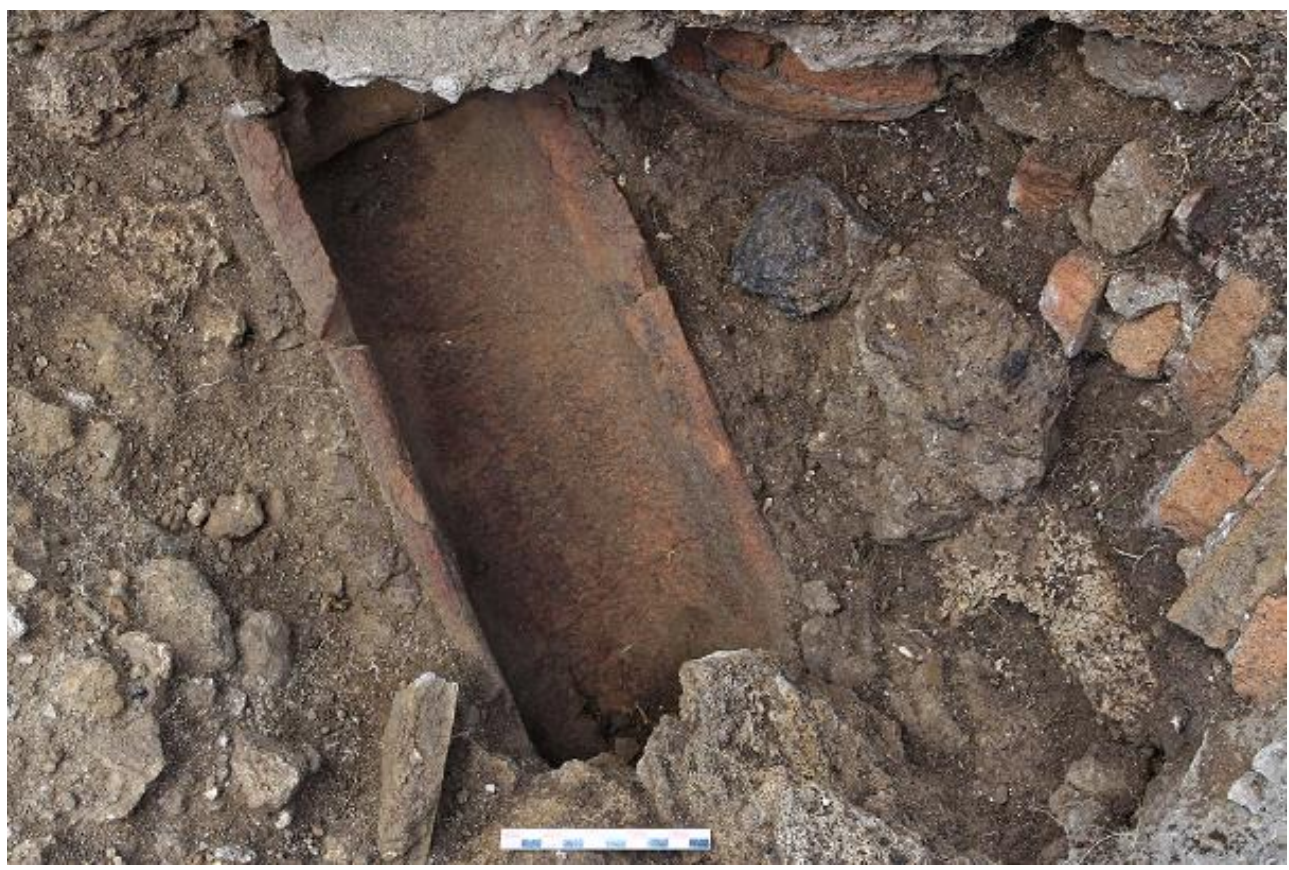

On distingue sur la droite la colonne constituant l'angle du bassin et son effondrement. En haut, la ligne de mortier visible constitue la base de la reconstruction moderne du bassin (vue de l'est).

Cliché : C. Salviani - EFR.

En avant du four, le nettoyage a permis de mettre partiellement au jour une probable cave encore remplie de matériel éruptif (fig. 38). 
Fig. 38 - Pompéi, boulangerie VII 2, 22 - Vue générale de l'espace en avant du four lors de la découverte de l'espace souterrain.

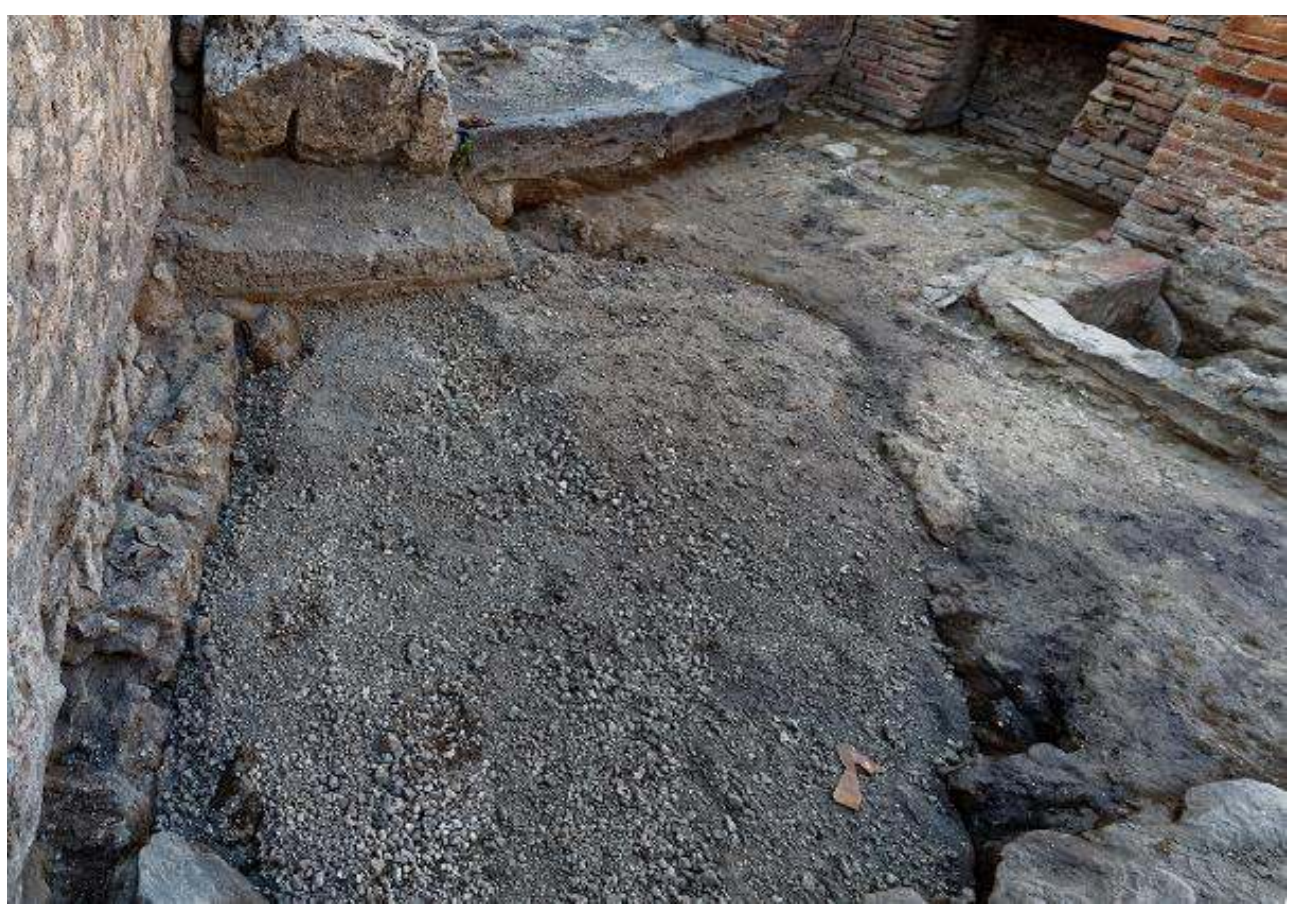

Mosaïque de photos ; vue du sud.

Clichés : N. Monteix - EFR.

Son dégagement intégral n'a pas pu être mené pour des raisons de sécurité : le vide qui aurait alors été créé aurait pu entraîner l'affaissement du mur de façade. Seuls trois côtés de cet espace souterrain ont été observés; l'éventuelle continuation de celui-ci vers le nord et la présence d'un bloc de calcaire « du Sarno » en position instable au-dessus de l'espace de fouille ont interdit l'observation de la paroi septentrionale. Chacune de ces parois est réalisée en moellons de basalte et de calcaire liés au mortier et disposés selon des assises irrégulières (fig. 39). 
Fig. 39 - Pompéi, boulangerie VII 2, 22 - Vue générale de l'espace souterrain lors de l'arrêt du dégagement.

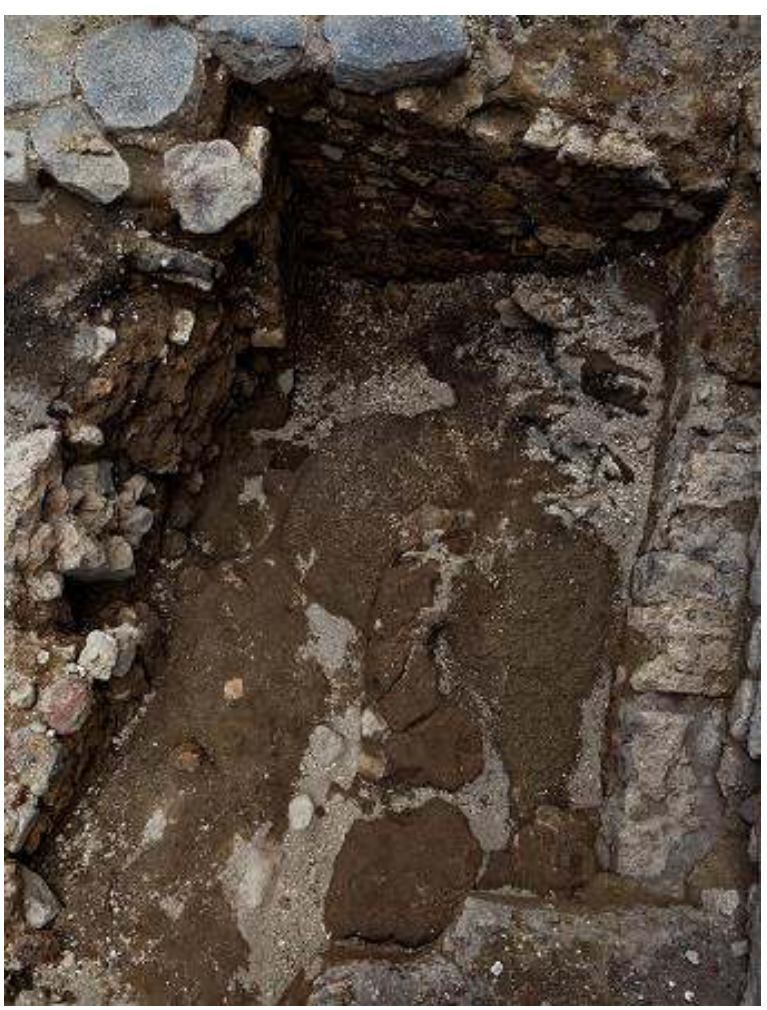

La paroi effondrée à gauche (à l'est) laisse apparaître un probable mur de refend est-ouest. Les restes effondrés du sol de béton sont visibles au premier plan (vue du nord).

Cliché : F. Pauvarel - EFR.

La partie observée de la paroi orientale est intégralement effondrée, vraisemblablement mise à bas lors de l'éruption par un mur antérieur, orienté est-ouest qui a poussé le parement. Tant sur les vestiges de cette paroi qu'au sommet de la paroi occidentale - qui exploite les fondations du mur de façade - des creusements de poutre ont été observés, permettant de supposer la présence d'un plancher au-dessus de la moitié méridionale. Par ailleurs, les nombreux clous, parfois solidaires de fragments de bois pris par l'oxydation, découverts dans cette portion de la cave appuieraient également cette proposition. Dans le quart nord-ouest, le dégagement s'est arrêté sur un niveau de béton épais de 0,12 m (fig. 40). 
Fig. 40 - Pompéi, boulangerie VII 2, 22 - Plan et coupe de l'espace souterrain.
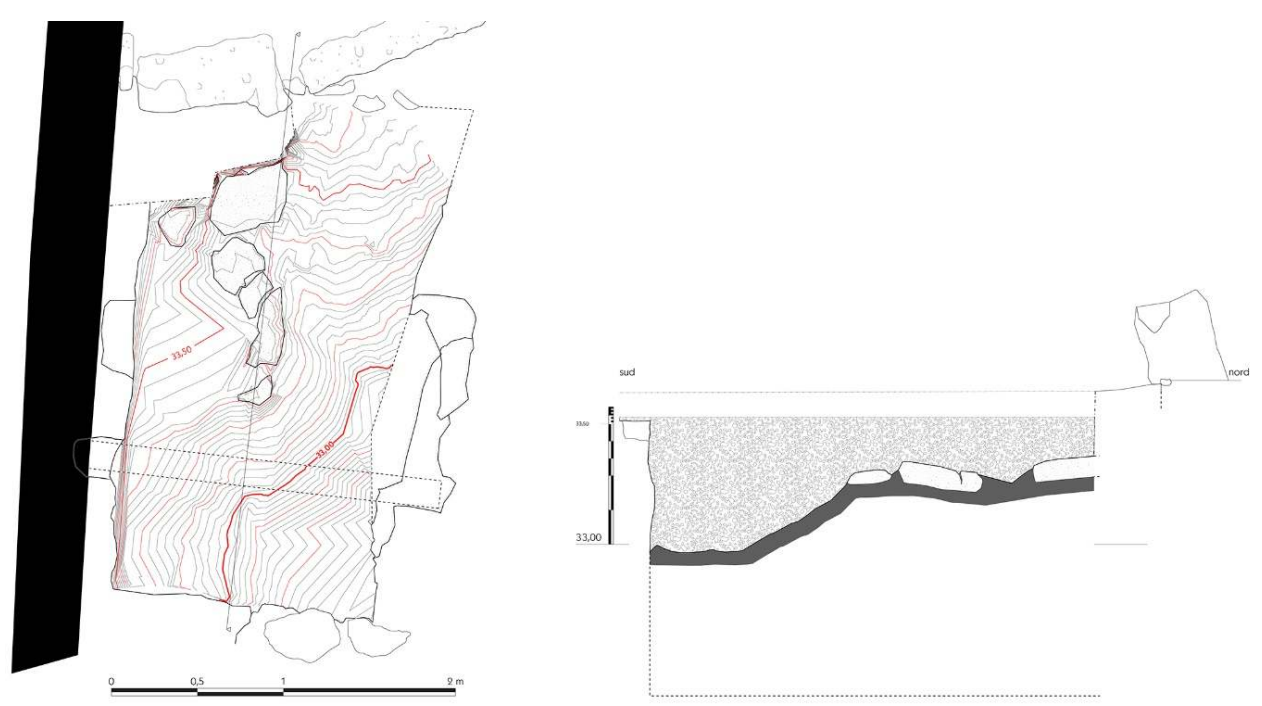

Les courbes de niveau du plan correspondent à l'arrêt de la fouille, sur le niveau de cendres éruptives (isoplèthes d'altitude chaque $2,5 \mathrm{~cm}$ ).

Échelle : $1 / 20$.

Relevé / dessin : F. Fouriaux / N. Monteix - EFR.

Ce niveau paraît avoir constitué le sol au-dessus de la cave au-delà du plancher. Il semble avoir cédé suite à la disparition des probables poutres le soutenant. Le pendage du matériel éruptif et de ce fragment de sol conduit à supposer l'existence d'un mur de refend orienté est-ouest. Cet aménagement pourrait avoir une profondeur maximale de $1,62 \mathrm{~m}$. Son extension vers le nord et sa fonction restent cependant indéterminées.

\section{12,7}

Si le nettoyage de cette boulangerie ne devait initialement porter que sur le four, il a été progressivement élargi à la pièce située à l'ouest de celui-ci afin de remettre au jour certains aménagements mentionnés dans les descriptions du XIX ${ }^{\mathrm{e}}$ siècle. Il aurait été nécessaire de disposer de plus de temps pour nettoyer également la pièce 5 , située au nord, où se déroulait vraisemblablement la préparation des pains (fig. 41). 
Fig. 41 - Pompéi, boulangerie VII 2, 7 - Relevé de l'ensemble de la boulangerie.

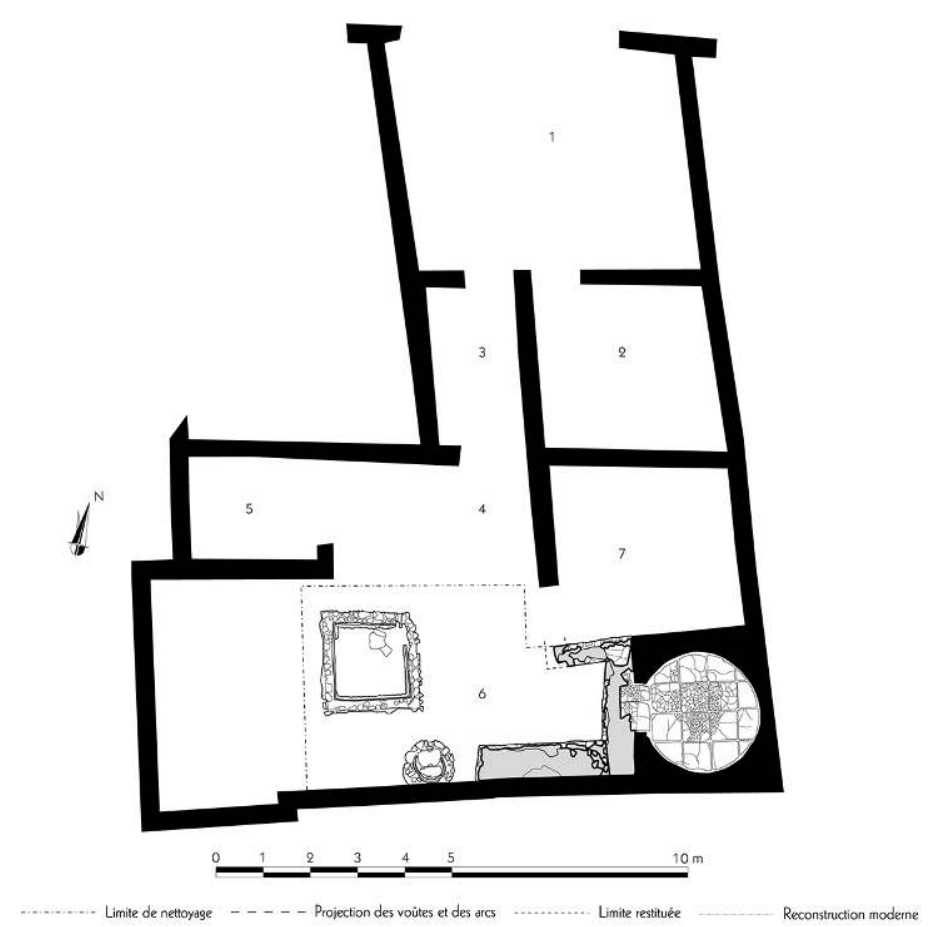

Échelle : 1/100

Relevé / dessin : F. Fouriaux / A. Watel / S. Mencarelli - EFR.

Cette boulangerie, dégagée dans les années 1860, a subi un ensevelissement consécutif à la fouille d'environ $0,50 \mathrm{~m}$, mais également d'importantes restaurations parfois conduites avec une certaine légèreté. C'est l'une des rares -7 boulangeries sur les 40 reconnues à Pompéi - à ne pas présenter de meule parmi ses aménagements et à avoir, en raison de cela, été considérée abusivement comme pistrinum dulciarius.

Hors nettoyage, le four apparaîtrait comme une simple coupole intégrée dans un cube de maçonnerie, posé sur un massif (fig. 42). 
Fig. 42 - Pompéi, boulangerie VII 2, 7 - Coupe transversale, coupe longitudinale et élévation du four.

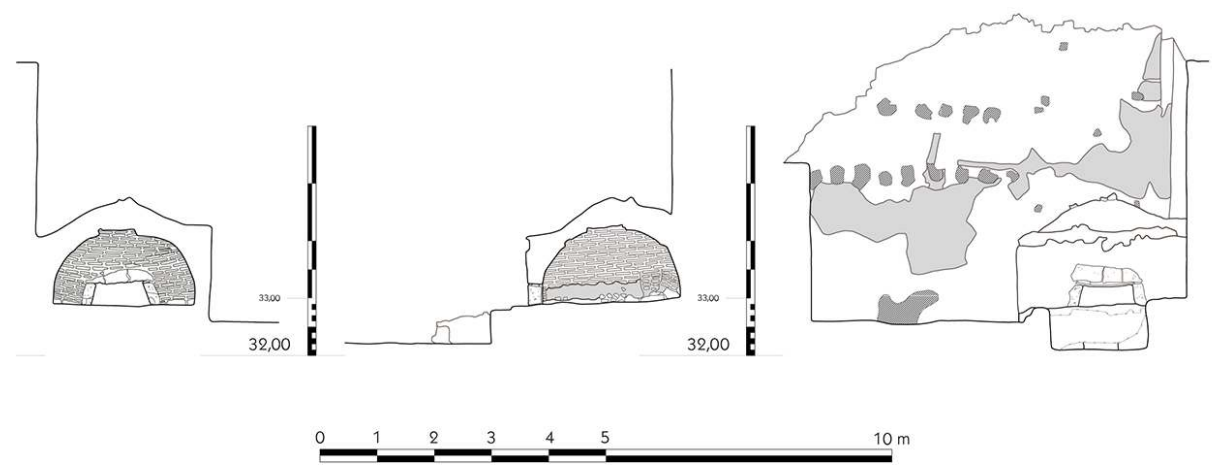

Échelle : 1/100

Relevé / dessin : F. Fouriaux / S. Mencarelli - EFR.

Il serait dépourvu de tout aménagement ${ }^{23}$. En fait, cette impression n'est que le résultat des importantes restaurations effectuées sur les parties en élévation du four qui ont été intégralement reconstruites - parementées à neuf - et des destructions qui ont affecté les autres maçonneries ${ }^{24}$. Le four était vraisemblablement inséré entre trois murs préexistants. Le mur le séparant au nord de la pièce n'est plus conservé que sur $0,73 \mathrm{~m}$ et toute sa tête manque par comparaison avec les plans publiés par G. Fiorelli ${ }^{25}$. Une ouverture devait avoir été pratiquée dans ce mur pour insérer un passe-pains, comme en témoigne une brique bipedalis préservée à l'extrémité septentrionale de l'autel (/table) et légèrement inclinée vers le sud. Initialement, l'autel (/table) n'était pas intégralement maçonné. Comme dans presque tous les fours, une niche était ménagée sur sa face antérieure - largeur : 0,48 m-, surmontée d'une dalle de basalte. La niche a été murée par des restaurations réalisées sans remettre au jour le sol, la dalle abandonnée devant l'autel (/table) (fig. 43). 
Fig. 43 - Pompéi, boulangerie VII 2, 7 - L'autel (/table) du four en cours de dégagement.

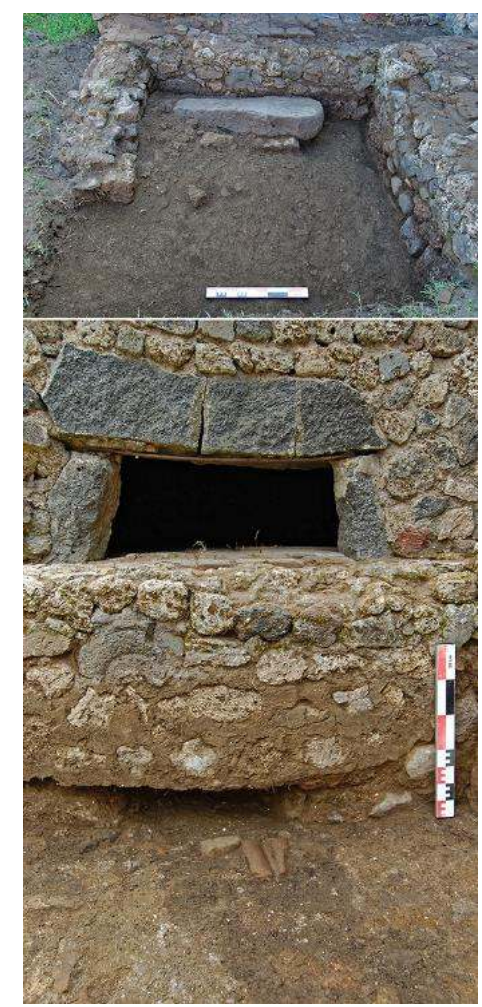

En haut, le bloc d'autel a été abandonné sur place malgré les restaurations effectuées qui ont bouché la niche (en bas; vues de l'ouest).

Cliché : A. Watel - EFR.

Enfin, sur le côté méridional, en avant de l'autel (/table) se trouve un massif maçonné actuellement légèrement plus haut que celui-là ${ }^{26}$. La largeur de ce massif $-0,73 \mathrm{~m}-$ semble interdire de restituer un mur arasé. Il se serait donc agi d'une table complémentaire. L'observation d'un tuyau de plomb, coupé à ras du mur oriental, permet de supposer l'existence d'un chauffe-eau, soit déposé sur la table complémentaire, soit à l'extrémité méridionale de l'autel (/table), alimenté par ce tuyau. Au final, malgré son aspect fruste, ce four présente donc presque l'ensemble des transformations induites par la construction d'un mur diaphragme (passe-pains, chauffe-eau) sans pour autant que ce dernier n'ait été érigé. 
Fig. 44 - Pompéi, boulangerie VII 2, 7 - Four de type clibanus composé d'un dolium en remploi inséré dans un massif de maçonnerie.

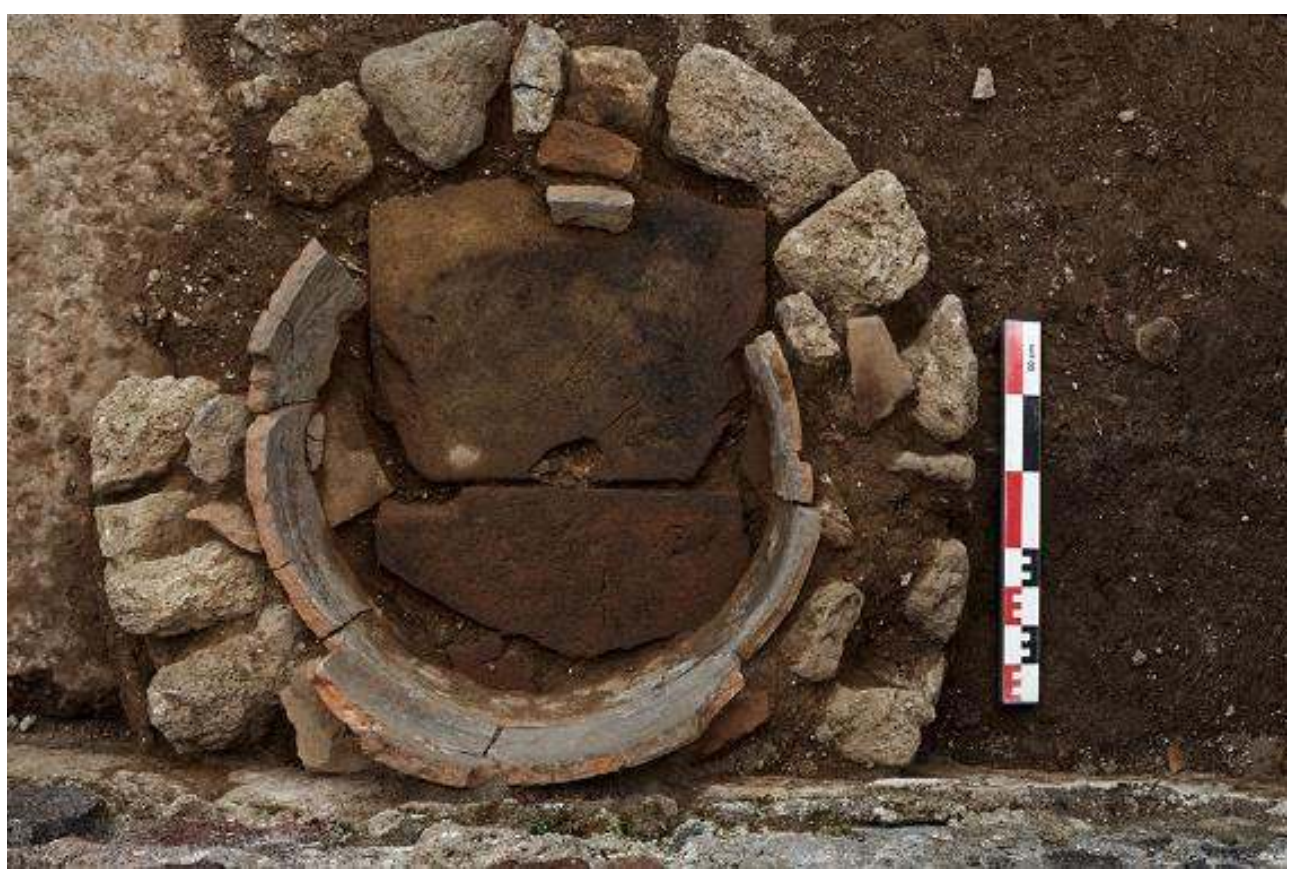

La sole est constituée de tuiles fragmentées (vue du sud).

Cliché : F. Pauvarel - EFR.

Fig. 45 - Pompéi, boulangerie VII 2,7 - Four de type clibanus composé d'un dolium en remploi inséré dans un massif de maçonnerie.

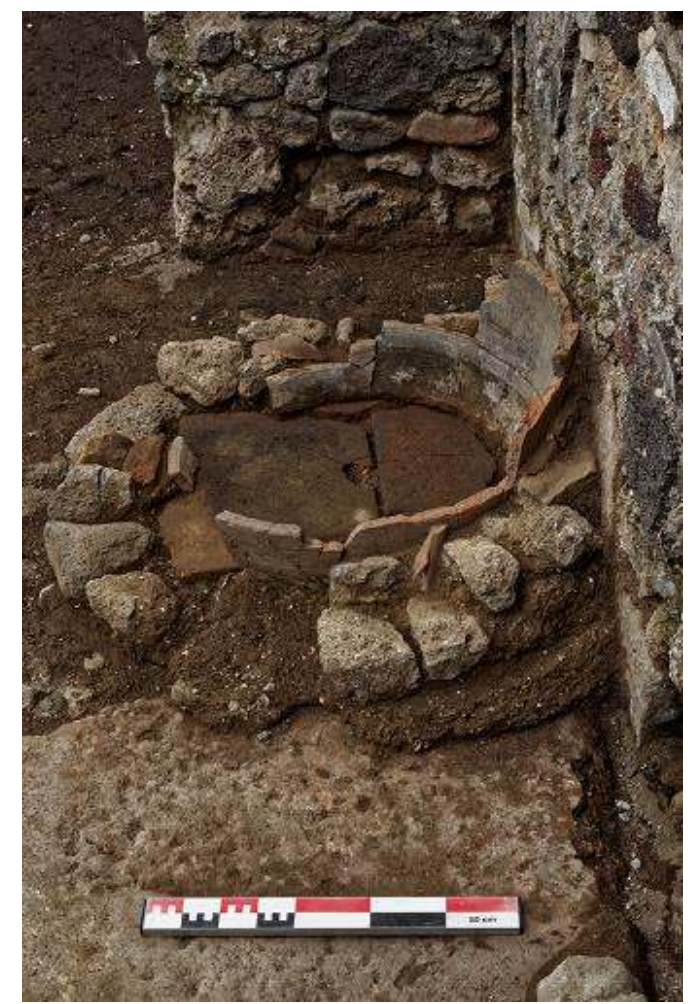

La sole est constituée de tuiles fragmentées (vue de l'ouest).

Cliché : F. Pauvarel - EFR. 
Fig. 46 - Pompéi, boulangerie VII 2, 7 - Plan et profil du four de type clibanus.
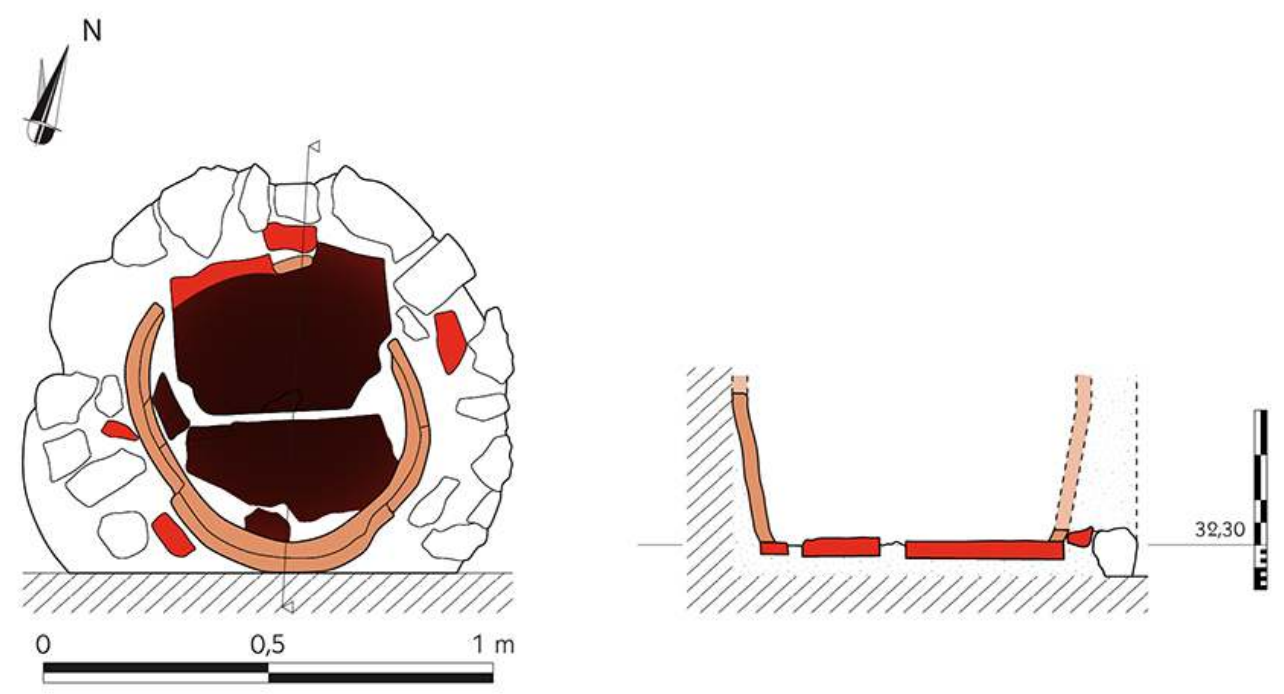

Échelle : 1/20.

Relevé / dessin : A. Watel / S. Mencarelli - EFR.

Deux autres aménagements ont été étudiés au cours de ce nettoyage. Le premier, situé à l'ouest de la table maçonnée construite contre le mur méridional, a été interprété par G. Fiorelli comme un dolium destiné à recevoir de l'eau ${ }^{27}$. L'ensemble est maçonné avec des moellons de calcaire du Sarno et présente un plan circulaire (fig. 44-46). Au centre, deux tuiles fractionnées et posées à plat ont été utilisées comme surface de chauffe, comme le souligne l'effet de paroi qui limite au nord-ouest les traces de carbonisation. Sur cette surface, un dolium, très mal conservé, a été posé, serti dans la maçonnerie. Il était percé à sa base, au nord-est, afin de ménager un évent, comme l'indiquent également les traces de carbonisation. La faible conservation de l'ensemble interdit toute restitution de la hauteur. Bien qu'il s'agisse d'un aménagement maçonné, on le rapprochera des fours en cloche découverts en Narbonnaise ou en Bretagne ${ }^{28}$. On supposera dès lors que le dolium était ouvert à son sommet et que cette ouverture permettait l'insertion de galettes non levées, destinées à cuire contre la paroi; il s'agirait de ce fait du premier clibanus découvert à Pompéi ${ }^{29}$.

Le second aménagement remis au jour est une vasque d'impluvium située à l'ouest du four (fig. 47). Fortement dégradé, ce bassin est délimité par des murets d'opus incertum de moellons de basalte et de calcaire « du Sarno ». 
Fig. 47 - Pompéi, boulangerie VII 2, 7 - Bassin d'impluvium ( ?) dont l'évacuation est bouchée mais qui est maintenu dans la boulangerie.

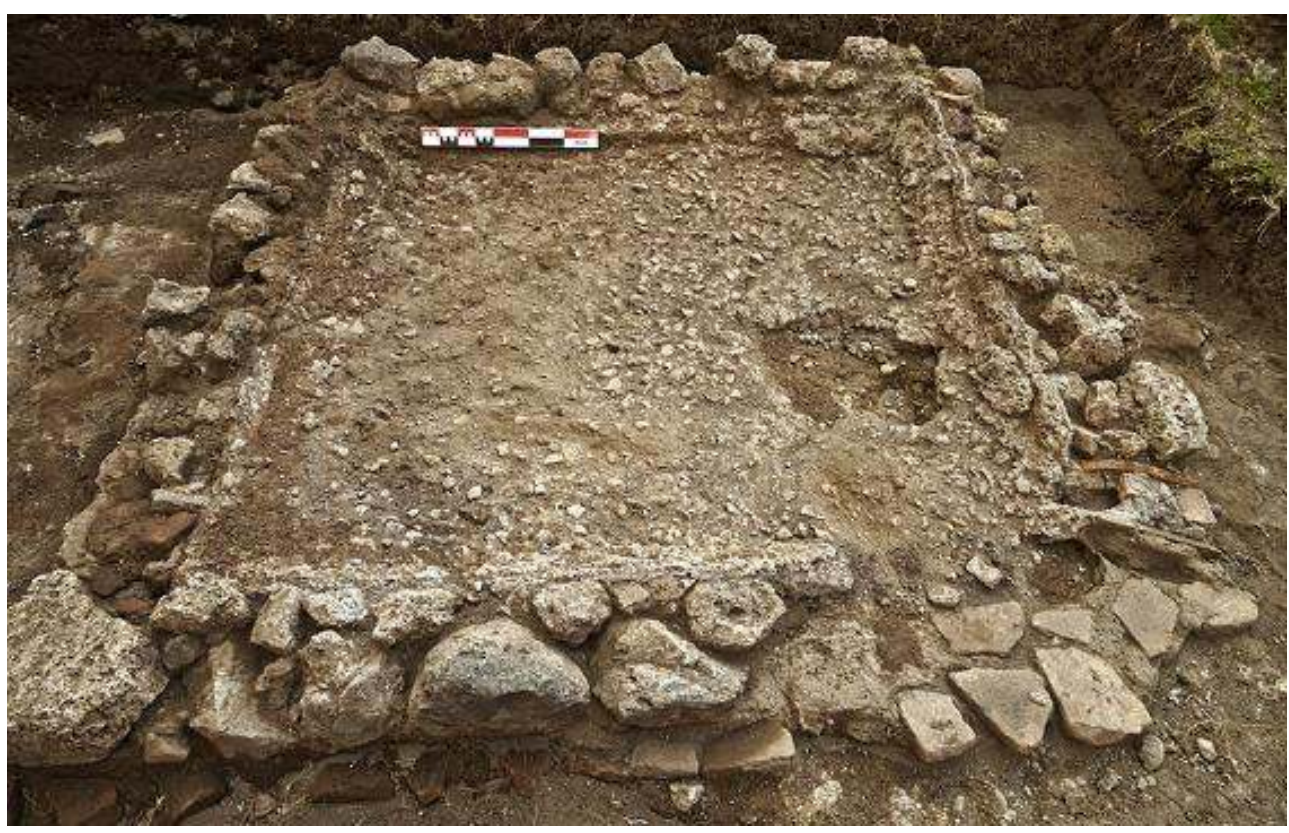

Vue de l'est.

Cliché : F. Pauvarel - EFR.

Dans sa première phase, il dispose d'un exutoire à l'angle nord-est, aménagé avec des tuiles couvre-joints en remploi ${ }^{30}$. Dans un moment successif, le revêtement hydraulique $\mathrm{du}$ bassin est refait, avec notamment l'adjonction d'un boudin de mortier à l'intersection entre la paroi verticale et le fond. L'exutoire paraît alors être bouché sans être pour autant remplacé par un autre. L'utilisation d'un tel aménagement dans le cadre de la production boulangère semble a priori d'autant plus incongrue que cet atelier ne dispose d'aucune meule. Il semble de ce fait nécessaire d'exclure son emploi comme bassin pour l'humidification des grains, puisque les grains n'étaient pas traités directement ici. À titre d'hypothèse, il serait possible de supposer que ce «bassin » n'ait pas eu, lors de sa seconde phase d'existence, de rôle hydraulique, mais seulement celui d'espace de stockage, en particulier de la farine utilisée pour fabriquer pains et galettes ${ }^{31}$.

\section{12, 11}

41 Comme en VII 12, 7, la boulangerie VII 12, 11 ne présente ni meule, ni pétrin mécanique. Plusieurs pièces ont été partiellement ou intégralement nettoyées afin de tenter de mieux comprendre l'organisation de l'espace, en dépit de certaines interventions modernes qui nous ont interdit de nettoyer certaines pièces. Ainsi, la pièce 5 ne peut pas être atteinte à l'heure actuelle suite au bouchage de la porte la mettant en communication avec la pièce $4^{32}$. Les pièces 6 et 9 - cette dernière étant une probable latrine - servent à contenir des résidus d'éboulis amassés au fil des années (fig. 48). 
Fig. 48 - Pompéi, boulangerie VII 2, 11 - Relevé de l'ensemble de la boulangerie.

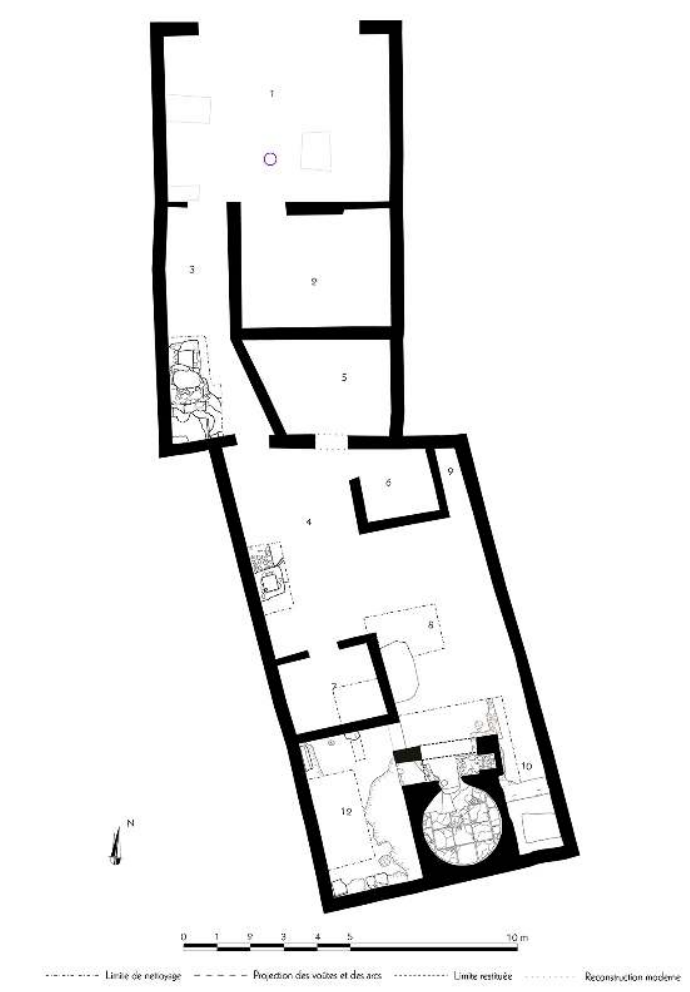

Échelle : 1/100

Relevé / dessin : F. Fouriaux / S. Aho / S. Mencarelli - EFR.

La boulangerie est installée dans la partie méridionale de l'édifice. Cette fraction est remarquable par son uniformité de construction, en particulier dans ses murs périmétriques. L'intégralité du mur occidental et la majeure partie du mur oriental - au nord de la pièce 12 - sont réalisées en opus incertum mélangeant moellons de calcaire « du Sarno ", basalte et tuf jaune, disposés au-dessus d'un massif de réglage construit avec six assises de tuiles ou de briques. Il est très probable que ce mur soit une reconstruction à l'identique d'un mur préexistant ayant le même tracé ; sa restauration pourrait alors remonter aux travaux consécutifs au séisme de $62 / 63^{33}$.

Les éléments renvoyant aux phases antérieures à l'installation de la boulangerie sont peu nombreux et rarement clairs. Le mur méridional sur lequel s'appuie le four et l'ensemble des structures observées est le plus ancien. On notera également, dans l'angle sud-est de la pièce 10 , les vestiges d'un aménagement d'interprétation incertaine (fig. 49) ${ }^{34}$. Les éléments maçonnés subsistant prennent la forme d'un quadrilatère - se prolongeant éventuellement vers l'ouest - avec une dépression en son centre. Cet amas était enduit sur son côté septentrional et était bordé, toujours vers le nord, pas un sol en béton gris lissé. Dans une phase postérieure à la démolition de cette construction, un muret estouest est bâti immédiatement au nord de celle-ci. 
Fig. 49 - Pompéi, boulangerie VII 2, 11 - Vue d'ensemble de la pièce 10 après son nettoyage.

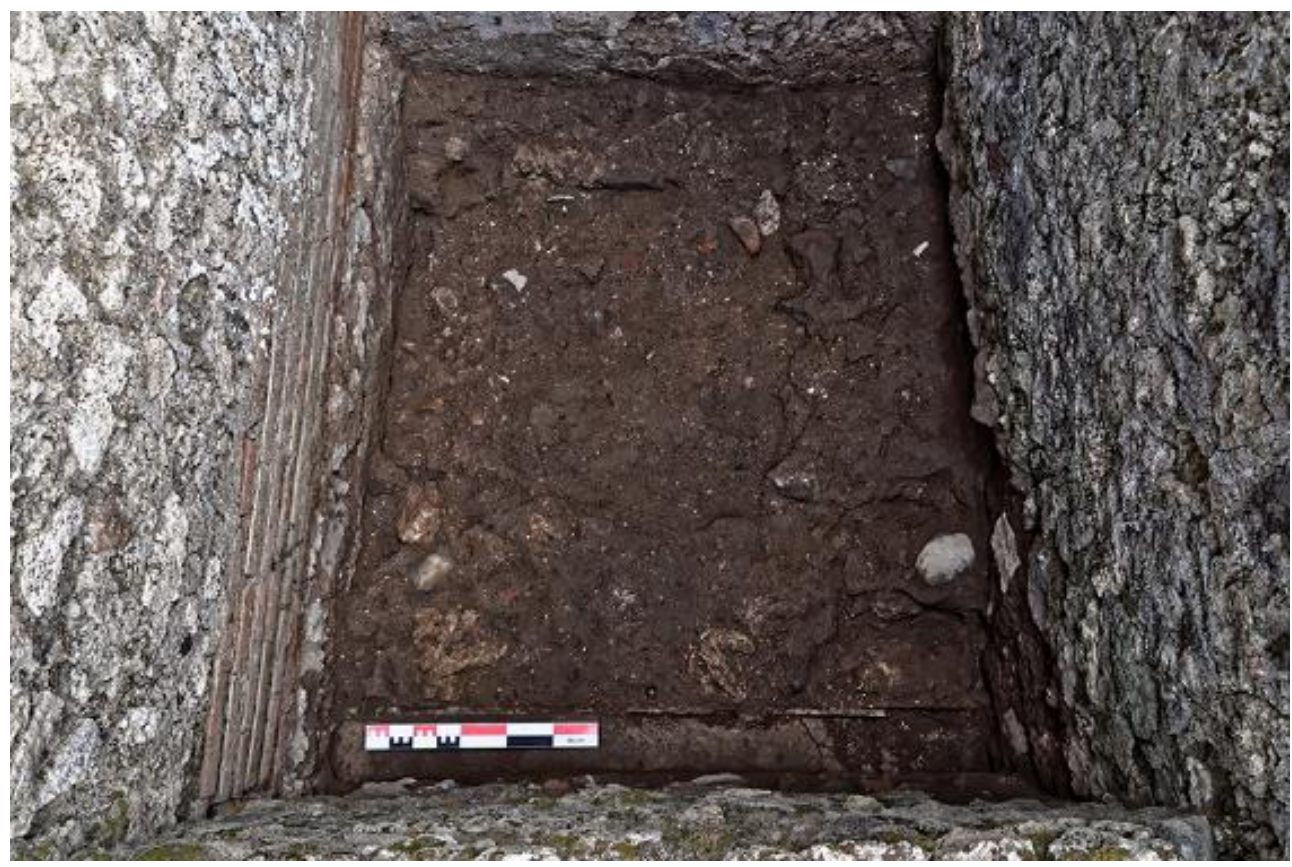

Vue du nord.

Cliché : S. Aho - EFR.

Le four a été construit en appui sur le mur méridional et sur un mur préexistant à l'ouest, utilisé comme refend avec la pièce 12. Lors de sa construction, il apparaît dépourvu de mur diaphragme. Sa façade aurait cependant déjà comporté des tuiles (fig. 50); en avant se développait un autel (/table). 
Fig. 50 - Pompéi, boulangerie VII 2, 11 - Chauffe-eau incorporé dans le mur diaphragme du four dans une seconde phase.

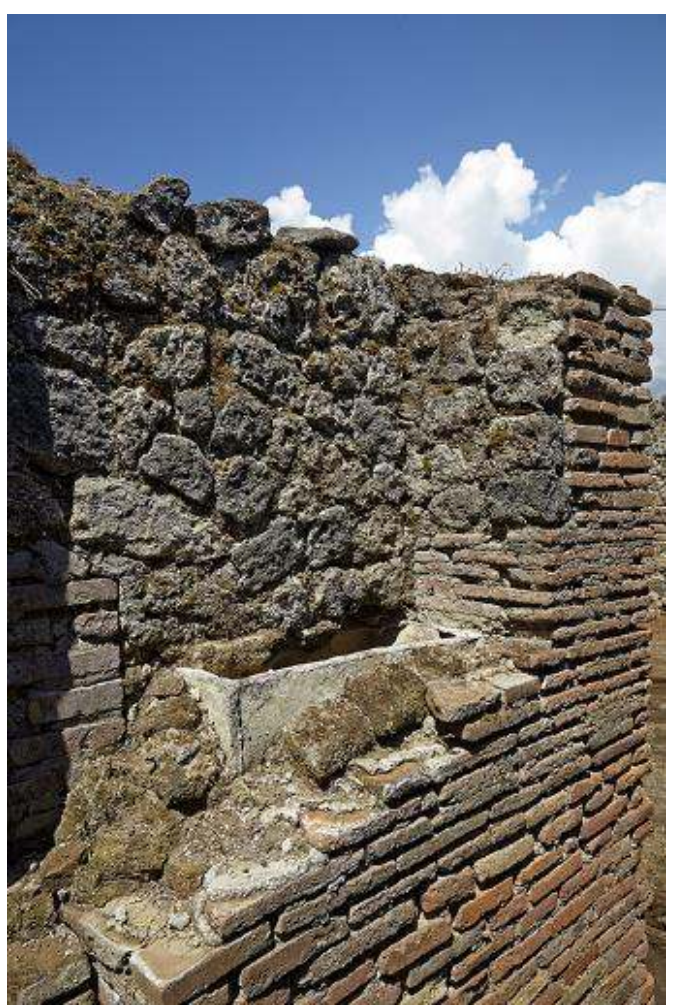

On note que la façade initiale (à gauche) était construite en tuiles (vue du sud-est).

Cliché : F. Pauvarel - EFR.

Il n'est pas possible de définir si un passe-pains avait déjà été percé dans le mur occidental : son parement a été intégralement restauré, interdisant toute lecture des transformations de la maçonnerie. Il semble cependant que, durant cette première phase, l'accès à la pièce 12 n'ait pas été placé dans l'immédiate proximité de l'autel du four : un mur de refend continu pourrait avoir longé le four. Enfin, il est possible que l'espace disponible en avant du four ait été limité par un muret orienté nord-sud dont ne subsistent que les fondations, suite à son arasement lors de la phase suivante.

Ce n'est probablement que lors de la construction du mur diaphragme et de ses différents équipements que la configuration spatiale de la boulangerie change. La pièce 7 est définie par la construction d'un mur la séparant de la pièce 12. Aucune activité liée à la boulangerie ne semble y être installée ${ }^{35}$. Le four est doté d'un avant-corps qui comprend, à l'est, un chauffe-eau alimenté par un tuyau en plomb, et à l'ouest, un passe-pain communiquant avec le fournil désormais installé dans la pièce 12 . Au pied du massif constituant le mur diaphragme, à l'est, un fond de Dressel 20 a été installé, afin de recevoir l'eau en excès provenant du chauffe-eau (fig. 51$)^{36}$. 
Fig. 51 - Pompéi, boulangerie VII 2, 11 - Fond d'amphore utilisé pour recevoir l'eau en surplus issue du chauffe-eau.

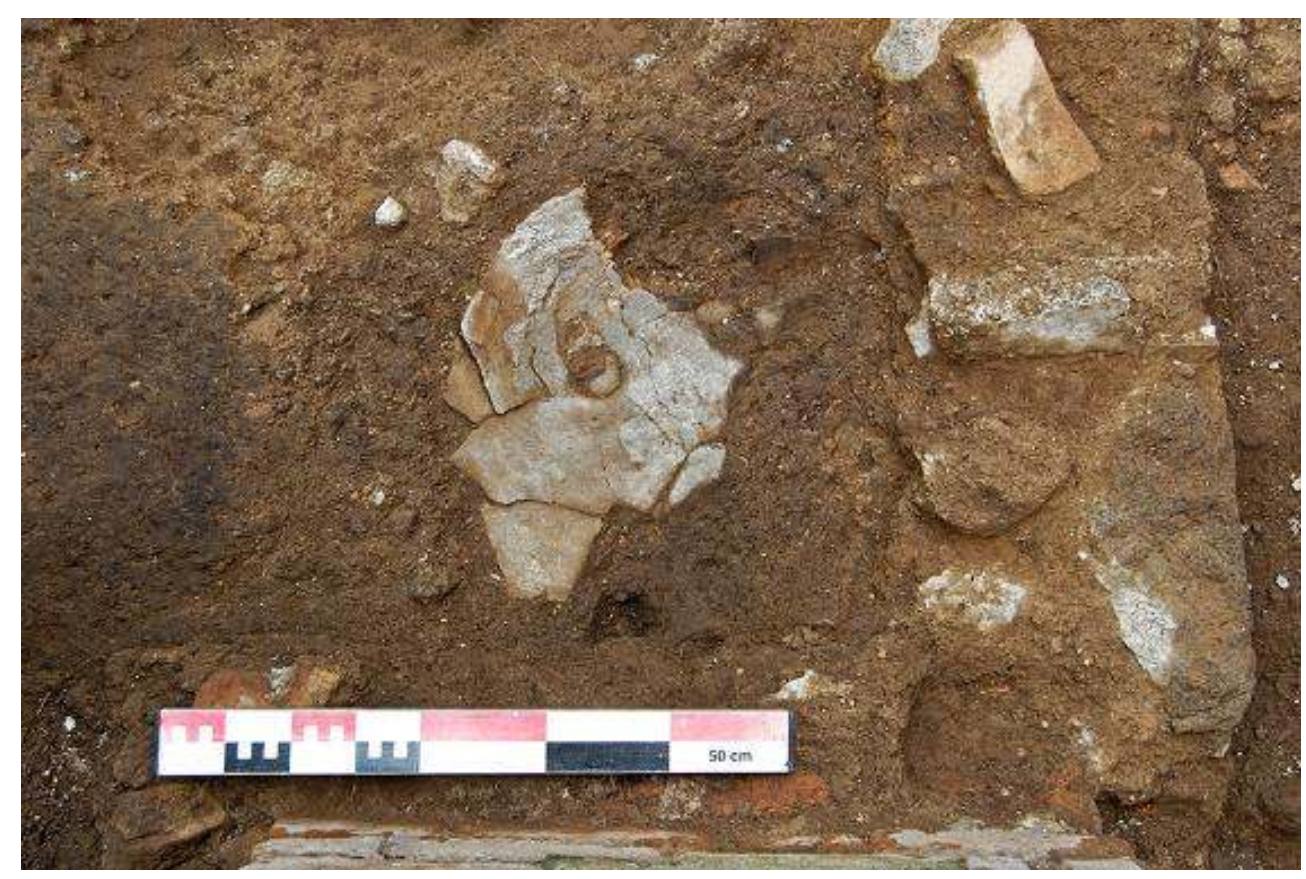

Vue du sud.

Cliché : S. Aho - EFR.

Le couvrement de l'espace entre le mur diaphragme et la façade du four est assuré par une voûte constituée de fragments de briques. Une cheminée est construite au sommet ; le conduit, réalisé avec un tuyau céramique, est protégé par un massif de maçonnerie sensiblement quadrangulaire (fig. 52-53). 
Fig. 52 - Pompéi, boulangerie VII 2, 11 - Élévation de la façade.
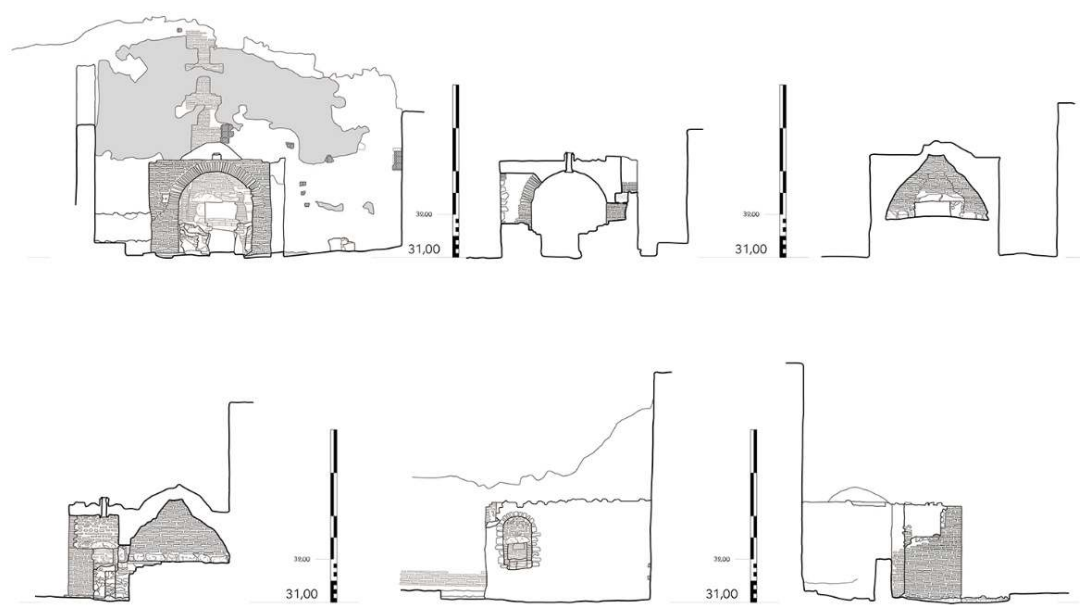

Échelle : 1/100

Coupe transversale en arrière du mur diaphragme, coupe transversale dans la chambre de cuisson (en haut) ; coupe longitudinale, élévation occidentale et élévation orientale four (en bas).

Relevé / dessin : F. Fouriaux / S. Mencarelli - EFR.

Fig. 53 - Pompéi, boulangerie VII 2, 11 - Vestiges du massif gainant le conduit de cheminée.

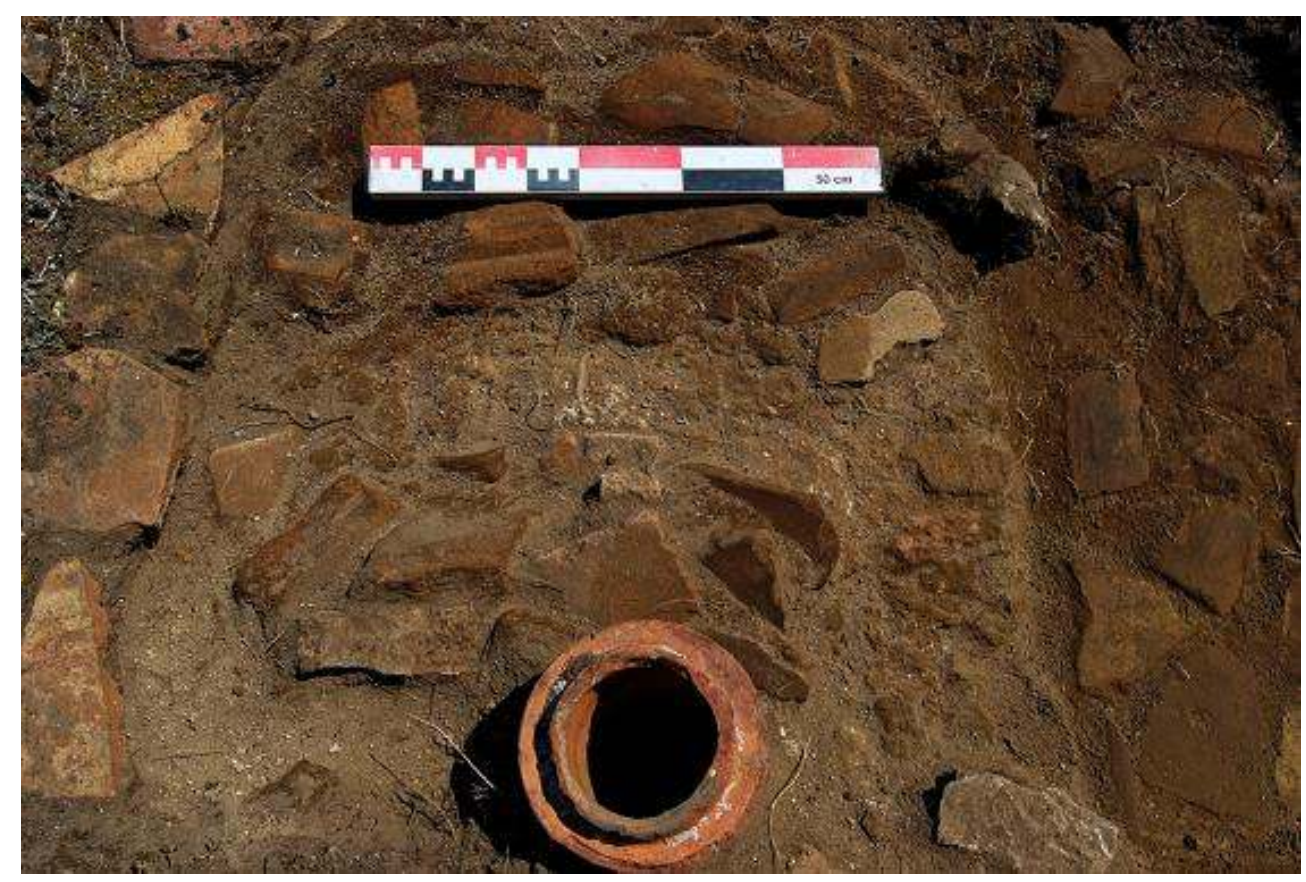

Vue de l'ouest.

Cliché : N. Monteix - EFR. 
Dans la pièce 12, des tables de façonnage et des étagères sont installées. Comme souvent, ne subsistent de ces aménagements que des vestiges d'interprétation délicate, en raison notamment des techniques de construction déployées, qui montrent une adaptation aux matériaux disponibles plus qu'un choix véritablement raisonné. Ainsi, les deux pieds de tables disposés contre le mur méridional sont construits en remployant des blocs de basalte pour l'un, tandis que de l'autre ne subsiste qu'une tuile fragmentaire posée à plat sur un lit de mortier (fig. 54).

Fig. 54 - Pompéi, boulangerie VII 2, 11 - Vue générale de la salle de façonnage.

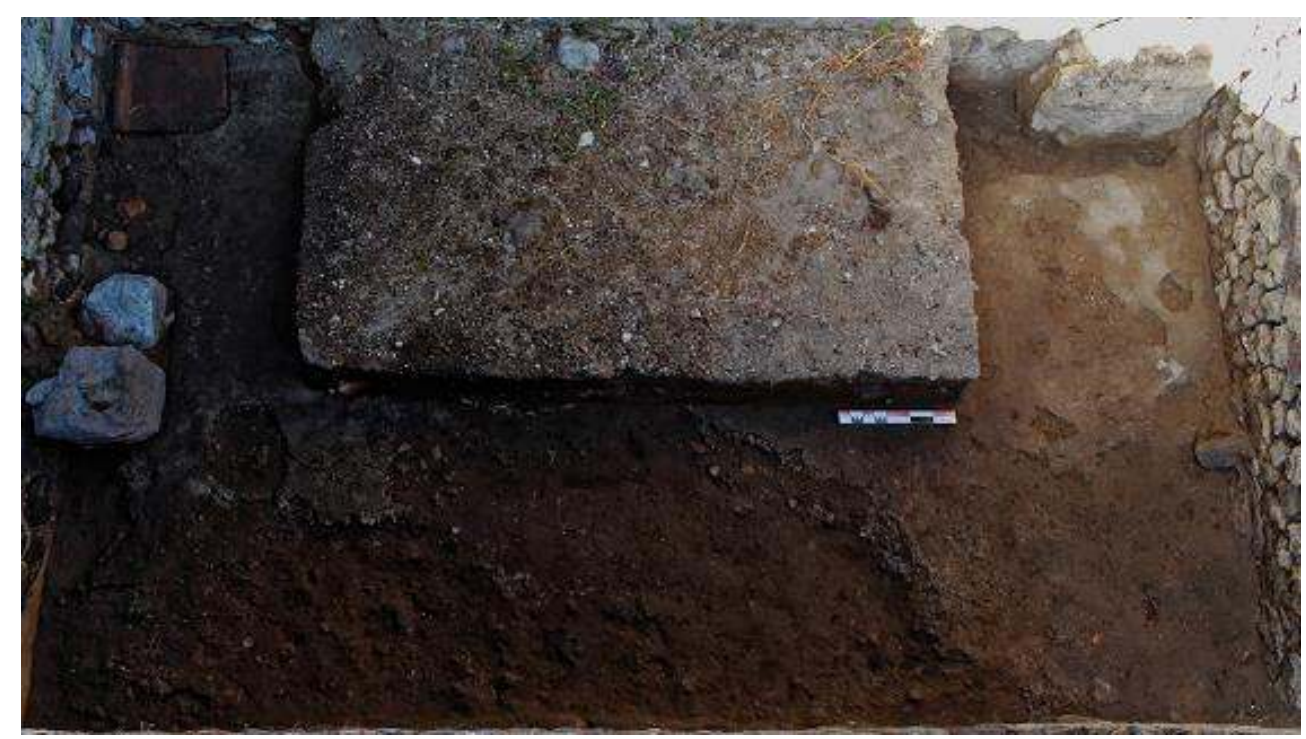

Vue de l'est.

Cliché : S. Aho - EFR.

Le pied installé contre le mur occidental au nord témoigne d'un bricolage élevé au rang de grand art: un fragment de mur maçonné a été remployé presque tel quel avec quelques éléments ajoutés au sommet, le tout déposé sur un lit de mortier (fig. 55). 
Fig. 55 - Pompéi, boulangerie VII 2, 11 - Pied de table maçonné, remployant un fragment de mur.

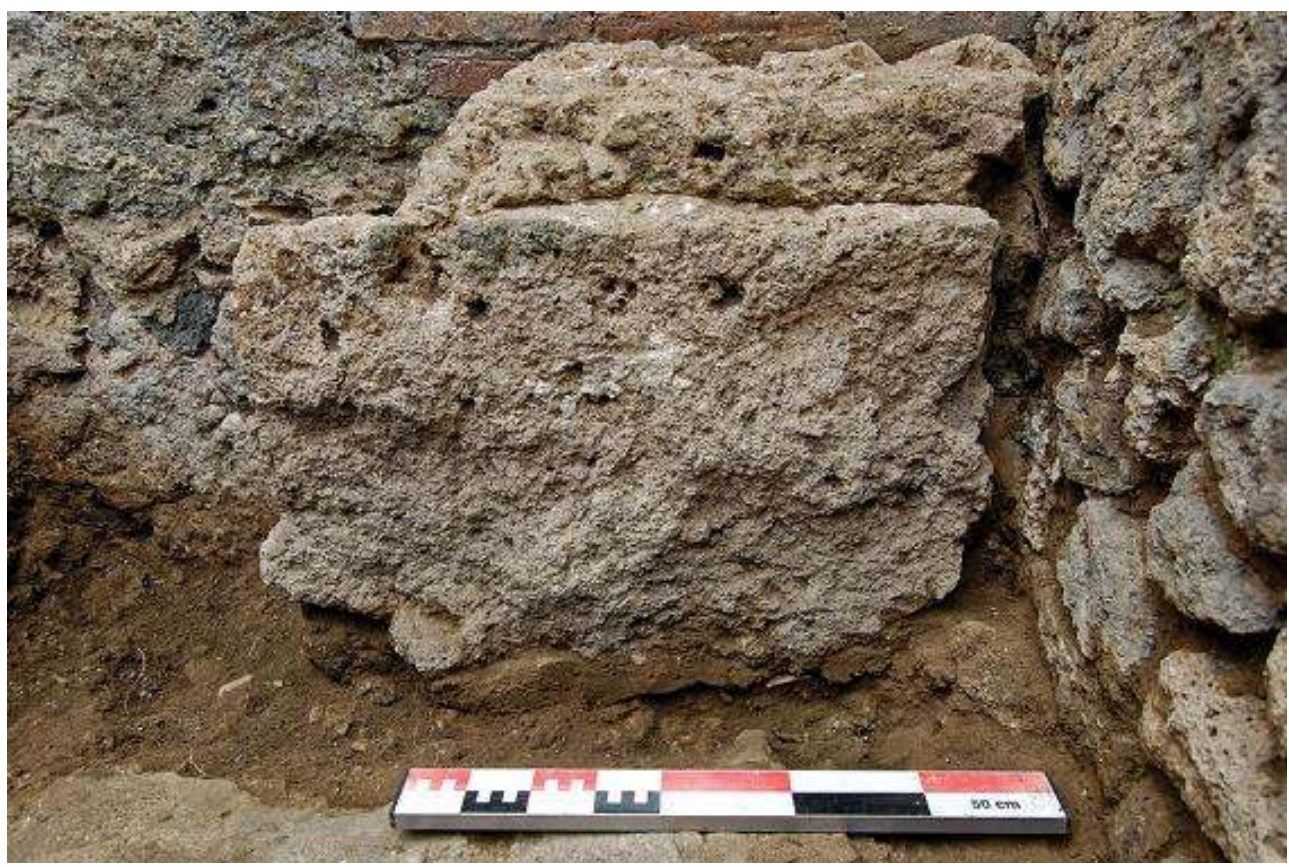

Vue de l'est.

Cliché : S. Aho - EFR.

La construction de son pendant, situé à 1,14 m plus à l'est, a été réalisée avec un tel soin qu'il n'en reste qu'un moellon de basalte dans un lit de mortier. En outre, quatre étagères superposées ont été installées sur les murs sud et ouest. Les encoches creusées dans la partie occidentale du mur méridional ont disparu, rebouchées par des restaurations modernes, ce qui rend difficile la restitution de l'ensemble. Cependant, comme pour les pieds de table, une certaine improvisation semble avoir présidé à la mise en place de ces étagères : seul, et c'est heureux, le principe d'horizontalité a été considéré ; l'alignement vertical des supports est beaucoup plus hasardeux (fig. 56). En tout, ce sont néanmoins entre 12 et $20 \mathrm{~m}$ linéaires permettant d'entreposer les pâtons pendant la levée qui ont été mis en place $^{37}$. 
Fig. 56 - Pompéi, boulangerie VII 2, 11 - Mur méridional de la salle de façonnage.

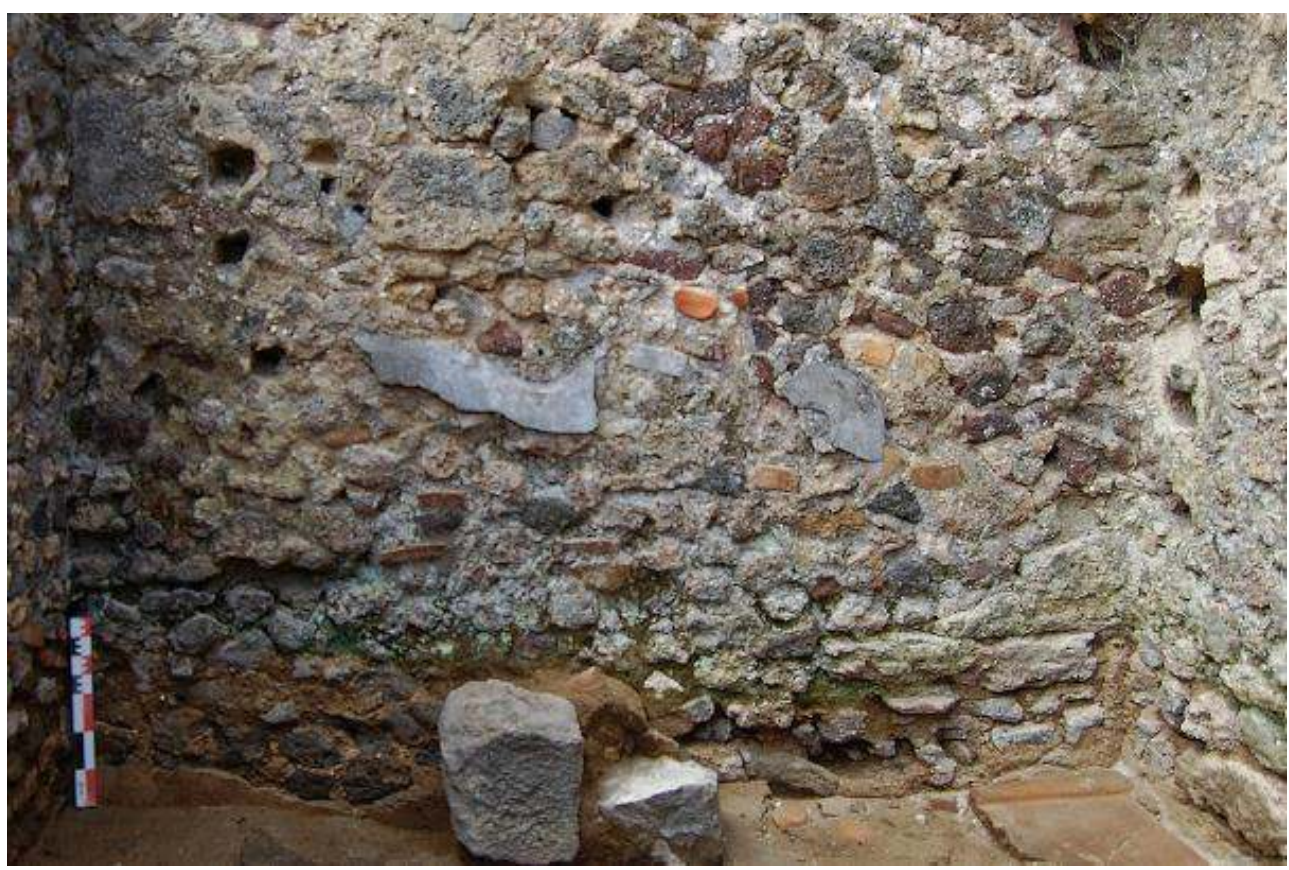

Vue du nord

Cliché : S. Aho - EFR.

Enfin, bien que sans lien immédiatement clair avec la production de pain, divers aménagements liés à l'approvisionnement en eau ont été observés. Tout d'abord, dans la salle 4 , un nettoyage ciblé a permis de comprendre le fonctionnement du large tuyau de plomb vertical fixé au mur occidental de la pièce (fig. 57). Cette fistula recueillait les eaux météoriques pour les convoyer dans un bassin quadrangulaire dont seul le fond est constitué d'un revêtement hydraulique, suite à la disparition de l'enduit des parois. Un tuyau céramique inséré dans la paroi septentrionale du bassin permet l'évacuation des eaux reçues. Son parcours est ensuite protégé par un massif maçonné, jusqu'à ce que, selon toute hypothèse, il rejoigne la citerne de l'édifice.

Fig. 57 - Pompéi, boulangerie VII 2, 11 - Bassin de réception des eaux météoriques en cours de nettoyage (à g.) et à l'achèvement de celui-ci (au centre ; vues de l'est). À droite, détail de la canalisation d'évacuation (vue du nord).

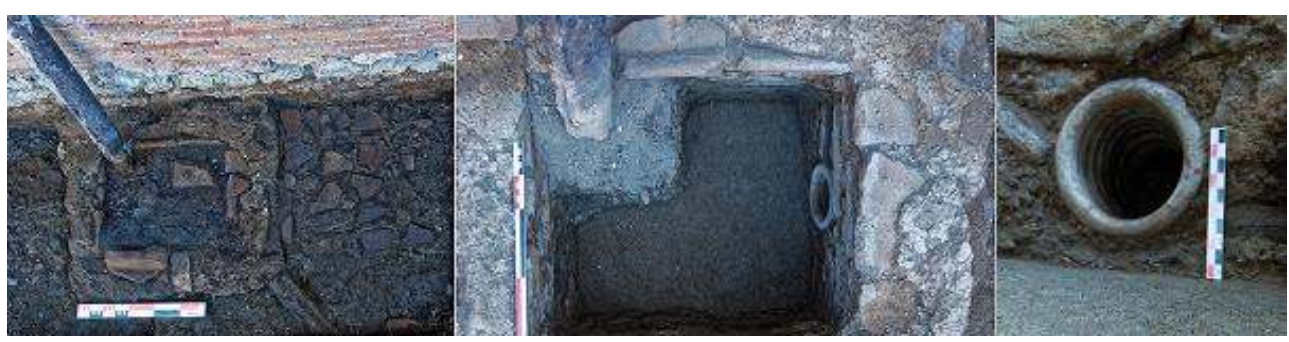

Clichés : S. Aho - EFR.

La bouche de celle-ci a été observée dans le couloir 3 qui relie la boutique de façade aux espaces de fabrication (fig. 58). 
Fig. 58 - Pompéi, boulangerie VII 2, 11 - Bouche de citerne et bassin de réception des eaux dans la pièce 3 .

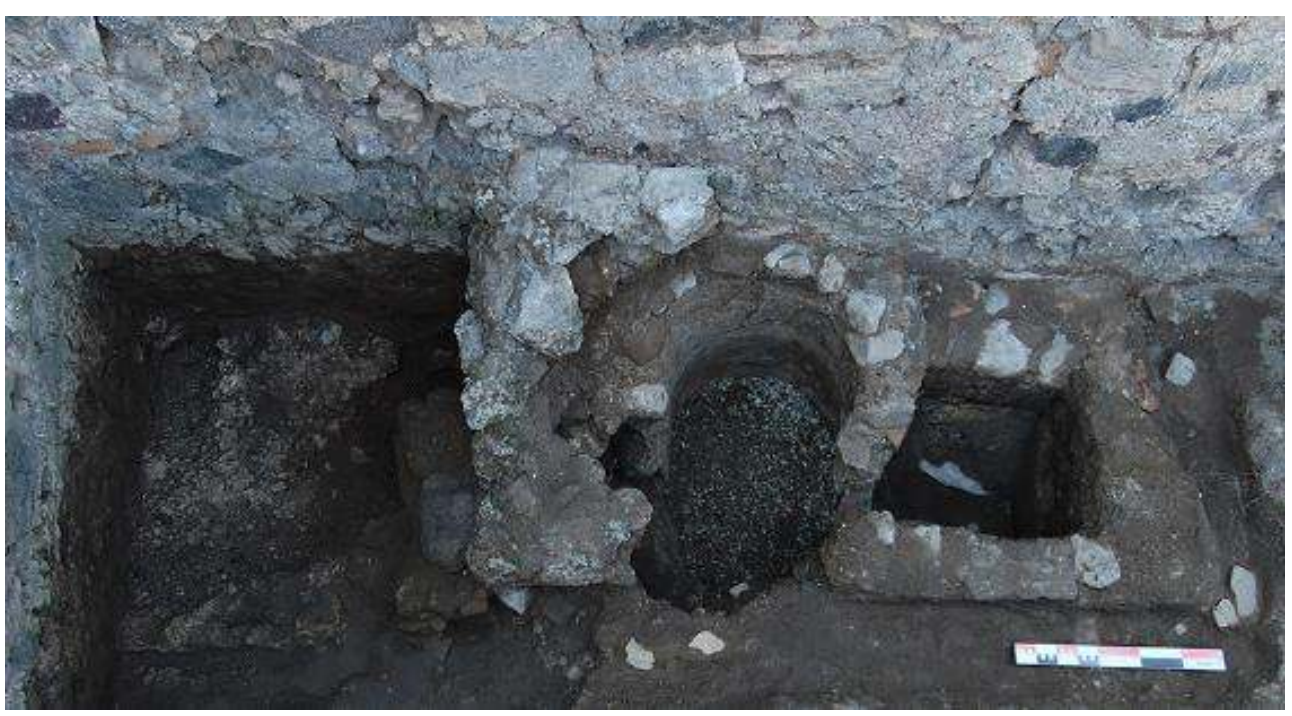

Vue de l'est.

Cliché : S. Aho - EFR.

Un catillus fortement usé avait été déplacé par-dessus, nous amenant à nettoyer la zone pour comprendre son éventuelle utilisation en remploi, d'autant plus intrigante que la boulangerie n'est pas supposée avoir eu des meules ${ }^{38}$. La bouche de citerne appartient à un ensemble plus complexe qui parait avoir subi des remaniements. Tandis que dans l'angle sud-ouest de la pièce se trouve un remblai inachevé ou partiellement détruit, à la bouche, de plan circulaire, a été accolé un bassin quadrangulaire qui communique avec elle par une perforation effectuée dans sa paroi septentrionale ${ }^{39}$. Le bassin, plus profond que celui de la pièce 4, présente un profil arrondi à l'ouest, vertical sur les autres côtés. Sa paroi orientale est percée de deux canaux. L'un, provenant de l'est, est réalisé avec un tube céramique; le second, aménagé directement dans la maçonnerie avec un petit linteau en basalte, se dirige plus vers le sud-est. Bien qu'aucun tuyau d'adduction n'a été conservé, le parallèle entre le bassin de la pièce 3 et celui de la pièce 4 est assez marquant. Ces deux constructions pourraient donc être le signe d'une réfection du système de captage des eaux de toiture, destinées à être recueillies dans une citerne préexistante.

\section{1, 3.33}

Le travail de nettoyage en IX 1, 3.33 n'a concerné qu'une partie de cet ensemble constitué d'une boulangerie et d'un commerce alimentaire s'ouvrant sur la via Stabiana (fig. 59). 
Fig. 59 - Pompéi, boulangerie IX 1, 3.33 - Relevé de l'ensemble de la boulangerie.

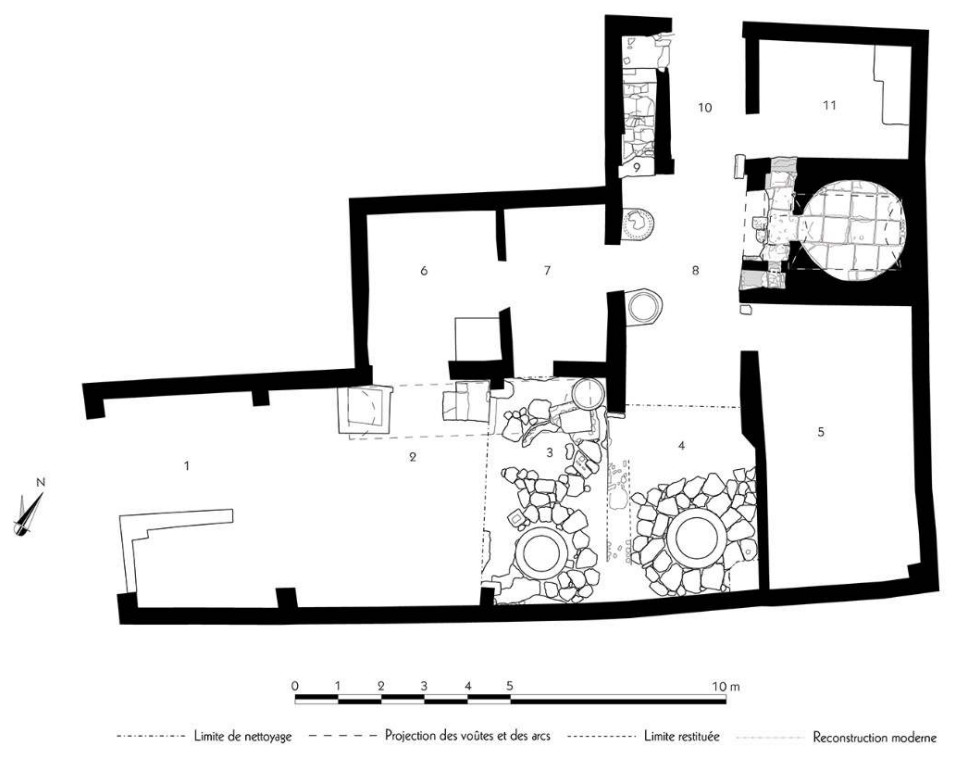

Échelle : 1/100.

Relevé / dessin : F. Fouriaux / S. Aho / A. Dufond / B. Bauvit / S. Mencarelli - EFR.

Le dégagement de la pièce 12 , située immédiatement au nord du four, n'a donné aucun résultat: bien que l'on eût pensé mettre en évidence des aménagements propres à la préparation des pâtons en raison de la présence d'un passe-pain reliant cette pièce au four, un épais béton moderne, disposé sur toute la surface a empêché toute observation. D'autres interventions réalisées depuis la fouille de la boulangerie sont à signaler. Le pétrin mécanique, dont l'emplacement initial n'a pas pu être déterminé, a été déplacé, probablement à plusieurs reprises depuis son dégagement. Il se situe actuellement au sud-est de la salle des meules, sur le dallage en basalte ${ }^{40}$. De la même manière, sur les trois meules actuellement conservées dans la boulangerie, seules deux sont encore insérées dans un massif de maçonnerie. Entre la visite de P. Gusman au début du XXe ${ }^{\mathrm{e}}$ s. et au moins 1959, le catillus et la meta de la troisième meule étaient assemblés l'un sur l'autre; ce n'est plus le cas depuis les années 2000 au plus tard ${ }^{41}$. Il est possible que cette situation soit elle-même consécutive à un déplacement survenu rapidement après la fouille. En effet, la position initiale de cette meule, au nord de la pièce 3 , est perceptible grâce aux restes du dallage en basalte. Cependant, ces dalles sont partiellement recouvertes par une ouverture quadrangulaire de facture moderne qui donne dans la citerne s'étendant d'ouest en est entre les salles 2 et 3 . Tout en laissant de côté la reconstruction intégrale des supports des jattes de pointage, notons que le sol en avant du four, assez fortement incliné, a été très érodé par les visites et les intempéries, interdisant toute observation. Enfin, les observations menées dans la cave sous-jacente au four (fig. 60) n'ont été guère conclusives : à $1,28 \mathrm{~m}$ sous la voûte, sous une épaisseur de $0,50 \mathrm{~m}$ de remblai moderne, un niveau de béton, identique à celui disposé dans la salle 12, a été perçu. Comme celle de VI 3, 3.26-27, la cave de IX 1, 3.33 conservera les mystères de sa structure et de sa fonction ${ }^{42}$. 
Fig. 60 - Pompéi, boulangerie IX 1, 3.33 - Élévation de la façade.
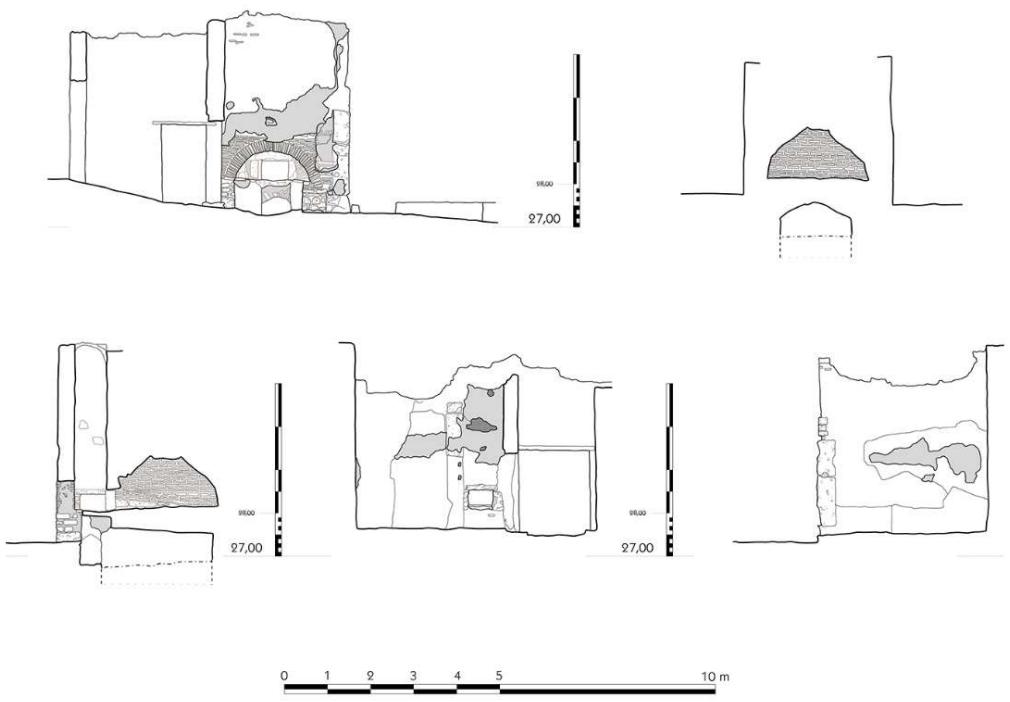

Échelle : 1/100

Coupe transversale dans la chambre de cuisson (en haut) ; coupe longitudinale, élévation septentrionale et élévation méridionale du four (en bas).

Relevé / dessin : F. Fouriaux / S. Mencarelli - EFR.

L'observation de phases antérieures à l'éruption a été rendue particulièrement complexe par les nombreux remaniements modernes. Cependant, la boulangerie s'installe alors que les pièces 3 et 4 sont encore séparées par un mur (fig. 61) ${ }^{43}$. 
Fig. 61 - Pompéi, boulangerie IX 1, 3.33 - Salle des meules.

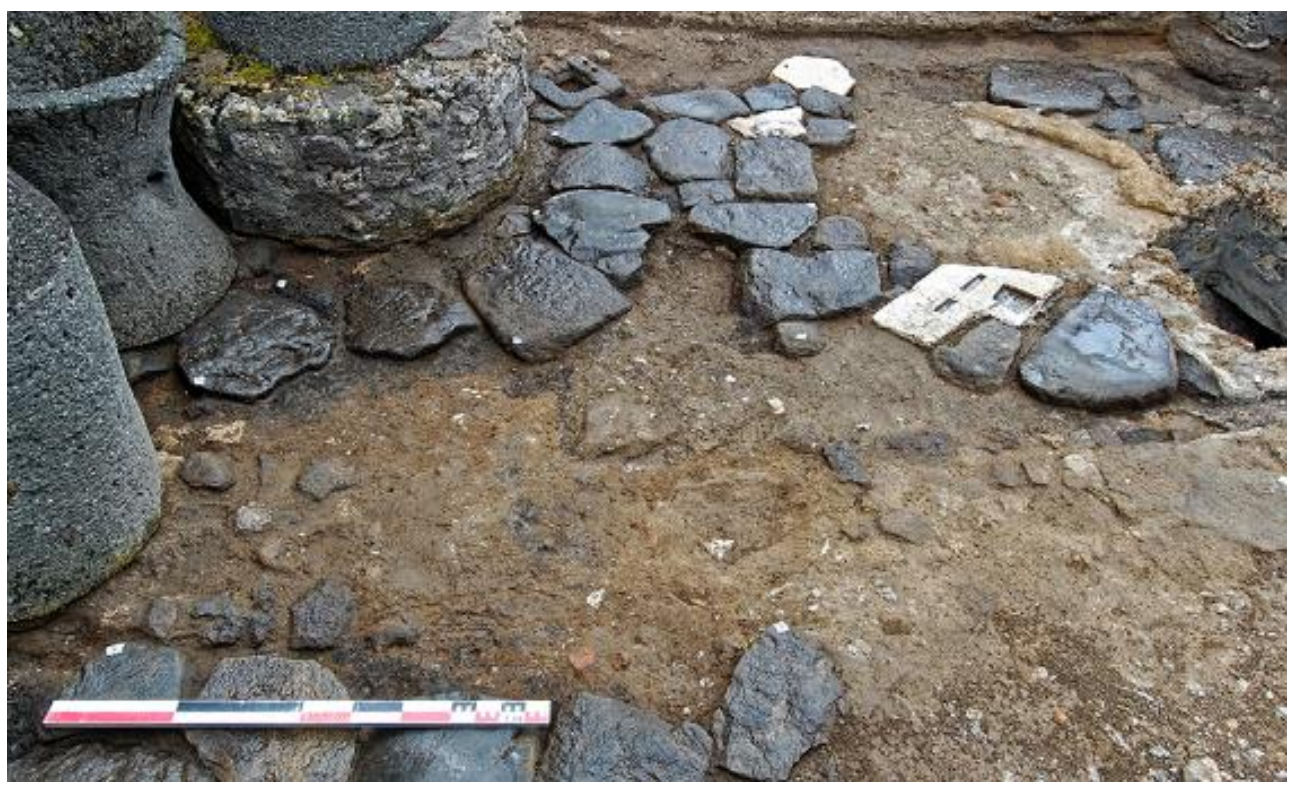

On note un mur arasé entre la pièce 3 et la pièce 4 (vue de l'est).

Cliché : S. Aho - EFR.

En effet, outre les vestiges de celui-ci affleurant sous les niveaux de circulation de terre battue, les dallages observés dans les pièces 3 et 4 respectent parfaitement ce refend, sans jamais s'appuyer dessus. Il est cependant difficile de déterminer avec certitude que les meules occidentales, situées dans la pièce 3 , ont été installées après celle de la pièce 4 : aucun indice, en particulier aucune trace d'usure différentielle, ne permet d'appuyer cette hypothèse seulement vraisemblable. Lors de la construction des meules dans la pièce 3, l'escalier est transformé et déplacé : à une échelle de meunier appuyée contre le mur méridional - et dont la trace est encore visible dans l'enduit -, succède un escalier de pente indéterminée disposé contre le mur septentrional de la pièce 2 .

Les trois meules ont fonctionné, comme semblent en témoigner les lambeaux de terre battue subsistant autour des différents dallages et présentant des poches d'éléments charbonneux contenant des fragments d'olives. Cependant, la situation observée est relativement confuse, si tant est qu'elle corresponde à l'état final de la boulangerie au moment de l'éruption. D'une part, une partie du dallage de basalte manque à l'ouest des meules de la salle 3; certaines "dalles» subsistant sont des éléments de remploi, fragments de seuils en calcaire ou en basalte notamment. La meule située au nord de cette pièce a été, comme nous l'avons dit plus haut, déplacée et démantelée. Il est cependant intéressant de noter que le catillus est neuf - ne présente presque pas d'usure tandis que la meta a déjà servi et a dû être retaillée pour lui ajuster le catillus. Il est possible que l'état dans lequel nous avons observé la boulangerie corresponde à un moment de changement la meule: l'empreinte de la base maçonnée préexistante est visible. Ces travaux auraient alors pu induire, en étonnant complément, une réfection partielle du dallage. La confusion de cette situation est accrue par la nature du regard oriental de la citerne qui se développe entre les pièces 2 et 3 . Comme indiqué précédemment, ce regard présente tous les signes de la construction moderne : il est décentré par rapport à l'axe de la citerne; les joints du parement sont fortement surchargés et ne sont pas réalisés en mortier hydraulique, contrairement au revêtement 
de la citerne ; la composition du mortier à sa base semble faire intervenir du matériel éruptif. Cependant, ce regard est décrit et dessiné par G. Fiorelli, même s'il le distingue du regard occidenta ${ }^{44}$. $L$ 'histoire des fouilles peut éventuellement éclairer cette situation. La boutique a été fouillée en deux temps, en 1852 depuis la via Stabiana, puis en 1866 depuis le vicolo di Balbo. En 1852, la fouille semble fortement liée à la visite du duc de Luynes, le 13 avril. Dans les jours qui suivent la fouille se poursuit pour ricercare e crivellare le terre ; le 16 avril, un "souterrain" est découvert dans la boutique, où sont retrouvés de nombreux objets ${ }^{45}$. Selon les plans publiés avant la reprise de 1866, la limite de fouille pourrait correspondre au côté oriental de la pièce $3^{46}$. L'hypothèse selon laquelle le regard « moderne » soit lié à un effondrement partiel de la citerne, restauré dès les années 1850, semble constituer une solution recevable.

Un dernier nettoyage a été effectué, à l'ouest du four et de l'accès IX 1, 33. Le long couloir que constitue la pièce 9 est apparu comme une probable latrine (fig. 62).

Fig. 62 - Pompéi, boulangerie IX 1, 3.33 - Angle nord-est de la pièce 3.

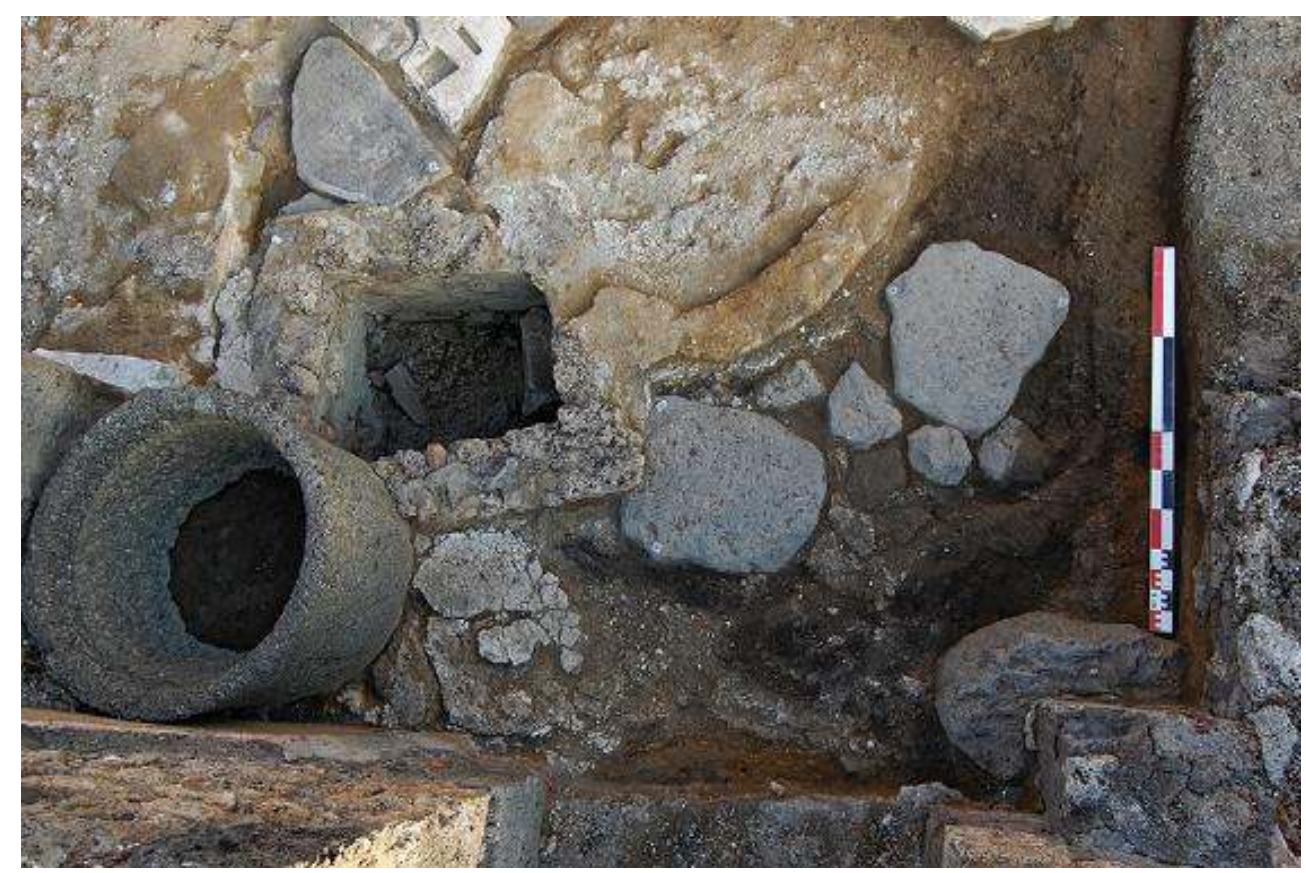

Vue du nord.

Ouverture moderne ( ?) vers la citerne se développant entre les pièces 2 et 3. La bouche est construite sur l'emplacement d'une meule.

Cliché : S. Aho - EFR. 
Fig. 63 - Pompéi, boulangerie IX 1, 3.33 - Probable latrine installée dans la pièce 9.

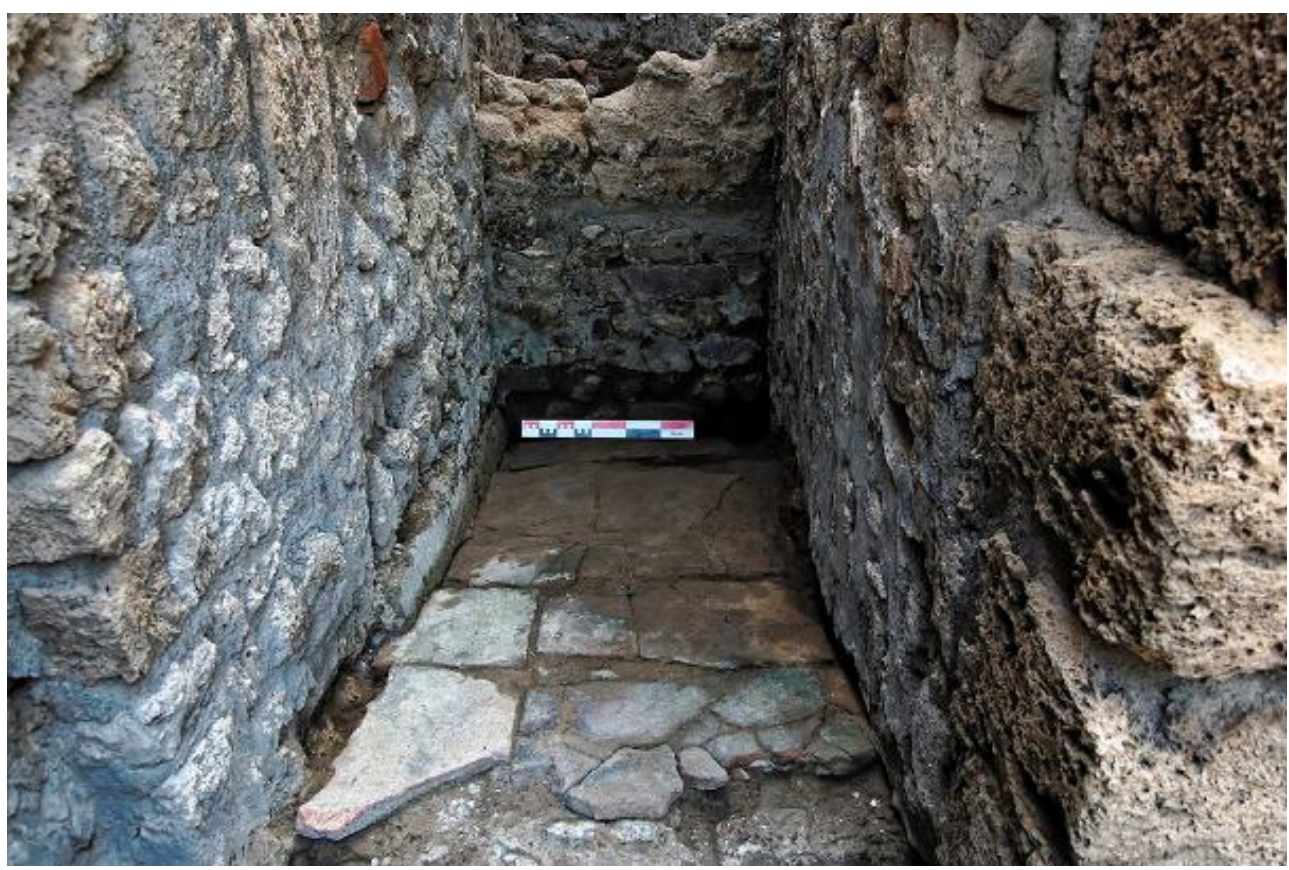

Vue du sud.

Cliché : B. Bauvit - EFR.

Le sol, en pente assez accentuée vers le nord, est recouvert de tuiles bipedales fragmentées. Un avaloir a été observé dans le mur nord, à l'est. Les fortes restaurations effectuées ont interdit toute observation d'autres aménagements.

\section{3, 10-12}

Lors de cette campagne, le nettoyage s'est concentré sur deux pièces de la boulangerie IX 3,10-12 qui s'ouvre sur la via Stabiana et sur le vico degli Augustali. En plus du relevé du four, fortement restauré, la salle des meules et la pièce située au nord du four ont été dégagées de leur comblement moderne (fig. 64-65). 


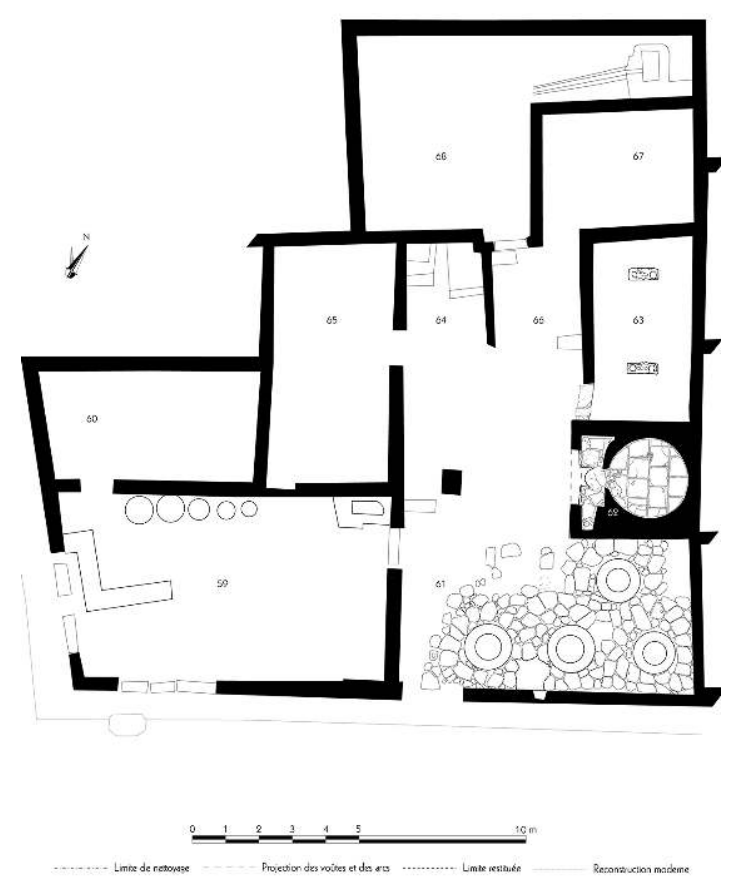

Échelle : 1/100

Relevé / dessin : M. Holappa (EPUH) / F. Fouriaux / A. Delvigne-Ryrko / A. Béranger / S. Mencarelli EFR.

Fig. 65 - Pompéi, boulangerie IX 3, 10-12 - Élévation de la façade et coupe transversale du four.

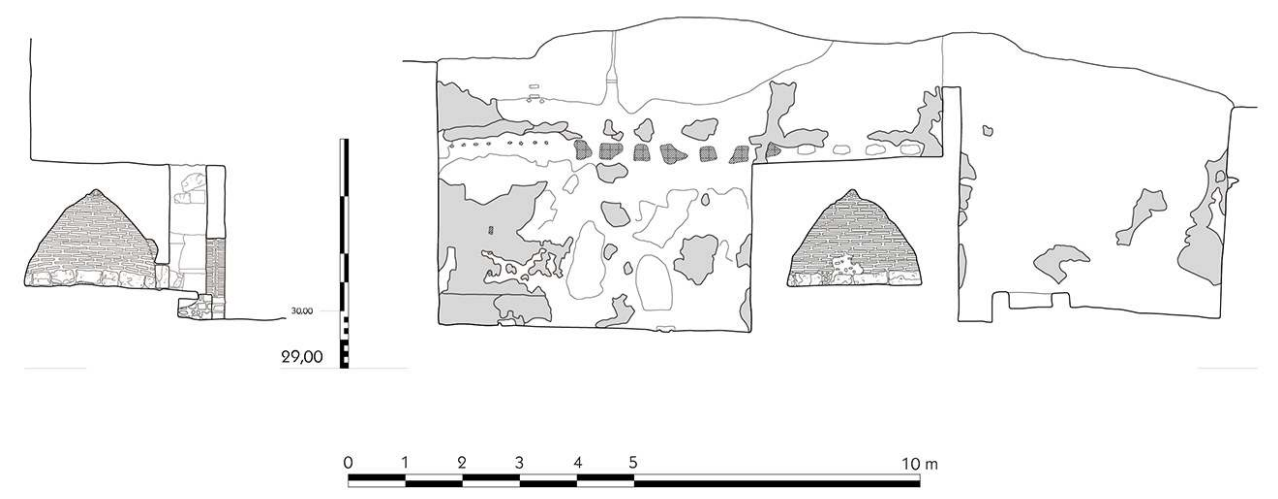

Échelle : 1/100

Relevé / dessin : F. Fouriaux / S. Mencarelli - EFR.

\section{Pièce 61}

Le nettoyage, qui n'avait pour autre but que de faciliter le relevé des blocs de basalte, a permis de révéler deux importantes lacunes dans le dallage. Toutes les deux sont situées autour de la meule au centre des trois disposées le long du mur méridional de la pièce. La 
plus importante s'est avérée être une fosse remplie de matériel éruptif non remanié (fig. 66-67).

Fig. 66 - Pompéi, boulangerie IX 3, 10-12 - Vue générale de la salle des meules.

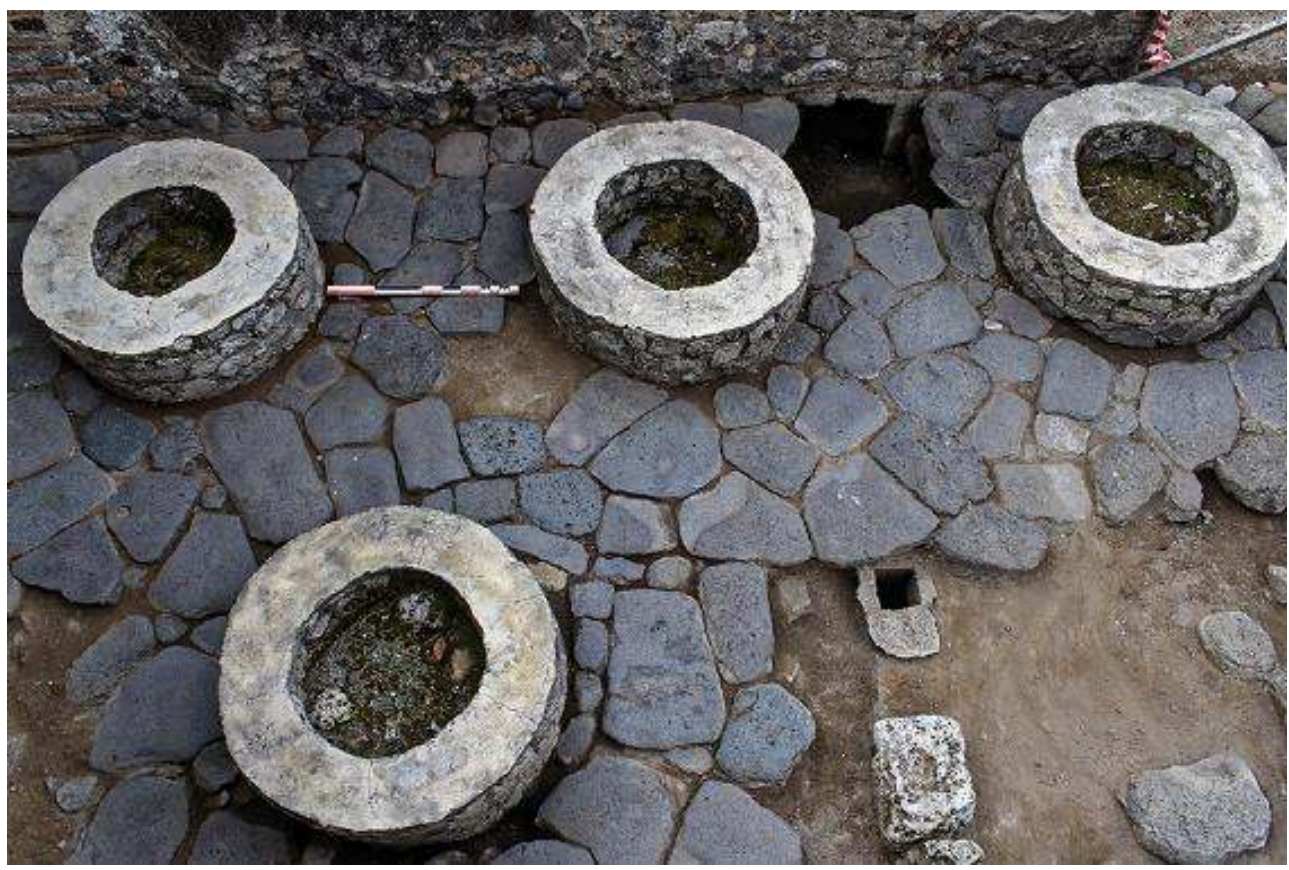

On note la fosse ouverte dans le dallage, qui continue dans le mur méridional (vue du nord).

Cliché : A. Delvigne-Ryrko - EFR.

Fig. 67 - Pompéi, boulangerie IX 3, 10-12 - Salle des meules, creusement percé dans le mur méridional rempli de matériel éruptif.

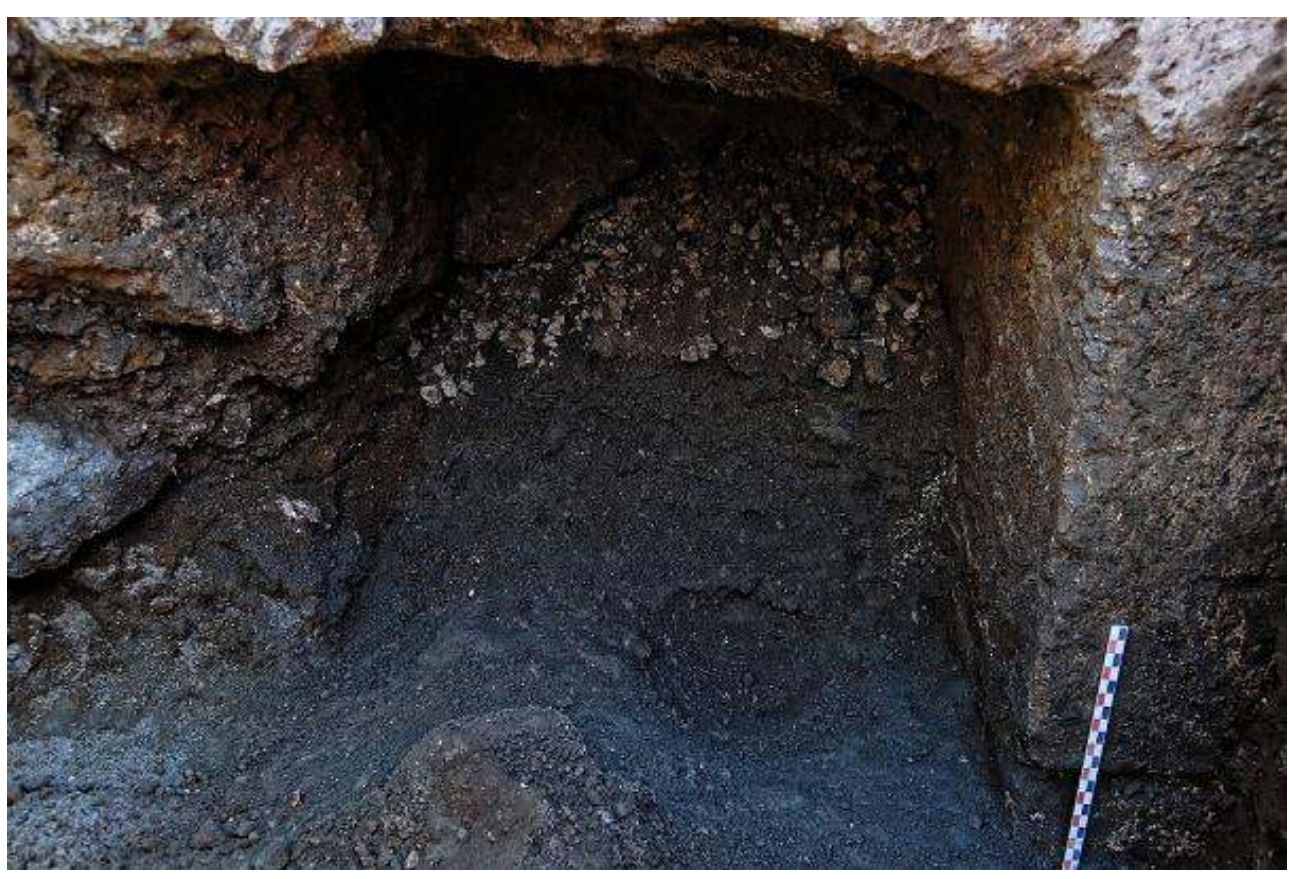

Vue du nord.

Cliché : A. Delvigne-Ryrko - EFR. 
De forme sub-circulaire, elle s'étend sous le mur méridional, délimitée à l'ouest de ce percement par des blocs en calcaire «du Sarno $»^{47}$. À partir de $0,74 \mathrm{~m}$ de profondeur, un premier palier est atteint et la fosse se réduit alors, prenant une forme rectangulaire en plan, contre la seule paroi occidentale. Le fond de la fosse, atteint à l'altitude de $28,56 \mathrm{~m}$ s.l.m., pour une profondeur maximale de $1,28 \mathrm{~m}$, était constitué par un niveau de remblai hétérogène. Les différents éléments mis au jour lors de la fouille ne permettent pas d'interprétation univoque. Il est vraisemblable que ce creusement était en voie de comblement en 79 avec du tout-venant - tuiles, mobilier céramique en connexion, des éléments fauniques, fragments de cocciopesto. Cette fosse a permis d'observer le sol de béton antérieur à la mise en place du dallage de basalte (29,38 $\mathrm{m}$ s.l.m.). Au moment précis de l'éruption, cette boulangerie n'était donc guère fonctionnelle - à tout le moins deux des quatre meules ne pouvaient fonctionner -, sans qu'il ne soit toutefois possible de déterminer si cet état était transitoire ou non.

Enfin, ce nettoyage aura également permis de remettre en évidence les avanies subies par cette boulangerie depuis son dégagement. En effet, entre les années et le début du XX siècle, la meule située à l'ouest - aujourd'hui dépourvue de tout élément, qu'il s'agisse du catillus ou de la meta - a "bénéficié » d'un remontage intégral avec adjonction de pièces de bois permettant de la faire fonctionner à bras d'homme. Pour protéger cet essai d'archéologie expérimentale, une toiture a été construite, appuyée contre le mur et sur un poteau en bois dont les vestiges d'implantation ont été observés ${ }^{48}$.

\section{Pièce 63}

Située immédiatement au nord du four, cette pièce se singularise tout d'abord par son sol, constitué d'un béton de tuileau dont la superficie est rehaussée de fragments de calcaire blancs et de tessons de céramique disposés sans ordre. Deux petits massifs maçonnés rectangulaires occupent l'axe médian de la pièce (fig. 68-69). 
Fig. 68 - Pompéi, boulangerie IX 3, 10-12 - Salle de façonnage, vue générale.

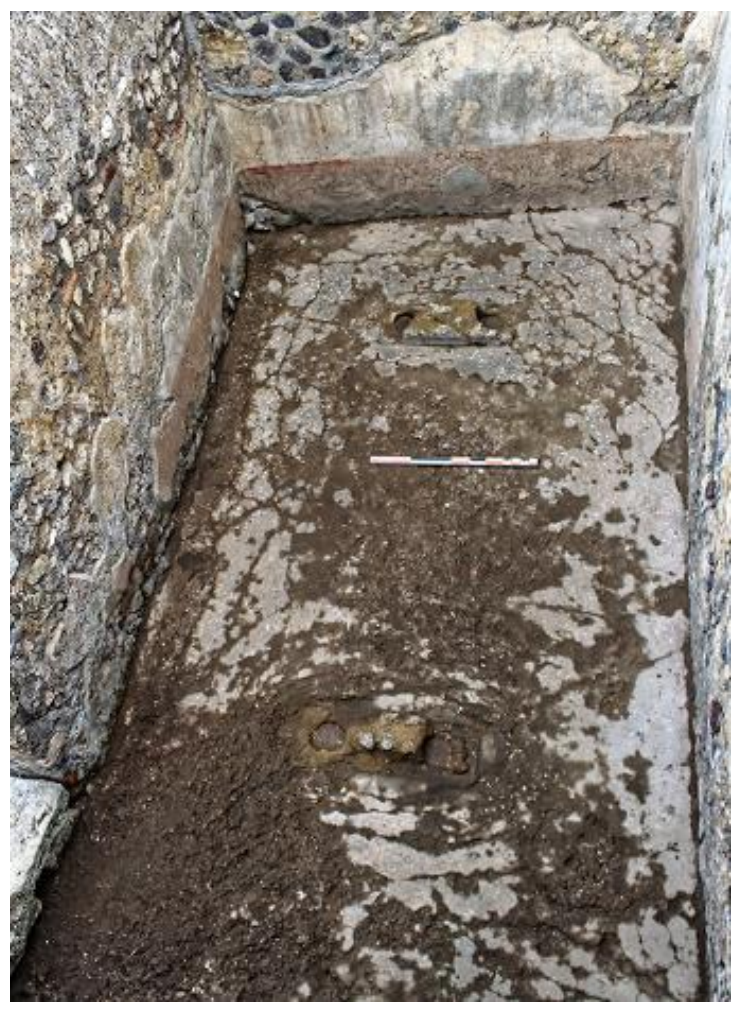

Vue du sud.

Cliché : A. Delvigne-Ryrko - EFR.

Fig. 69 - Pompéi, boulangerie IX 3, 10-12 - Salle de façonnage, pieds maçonnés prévu pour permettre l'encastrement d'un coffre de pétrissage.

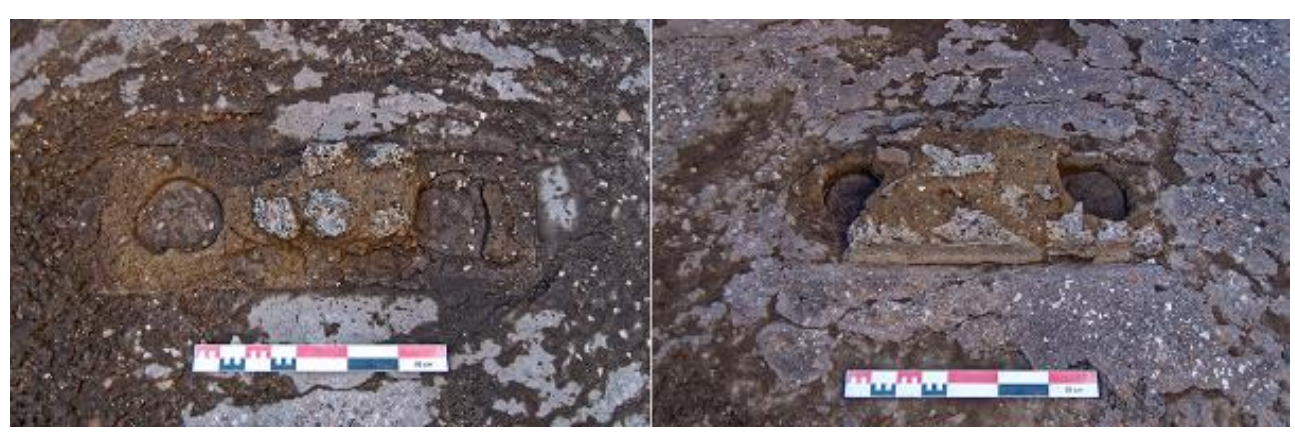

À g., pied méridional ; à d. pied septentrional ; vues du sud. Clichés : A. Delvigne-Ryrko - EFR. 


\section{BIBLIOGRAPHIE}

Construits directement sur le niveau de sol, sans aménagement antérieur ou « fondation », chacun de ces deux massifs présente deux cavités circulaires. L'aménagement qu'ils supportaient a créé une pression telle sur le sol que ce dernier s'est légèrement affaissé au niveau des massifs. Si la disposition de ces deux massifs tendrait à rappeler au premier abord des pieds maçonnés utilisés pour soutenir une table sur laquelle effectuer le façonnage des pains, la présence des cavités circulaires reste un cas unique parmi les exemples pompéiens. Un tel aménagement nous semble devoir être rapproché de ce qui a été observé lors de la campagne 2013 en VII 2, 3.6 : les traces d'un pétrin en coffre fermement ancré dans le sol ${ }^{49}$. L'absence de pétrin mécanique dans cette boulangerie tendrait à confirmer cette hypothèse. Ainsi, plutôt que d'avoir plusieurs tables avec des pieds maçonnés et un pétrin, la boulangerie IX 3, 10-12 aurait eu un vaste pétrin en coffre qui, une fois refermé, aurait permis le façonnage des pains sur son couvercle.

Barberan et al. 2006 = S. Barberan, G. Piquès, S. Raux, C. Sanchez, Un dispositif de cuisson original en Languedoc dans l'antiquité. Les fours à pain à cloche mobile en céramique, dans Sfecag-Actes du Congrès de Pézenas, Marseille, 2006, p. 257-271.

Bonnin 1984 = J. Bonnin, L'eau dans l'Antiquité : l'hydraulique avant notre ère, Paris, 1984 (Collection de la Direction des études et recherches d'Électricité de France, 47).

Breton 1870 = E. Breton, Pompeia décrite et dessinée, $3^{\mathrm{e}}$ éd., Paris, 1870 .

Cubberley - Lloyd - Roberts 1988= A.L. Cubberley, J.A. Lloyd, P.C. Roberts, Testa and Clibani: The baking covers of Classical Italy, dans Papers of the British School at Rome, 56, 1988, p. 98-119.

Dessales $2013=\mathrm{H}$. Dessales, Le partage de l'eau :fontaines et distribution hydraulique dans l'habitat urbain de l'Italie romaine, Rome, 2013 (Bibliothèque des Écoles françaises d'Athènes et de Rome, 351).

Dickmann 1999 = J.-A. Dickmann, Domus frequentata : anspruchsvolles Wohnen im pompejanischen Stadthaus, Munich, 1999 (Studien zur antiken Stadt, 4).

Dyer 1867= T.H. Dyer, Pompeii: its history, buildings and antiquities, Londres, 1867.

Eschebach 1993= L. Eschebach (éd.), Gebäudeverzeichnis und Stadtplan der antiken Stadt Pompeji, Cologne, 1993.

Evans 2014= J. Evans, The great Roman bake off? 'Portable' ceramic ovens and bake-stones, recent finds, dans The Study Group for Roman Pottery Newsletter, 57, 2014, p. 6-9.

$\mathrm{PAH}=\mathrm{G}$. Fiorelli, Pompeianarum antiquitatum historia quam ex cod. mss. et a schedis diurnisque [...] quae in publicis aut privatis bibliothecis servantur nunc primum collegit indicibusqve instruxit Ios. Fiorelli, Naples, 1860.

Fiorelli 1873 = G. Fiorelli, Gli scavi di Pompei dal 1861 al 1872, Naples, 1873.

Heke 2014= A. Heke, Portable ovens from Chester, dans The Study Group for Roman Pottery Newsletter, 57, 2014, p. 9-13.

Mau 1886 = A. Mau, Su certi apparecchi nei pistrini di Pompei, dans MDAIR, 1, 1886, p. 45-48.

Monteix 2008 = N. Monteix, La conservation des denrées dans l'espace domestique à Pompéi et Herculanum, dans MEFRA, 120, 1, 2008, p. 123-138. 
Monteix 2010 = N. Monteix, Les lieux de métier. Boutiques et ateliers d'Herculanum, Rome, 2010 (BEFAR ,344).

Monteix et al. 2013 = N. Monteix, S. Zanella, S. Aho, R. Macario, E. Proudfoot, Pompéi, Pistrina, dans Chronique des activités archéologiques de l'École française de Rome, 2013 (http:// cefr.revues.org/954).

Monteix et al. 2014 = N. Monteix, S. Aho, A. Coutelas, S. Zanella, Pompéi, Pistrina, dans Chronique des activités archéologiques de l'École française de Rome, 2014 (http://cefr.revues.org/1242).

Oberhofer 2008 = K. Oberhofer, Die Bäckerei VII, 2, 22 in Pompeji, dans G. Grabherr, B. Kainrath (éd.), Akten des 11. Österreichischen Archäologentages in Innsbruck. 23.-25.März 2006, Innsbruck, 2008 ( Ikarus, 3), p. 205-214.

Pedroni 2008 = L. Pedroni, Pompei, Regio VII,Insula 2, pars occidentalis. Le indagini dell'Institut für Archäologien dell'Universität Innsbruck finanziate dal FWF austriaco, dans M.P. Guidobaldi, P.G. Guzzo (éd.), Nuove ricerche archeologiche nell'area vesuviana (scavi 2003-2006), Roma, 2008 (Studi della Soprintendenza archeologica di Pompei, 25), p. 237-248.

Sorgente 1858 = C. Sorgente, Tabula Coloniae Veneriae Corneliae Pompeis, [Naples], 1858.

Van der Poel - García y García - McConnell 1986 = H.B. Van der Poel, L. García y García, J. McConnell, Corpus topographicum pompeianum. Pars 3A. The insulae of Regions I-V, Rome, 1986 ( Researches in Campanian archaeology).

Zanella 2014 = S. Zanella, Pompéi. Maison des mosaïques géométriques VIII 2, 3-16, dans Chronique des activités archéologiques de l'École française de Rome, 2014 (http://cefr.revues.org/1110).

\section{NOTES}

1. Fiorelli 1873, p. 75.

2. Dans le mur septentrional de cette pièce est visible un creusement destiné à recevoir une couche. Rien ne permet cependant de supposer qu'un tel meuble était disposé dans la pièce lors de la dernière phase.

3. Il est vraisemblable que le bras nord-sud du muret en équerre ait initialement constitué un piédroit d'échiffre soutenant l'escalier.

4. Si la dégradation de cette boulangerie est perceptible, en particulier avec l'affaissement du mur occidental de la pièce 1 et la chute du bloc constituant l'autel (/table) du four entre 2009 et 2010 ( $c f$. Pompeii in pictures $@$ Jackie \& Bob Dunn), l'état des bases de meules correspond à la description de G. Fiorelli (1873, p. 75) peu après la fouille : «Segue un pistrino con [...] nell'area delle macine (b) le basi di tre molae e gli avanzi di una quarta ».

5. Monteix et al. 2013, § 18, fig. 10.

6. C'est suite à cette construction que la Casa dei guerrieri prend le plan tel qu'on le connaît actuellement. Cette séparation d'avec I 3, 27 permet ainsi de construire une maison de plain-pied, malgré la forte déclivité du terrain.

7. Cette extension pourrait avoir lieu au gré du changement de projet. Elle a de toute façon eu lieu après la première reconstruction des murs séparant I 3, 27 de la Casa dei guerrieri, comme en attestent le pilier en tuiles situé dans le mur nord de la pièce 8 et les différentes techniques de construction.

8. Gageons que ce soit l'analyse en plan qui ait amené jusqu'à présent à associer ces deux boulangeries (cf. e.g. Fiorelli 1873, p.68-69; Van der Poel - García y García McConnell 1986, p. 8 ; Eschebach 1993, p. 29). Il existe pourtant un dénivelé de 0,40 m entre I 4, 17 et la pièce 8 de I 4,12 . 
9. Th. Dyer (1867, p. 473) mentionne seulement une fontaine. Les descriptions suivantes mentionnent le passage du tuyau (Breton 1870, p. 424 ; Fiorelli 1873, p. 16), sans qu'il ne soit possible d'être sûr que le tuyau décrit est celui contournant la vasque.

10. Après son dégagement, cette citerne était coiffée d'un "grand puteal de terre cuite raccommodé avec des attaches de plomb à queue d'aronde » (Breton 1870, p. 425), dont seules les traces de scellement au mortier sont encore visibles. L'absence de conduite visible entre l' impluvium et la citerne interdit de se prononcer sur le mode de remplissage de ce réservoir.

11. Fiorelli 1873, p. 16.

12. Breton 1870 , p. 425 ; Fiorelli 1873, p. 16

13. Une fois le réseau sous pression, le diamètre des tuyaux convoyant l'eau n'a que peu d'influence par rapport au diamètre à la sortie et au nombre de robinets ouverts simultanément.

14. Monteix et al. 2014, § 16-21.

15. Fiorelli 1873, p. 28-29

16. Pour un aperçu général, voir Dickmann 1999; Dessales 2013, p. 397-497. En termes de positionnement, seuls font exception les bassins des péristyles de VIII 4, 13 (Fiorelli 1873, p. 5), de VIII 2, 3-16 (Zanella 2014, § 21) et du jardin de VIII 4, 15-16.38 (BdI 1883, p. 198).

17. Voir Monteix et al. 2013, § 3-5, supra § 17 et infra § 34 .

18. Les restaurations effectuées sur les murets des autres bras interdisent de déterminer si les autres entrecolonnements ont été également bouchés. La lecture du plan proposé par G. Fiorelli (1873, pl. IX) ne permet pas de distinguer un traitement différencié entre le côté nord et les trois autres.

19. Ces caissons, fréquemment de forme cylindrique, permettent surtout d'amortir les « coups de bélier » engendrés dans un système de tuyauterie par l'arrêt brutal du débit. Le coussin d'air nécessairement présent dans ces caissons pourrait ainsi se comprimer en cas de "coup de bélier », réduisant ainsi les risques de rupture pour les tuyaux enterrés. Sur le « coup de bélier ", cf. Bonnin 1984, p. 233 et s.v. « coup de bélier », p. 402.

20. Sur ces fouilles, voir en particulier pour la boulangerie Oberhofer 2008. L'extension des sondages n'est cependant indiquée que dans l'article de L. Pedroni (2008, fig. 2, p. 238).

21. Les différentes photographies proposées sur Pompeii in pictures (๔ Jackie \& Bob Dunn) permettent voir les deux fragments de meules séparés jusque dans les années 1970 .

22. Mau 1886, p. 47, pl. III. Ce processus de dégradation des lames est également à l'œuvre dans les boulangeries V 3, 8 et IX 12, 6.8, dont les pétrins ont été respectivement dégagés en 2008 et en 1987.

23. Monteix 2010, p. 156.

24. Sur une photo prise en 1961 par S. Jashemski, le caractère récent du rejointoiement est patent. Cf. University of Maryland Library, Wilhelmina F. Jashemski Papers, J66f0642 (disponible sur Pompeii in pictures $@$ Jackie \& Bob Dunn).

25. Fiorelli 1873, pl. viI. Sur ce plan apparaît un montant en équerre fermant la pièce $d(=5)$.

26. Cette différence de niveau peut partiellement s'expliquer par la disparition des briques ou tuiles utilisées pour aménager une surface régulière au sommet de l'autel (/table).

27. Fiorelli 1873, p. 18

28. Sur les découvertes de Narbonnaise, voir Barberan et al. 2006 ; pour deux exemples de Bretagne, voir Evans 2014 ; Heke 2014. Notons que dans chacun de ces cas, il s'agit de productions céramiques ad hoc et non d'utilisation de récipients détournés de leur utilisation première pour former un four comme cela semble être le cas ici.

29. La consommation de ce type de pain non levé est attestée à Pompéi par l'inscription électorale CIL IV, 677 mentionnant des clibanarii. Il semble raisonnable d'utiliser le terme latin de clibanus pour ces fours semblables aux tabouna plutôt que d'y voir un type particulier de céramique de cuisine (contra Cubberley - Lloyd - Roberts 1988). 
30. Il n'a pas été possible de déterminer la destination de cet exutoire. Aucune canalisation n'a été observée dans son immédiate continuité.

31. Sur l'utilisation de « vasques » pour stocker du grain, voir Monteix 2008, p. 129-132.

32. Outre le bouchage de la porte visible dans la maçonnerie, le passage est donné comme ouvert par G. Fiorelli (1873, pl. viI).

33. Cette hypothèse s'appuie sur les observations effectuées en 2008 dans la boulangerie mitoyenne VII 12,13, où le même mur, appuyé sur un mur arasé, a été observé.

34. G. Fiorelli (1873, p. 18) y voit, sans explication ni conviction, un focolare.

35. Un nettoyage y a été effectué, pour vérifier l'éventuelle présence d'un pétrin, recherche fondée sur le système de poutraison qui aurait permis une telle installation. Rien n'a permis de confirmer cette hypothèse. Le sol, constitué de terre battue, ne présente aucune trace pouvant renvoyer à l'installation d'un pétrin.

36. Un tel aménagement est relativement fréquent dans les boulangeries munies d'un chauffeeau. Voir, e.g. Monteix et al. 2014, § 30, 35.

37. Il est possible que les étagères des murs sud et ouest n'aient pas fonctionné en même temps : vue la faible profondeur de la table méridionale, l'installation des étagères sur le mur sud aurait $\mathrm{pu}$ vraisemblablement gêner le travail de façonnage. Il n'est cependant pas possible de déterminer une éventuelle succession chronologique.

38. Ce catillus a été décrit par G. Fiorelli (1873, p. 18) en ces termes peu satisfaisants : « in fondo un'altro compreso $(b[=2])$, accanto al quale una fauce $(c[=3])$ ove in origine stavano le macine che poi furono tolte ".

39. Ce percement pourrait être lié à un effondrement partiel de la paroi séparant le bassin de la citerne.

40. Une photo prise par $\mathrm{T}$. Warscher à une date inconnue montre ce pétrin à un emplacement différent et plus complet qu'actuellement (Getty Research Institute, H.B. Vander Poel Campanian collection, box 122, photo TW 698).

41. Voir INHA, fonds P. Gusman, Plaques Phot 12 (31, $\mathrm{n}^{\circ} 5$; doublon en Plaques Phot 12, 49, $\mathrm{n}^{\circ} 21$ ), University of Maryland Library, Wilhelmina F. Jashemski Papers, J59f0113 (disponible sur Pompeii in pictures $\subset$ Jackie \& Bob Dunn).

42. Sur la cave de VI 3, 3.27-28, voir Monteix et al. 2013, § 13-14.

43. Il n'est pas possible de déterminer si, lors de l'installation de la boulangerie, les espaces IX 1, 3 et IX 1, 33 sont complètement séparés ou bien s'ils communiquent par la pièce 7 .

44. G. Fiorelli (1873, p. 60 et pl. XI) considère la bouche de la citerne comme un puits et l'ouverture «moderne" comme une bouche de citerne, sans signaler que les deux communiquent.

45. Cf. PAH II, p. 550-555. « 16 aprile [1852] - Si continue la ricerca delle terre nella bottega n. 71, trasportando i materiali esistenti in essa, egualmente che in un sotterraneo comparso nel pavimento della medesima, in dove si è rinvenuto [...]» (PAH II, p. 554). Sur la visite du duc de Luynes, voir également BullArchNap n.s., 20, 1852-1853, p. 157.

46. Sorgente 1858, pl. D4. L'essentiel de la fouille se déroule en juin 1866.

47. Il n'a pas été possible de saisir l'extension de ce creusement dans la vico degli Augustali.

48. On renverra également à la photographie prise par P. Gusman entre 1899 et 1906 [INHA, fonds P. Gusman, Plaques Phot $\left.12\left(43.2, \mathrm{n}^{\circ} 117\right)\right]$. Nos plus vifs remerciements à S. Zanella pour nous avoir mentionné l'existence de ce cliché. Notons également que la lacune dans le pavement est également perceptible sur ce cliché. $C f$. également le cliché non daté présenté sur le site Pompeii in pictures (@ Jackie \& Bob Dunn), sur lequel la toiture est visible.

49. Monteix et al. 2014, § 20-21. 
INDEX

Mots-clés : boulangerie, artisanat, approvisionnement hydraulique Index géographique : Pompéi

\section{AUTEURS}

NICOLAS MONTEIX

Université de Rouen - GRHis (EA 3831) - nicolas.monteix[at]univ-rouen.fr

\section{SANNA AHO}

Université d'Helsinki - sanna.aho[at]helsinki.fi

AUDREY DELVIGNE-RYRKO

Archéologue indépendant - delaudy[at]hotmail.fr

ARNAUD WATEL

Archéologue indépendant - watel.arnaud[at]gmail.com 